In cooperation with the United States Army Corps of Engineers New England District

\title{
Surface-Geophysical Investigation of a Formerly Used Defense Site, Machiasport, Maine, February 2003
}

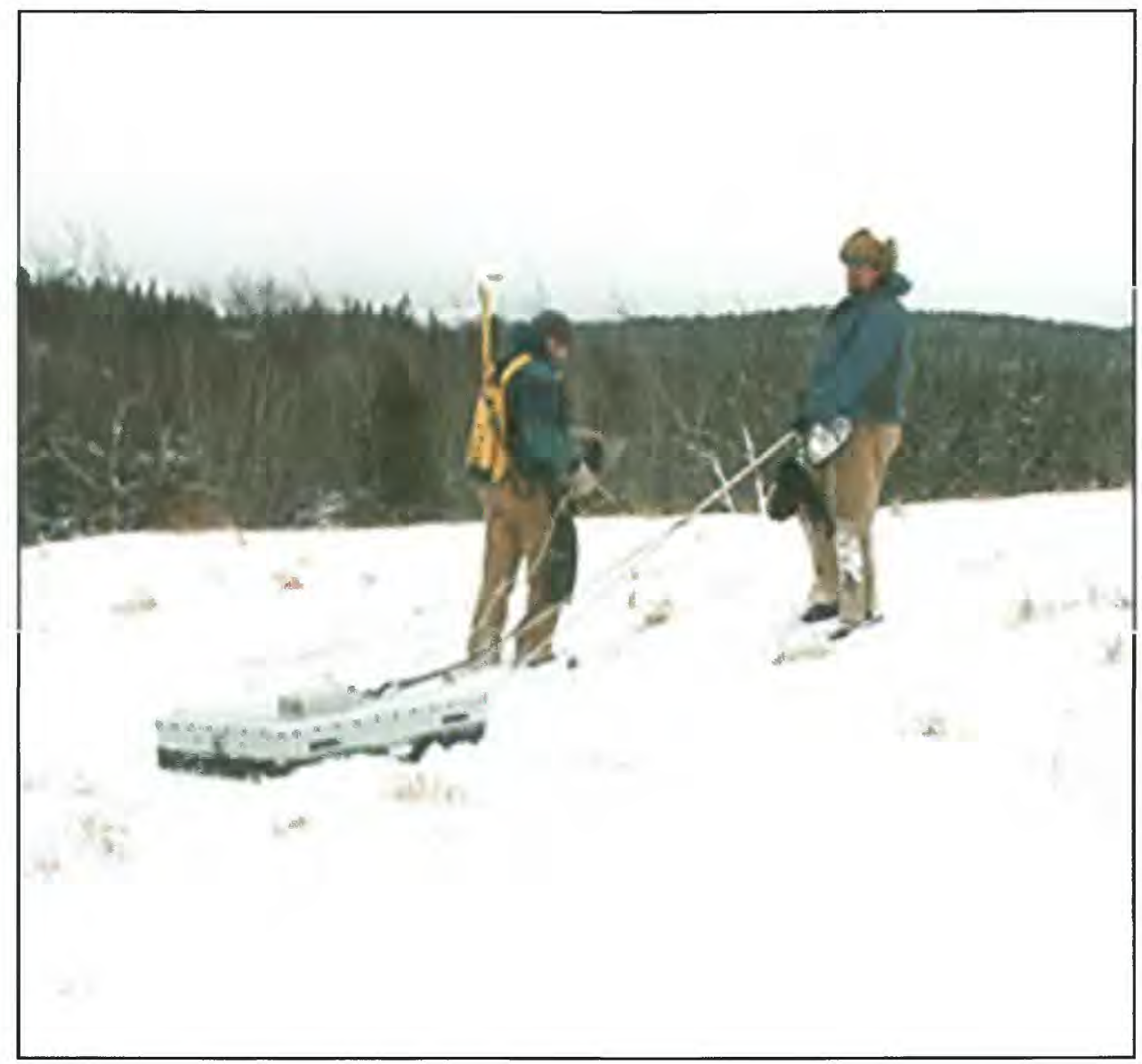

Scientific Investigations Report 2004-5099 
Cover.-Photograph showing ground-penetrating radar data being collected at Machiasport, Maine, February 2003. (Photograph by Drew Clemens, U.S. Army Corps of Engineers.) 


\section{Surface-Geophysical Investigation of a Formerly Used Defense Site, Machiasport, Maine, February 2003}

By Eric A. White', Michael D. Thompson², Carole D. Johnson', Jared D. Abraham ${ }^{3}$, Steven F. Miller ${ }^{2}$, and John W. Lane, Jr.'

Scientific Investigations Report 2004-5099 


\section{U.S. Department of the Interior \\ Gale A. Norton, Secretary}

\section{U.S. Geological Survey \\ Charles G. Groat, Director}

U.S. Geological Survey, Reston, Virginia: 2005

For sale by U.S. Geological Survey, Information Services

Box 25286, Denver Federal Center

Denver, CO 80225

For more information about the USGS and its products:

Telephone: 1-888-ASK-USGS

World Wide Web: http://www.usgs.gov/

Any use of trade, product, or firm names in this publication is for descriptive purposes only and does not imply endorsement by the U.S. Government.

Although this report is in the public domain, permission must be secured from the individual copyright owners to reproduce any copyrighted materials contained within this report.

\footnotetext{
${ }^{1}$ U.S. Geological Survey, Storrs, Connecticut

${ }^{2}$ Argonne National Laboratory, Chicago, Illinois

${ }^{3}$ U.S. Geological Survey, Denver, Colorado
} 


\section{Contents}

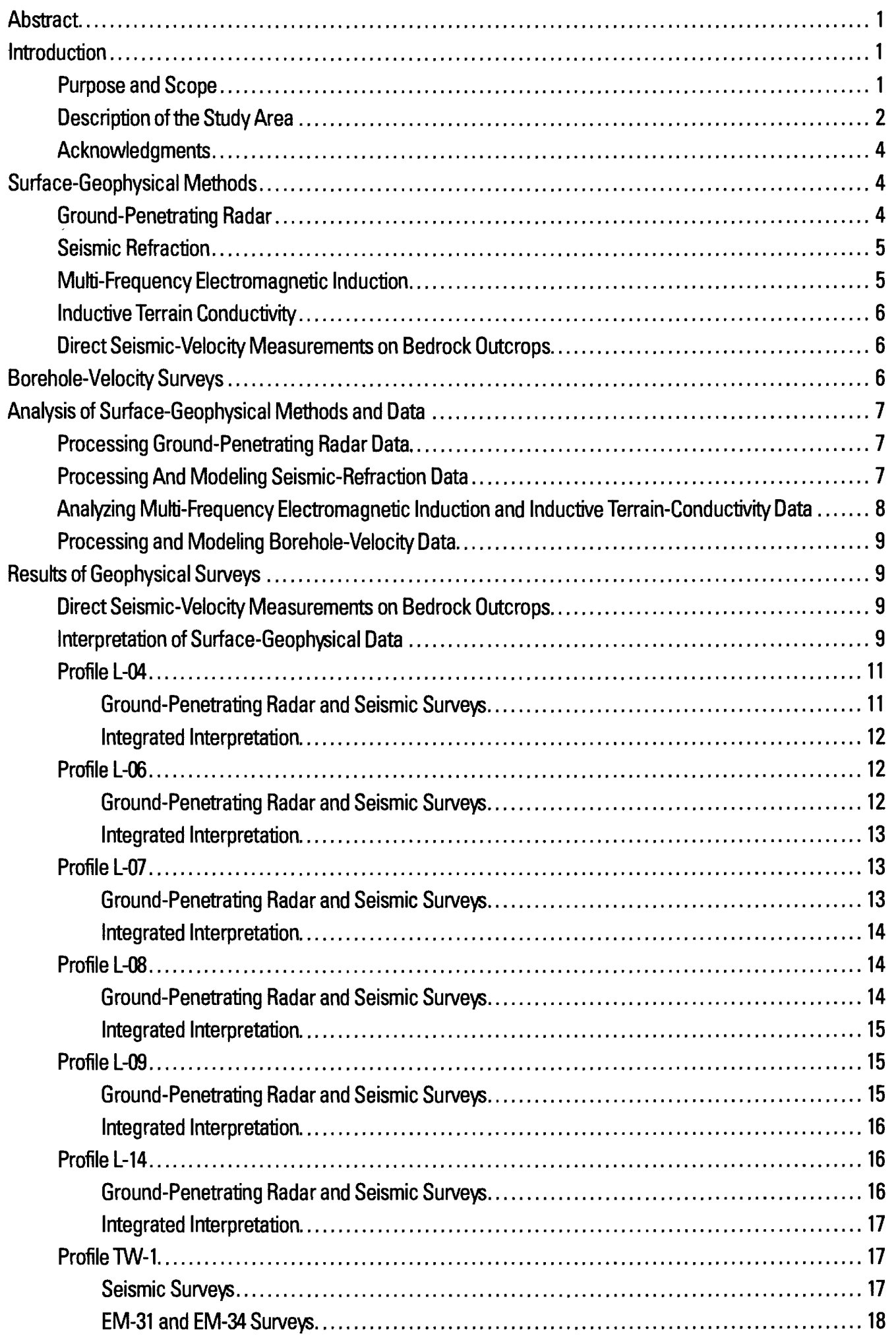




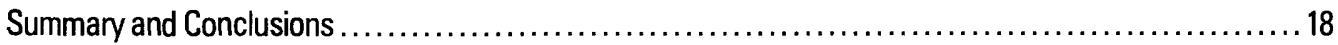

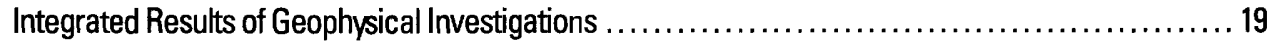

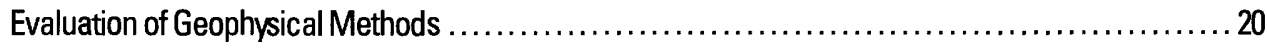

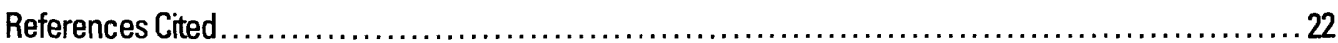

Appendix 1. Processed ground-penetrating radar data (a), borehole seismic velocity survey from borehole MW-4 (b), and seismic-refraction earth-layer and tomography models (c) from Profile L-04 at the formerly used defense site, Machiasport, Maine.

Appendix 2. Processed ground-penetrating radar data (a), borehole seismic velocity survey from borehole MW-6 (b), and seismic-refraction earth-layer and tomography models (c) from Profile L-06 at the formerly used defense site, Machiasport, Maine.

Appendix 3. Processed ground-penetrating radar data (a), and seismic-refraction earth-layer and tomography models (b) from Profile L-07 at the formerly used defense site, Machiasport, Maine.

Appendix 4. Processed ground-penetrating radar data (a), borehole seismic velocity survey from borehole MW-8b (b), and seismic-refraction earth-layer and tomography models (c) from Profile L-08 at the formerly used defense site, Machiasport, Maine

Appendix 5. Processed ground-penetrating radar data (a), and seismic-refraction earth-layer and tomography models (b) from Profile L-09 at the formerly used defense site, Machiasport, Maine....

Appendix 6. Processed ground-penetrating radar data (a), borehole seismic velocity survey from borehole MW-14 (b) and seismic-refraction earth-layer and tomography models (c) from Profile L-14 at the formerly used defense site, Machiasport, Maine.

Appendix 7. Borehole seismic-velocity survey from borehole TW-1 (a), seismic-refraction earth-layer and tomography models from Profile TW-1 (b), and inductive-terrain conductivity profiles (c) at the formerly used defense site, Machiasport, Maine

\section{Figures}

1. Map showing study area, showing locations of surface-geophysical surveys and boreholes at the Air Force Radar Tracking Station formerly used defense site study area, Machiasport, Maine. 3

2. Diagrams showing examples of selected (a) reflectors and (b) diffractions interpreted/observed in ground-penetrating radar data

\section{Tables}

1. Approximate maximum depths of investigation using the inductive terrain-conductivity method.....6 6

2. Distance, traveltime, and velocity data from direct seismic-velocity measurements at the

Air Force Radar Tracking Station formerly used defense site, Machiasport, Maine.

3. Depth to weathered bedrock and competent bedrock from exploratory drilling, ground-penetrating radar, and seismic-refraction surveys, Air Force Radar Tracking Station formerly used

defense site, Machiasport, Maine 


\section{Conversion Factors and Datum}

\begin{tabular}{lll}
\hline \multicolumn{1}{c}{ Multiply } & By & \multicolumn{1}{c}{ To obtain } \\
\hline centimeter $(\mathrm{cm})$ & 0.3937 & inch $(\mathrm{in})$. \\
meter $(\mathrm{m})$ & 3.281 & foot $(\mathrm{ft})$ \\
meter $(\mathrm{m})$ & 1.094 & yard $(\mathrm{yd})$ \\
cubic meter $\left(\mathrm{m}^{3}\right)$ & 1.308 & cubic yard $\left(\mathrm{yd}^{3}\right)$ \\
kilometer $(\mathrm{km})$ & 0.6214 & mile $($ mi) \\
kilogram $(\mathrm{kg})$ & 2.205 & pound avoirdupois $(\mathrm{lb})$ \\
\hline
\end{tabular}

Electrical conductivity in millisiemens per meter $(\mathrm{mS} / \mathrm{m})$ may be converted to millimhos per meter (mmho/m) as follows: $1 \mathrm{mmho} / \mathrm{m}=1 \mathrm{mS} / \mathrm{m}$.

Temperature in degrees Celsius $\left({ }^{\circ} \mathrm{C}\right)$ may be converted to degrees Fahrenheit $\left({ }^{\circ} \mathrm{F}\right)$ as follows: ${ }^{\circ} \mathrm{F}=\left(1.8 \mathrm{x}^{\circ} \mathrm{C}\right)+32$.

Vertical coordinate information is referenced to the North American Vertical Datum of 1988 (NAVD 88); horizontal coordinate information is referenced to the North American Datum of 1983 (NAD 83), unless otherwise noted.

\section{Other abbreviations used in this report}

$\begin{array}{ll}\mu \mathrm{s} & \text { microsecond } \\ \mu \mathrm{S} / \mathrm{cm} & \text { microsiemen per centimeter } \\ \mathrm{Hz} & \text { hertz } \\ \mathrm{kHz} & \text { kilohertz } \\ \mathrm{L} / \mathrm{min} & \text { liter per minute } \\ \mathrm{m} / \mathrm{ns} & \text { meter per nanosecond } \\ \mathrm{m} / \mathrm{s} & \text { meter per second } \\ \mathrm{MHz} & \text { megahertz } \\ \mathrm{mmho} / \mathrm{m} & \text { millimho per meter } \\ \mathrm{ms} & \text { millisecond } \\ \mathrm{mS} / \mathrm{m} & \text { millisiemen per meter } \\ \mathrm{mV} & \text { millivolt } \\ \mathrm{ns} & \text { nanosecond } \\ \mathrm{s} & \text { second } \\ \mathrm{W} & \text { watt }\end{array}$





\title{
Surface-Geophysical Investigation of the Formerly Used Defense Site, Machiasport, Maine, February 2003
}

\author{
By Eric A. White, Michael D. Thompson, Carole D. Johnson, Jared D. Abraham, Steven F. Miller, and \\ John W. Lane, Jr.
}

\section{Abstract}

Surface-geophysical surveys were conducted in February 2003 at a formerly used defense site in Maine, where residual chlorinated solvents are affecting off-site domestic water-supply wells. The U.S. Geological Survey and Argonne National Laboratory used surface-geophysical methods, including ground-penetrating radar and seismic-refraction tomography, to characterize the lithology and structure of the bedrock at the site and to identify highly fractured areas that may provide pathways for ground-water flow and contaminant transport. Multifrequency electromagnetic and inductive terrain-conductivity methods also were evaluated, but these techniques were adversely affected by a nearby naval computer and telecommunications station.

Interpretation of the data from ground-penetrating radar indicates that depth to the weathered bedrock surface is approximately 0.5 to 3 meters. Reflections from within the bedrock are visible throughout all ground-penetrating radar profiles, and zones of scattered electromagnetic energy may correlate to zones of highly fractured bedrock. Interpretation of the data from seismic-refraction tomography inversion indicates that zones of relatively low seismic velocity and topographic lows may correlate with fractured and water-producing intervals within the bedrock. Integrated interpretation of the results from ground-penetrating radar and seismic-refraction tomography was used to locate boreholes along the surface-geophysical profiles. An integrated analysis of information obtained from the surface- and borehole-geophysical surveys and test drilling will be used by the U.S. Army Corps of Engineers to develop a conceptual model of ground-water flow and solute transport at the site.

\section{Introduction}

The Department of Defense is responsible for environmental restoration of properties that were formerly owned by, leased to, or otherwise possessed by the United States under the jurisdiction of the Secretary of Defense. Such properties are known as Formerly Used Defense Sites (FUDS). The U.S. Army Corps of Engineers (USACE) manages and directs the FUDS program, which has more than 9,000 properties identified for potential inclusion. In the 1990's, numerous occurrences of ground-water contamination were found at an Air Force Radar Tracking Station near Machiasport, Washington County, Maine (fig. 1). The site came under the jurisdiction of the FUDS program after the Federal Aviation Administration (FAA) found that many of the World War II-era buildings contained asbestos insulation, lead paint, mercury, electrical switches, and electrical transformers containing polychlorinated biphenyls (PCBs). During operation of the facility, solvents, including trichloroethylene, trichloroethane, and tetrachloroethane were used for automotive maintenance, paint thinning, degreasing, and equipment cleaning.

In 1997, because domestic wells were determined to be affected by fuel and trichloroethylene contamination, the Maine Department of Environmental Protection (MEDEP) ordered the USACE to clean up the site and provide an alternative water supply for local residents (ABB Environmental Services, Inc., 1997). During the clean-up effort, approximately $18,350 \mathrm{~m}^{3}$ (cubic meters) of contaminated soil were excavated and disposed of off site (ABB Environmental Services, Inc., 1997). Data on the distribution of contaminants indicated that potential trichlorethylene source areas are present in three areas: near a transmitter site southeast of Howard Mountain, near the radar tracking station along the southern part of Howard Mountain, and near a former ground/air transmitter/receiver site southeast from the top of Miller Mountain (Weston Solutions, 2003).

Since 2000, the USACE has worked with the Restoration Advisory Board, the town of Machiasport, the MEDEP, and Maine's congressional representatives to determine the steps needed to provide remedial alternatives for the FUDS site in Machiasport. Through a review process with MEDEP, State, and local representatives, the USACE determined that additional subsurface information was needed to further characterize the bedrock aquifer (U.S. Army Corps of Engineers, 2002). To assist in this effort, the U.S. Geological Survey (USGS) and Argonne National Laboratory (ANL) conducted an investigation in February 2003, in cooperation with the USACE, to identify surface-geophysical methods that could provide information for locating boreholes in the fractured-bedrock environment that could then provide additional information about the nature of the subsurface and the contamination. An additional aspect of the study was to evaluate the effectiveness of the surface-geophysical methods under winter conditions.

\section{Purpose and Scope}

This report describes the surface-geophysical methods and data-collection efforts used at the Air Force Radar Tracking Station FUDS site in Machiasport, Maine. Because of the site's proximity to the coast and a small village in Machiasport, the site also may be known as the Bucks Harbor FUDS site. In this 


\section{Surface-Geophysical Investigation of the Formerly Used Defense Site, Machiasport, Maine}

report, the term "study area," includes all the areas around and between Howard, Miller, and Bucks Mountains (fig. 1).

The surface-geophysical methods used in this investigation are ground-penetrating radar (GPR), seismic-refraction tomography, multi-frequency electromagnetics (GEM-2), and inductive terrain conductivity (EM-31 and EM-34), which measure variations in the electromagnetic, acoustic, and electrical properties of the subsurface. The report presents interpretations of the geophysical dáta including the depth to bedrock, locations of fractures that may be capable of transporting groundwater contamination, and sites for exploratory bedrock boreholes. The report also compares the results from selected geophysical methods with the known mapped bedrock geology and drilling records.

In February 2003, surface-geophysical surveys were conducted to identify possible fractures that could potentially serve as contaminant pathways in the crystalline bedrock. After preliminary interpretations of the surface-geophysical data, drilling locations were determined, and 12 boreholes (11 monitoring wells and 1 test well) were drilled from February through May 2003. Seven of the boreholes were drilled adjacent to the surface-geophysical profiles to further characterize features that were observed in the profiles and to further describe the subsurface geohydrology. Drilling logs and bedrock core collected from the boreholes were summarized by Weston Solutions (2003). Borehole-velocity surveys were conducted in six boreholes along the surface-geophysical profiles; results were used to help improve the interpretation of the seismic-refraction tomography.

\section{Description of the Study Area}

The study area is characterized by small hills that have been shaped by glacial and recent erosion. This created a drainage pattern that is oriented northwest-southeast, parallel to the direction of glacial movement. Three major rock assemblages are mapped in the study area (Gates and Moench, 1981). The oldest rock exposed at land surface is a sedimentary unit in the early Devonian Eastport Formation, present on the southern side of Miller Mountain. The unit consists of shale, siltstone, and fine-grained bedded tuffs, and is gray and maroon in color. The second oldest rock is a bimodal volcanic unit in the Eastport Formation consisting of silicic members that include a rhyolitic eruptive unit with flow-banded stony, vitrophyre, autobreccia, and pyroclastic zones. Dacite and tuff breccias also are present. This volcanic unit is the most abundant rock in the area, and has been mapped on Howard Mountain southward and eastward to the coast. The bimodal volcanic units were intruded or erupted along a fault bordering the Machias syncline.

The third major assemblage in the study area is a plutonic igneous rock unit (Devonian age) consisting of hornblendebearing biotite granodiorite and quartz monzonite (a bimodal suite of gabbro/granodiorite with quartz diorite to diorite) that was intruded into the Eastport Formation. The granodiorite has been mapped on the northwestern side of Howard Mountain and on the south-southwestern flank of Miller Mountain. The unit also has been observed to a depth of about $16 \mathrm{~m}$ (meters) below land surface in core from borehole MW-14 located on the southsouthwestern flank on Miller Mountain (Weston Solutions, 2003). In addition, several Silurian-Devonian-age diabase and gabbro dikes, sills, and irregular small plutons have intruded into the local formations. Many of these mafic intrusions are oriented northwest.

Large-scale regional structures include a syncline, normal faults, and block faults. The Machias syncline, which is a postearly Devonian, northwest-trending fold, includes the Pembroke Group and Eastport Formation. The Lubec fault zone, a northeast-trending fault, was mapped offshore from the FUDS site and is characterized by sheared and tightly folded rocks of the Eastport and Quoddy Formations (Gates and Moench, 1981). Subsequent block faulting associated with Silurian volcanism created numerous northwest-trending faults. A large normal fault transects the study area and is coincident with the northwest-southeast trending drainage between Howard and Miller Mountains. The fault is mapped from Howard Cove several kilometers to the northwest. Numerous northwest-southeast trending faults dissect the study area with scattered northeastsouthwest faulting and folding (Gates, 1981). These faults and fractures appear to have affected the development of the surface drainage and may have strong controls on ground-water flow within the bedrock aquifer.

Maps of the surficial deposits indicate that most of the study area is covered by a thin veneer of till and brown silty sand and gravel of Pleistocene age (Borns, 1974). ABB Environmental Services, Inc. (1995) however, indicated that the Downeast Correctional Facility housing area, on the western slope of Howard Mountain, is underlain by mixed fill, silt, sand, and gravel glaciomarine deposit overlying gray glacial marine clay. The thickness of the clay in this area ranges from at least 6 to greater than $8 \mathrm{~m}$. No substantial amounts of overburden material have been mapped in the study area.

The geophysical surveys and boreholes were focused in three locations, which are downgradient of suspected contamination source areas, and are suspected of containing locally important fractures that have been mapped by photolinear fracture-trace analysis (ABB Environmental Services, Inc., 1997). Profiles (geophysical-survey lines) L-04, L-06, and L-07 are hydrologically downgradient from the transmitter site, which is on a hill west of Howard Mountain. The hill consists of glacial and end moraine till that ranges in thickness from 0 to more than $3.5 \mathrm{~m}$ (Borns, 1974). The transmitter site is underlain by fractured stony vitrophyric rhyolite locally intruded by northweststriking mafic dikes (Gates, 1981). Profiles L-08 and L-09 are downgradient and southeast of the Air Force Radar Tracking Station on top of Howard Mountain, which is underlain by highly fractured banded stony rhyolite (Gates and Moench, 1981). Profile TW-1 is north of Howard Mountain. Profile L-14 is southeast and downgradient from the former ground/air transmitter/receiver site, north of Bucks Harbor on Miller Mountain, which has a thin ( 0 to more than $1.5 \mathrm{~m}$ ) veneer of till and is underlain by a granodiorite that has been intruded by diabase dikes, and sills and dikes of gabbro (Gates, 1981). 


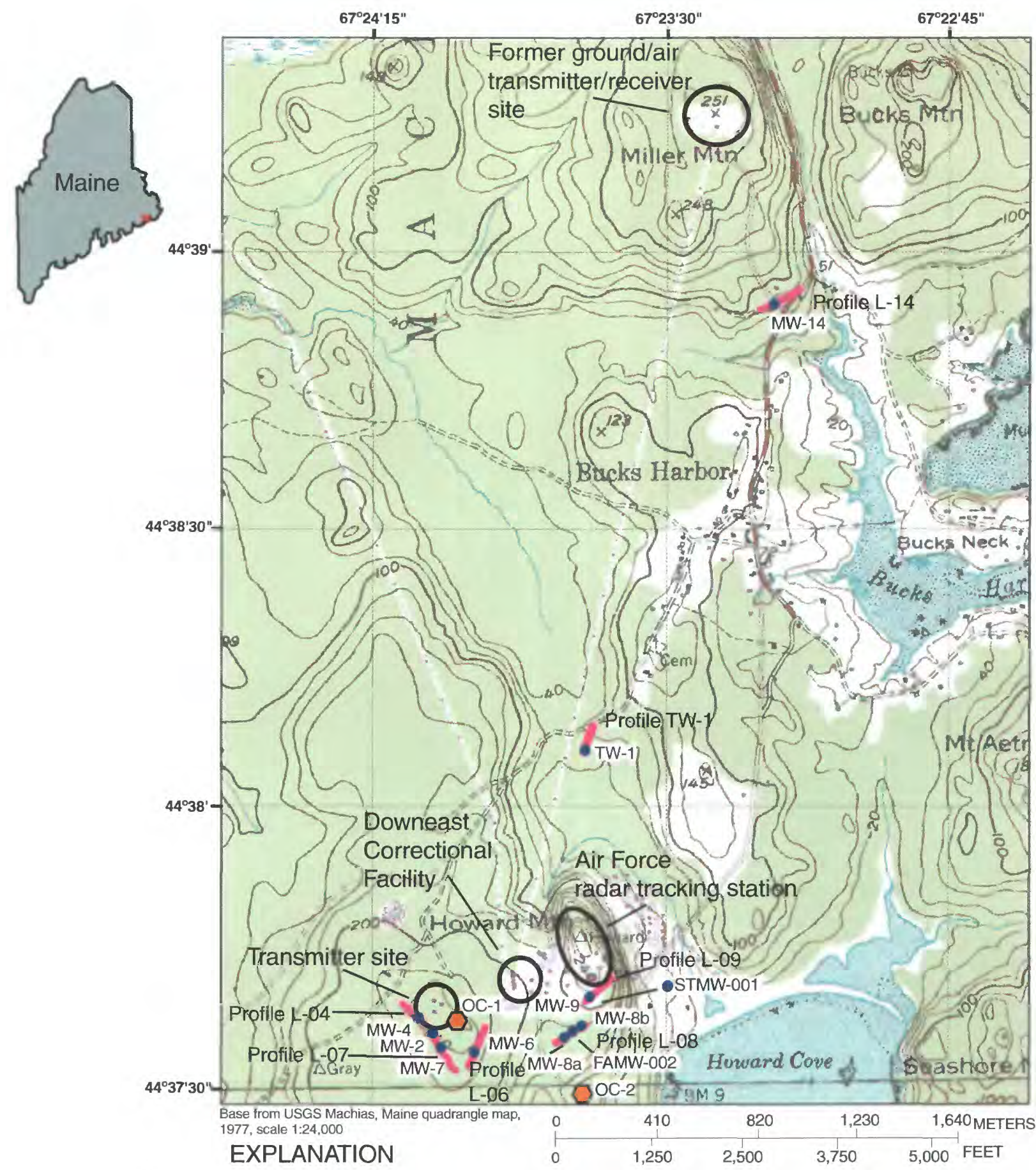

MW-4 Borehole and identification number

Geophysical profile
Outcrop location

OC-1 and identification number

Elevation contour interval is 20 feet

Figure 1. Study area, showing the locations of surface-geophysical surveys and boreholes at the Air Force Radar Tracking Station formerly used defense site, Machiasport, Maine. 


\section{Surface-Geophysical Investigation of the Formerly Used Defense Site, Machiasport, Maine}

\section{Acknowledgments}

This work was conducted in cooperation with the U.S. Army Corps of Engineers, New England District, under MIPR W13G8630245226. The authors would like to acknowledge the support and assistance of Drew Clemens of the USACE. All borehole-velocity data were collected by Mark Blackey of Geophysical Applications Inc. Additionally, the authors appreciate the technical assistance of Frederick Day-Lewis and Marcel Belaval of the USGS. Finally, the authors are grateful to Jeff Lucius and Beth Burton for technical reviews of this work.

\section{Surface-Geophysical Methods}

Several previous investigations have addressed the heterogeneous nature of fractured rock and the importance of integrating data from a variety of geophysical methods to characterize fractured-rock aquifers (for example, see Shapiro and others, 1999). This investigation used surface-geophysical methods as a cost-effective, non-invasive means to optimize the siting of the boreholes to be used for additional subsurface investigation.

Four surface-geophysical methods were tested to determine their utility for locating highly fractured bedrock. Groundpenetrating radar was used to determine the thickness of the overburden sediments and the depth to fractured bedrock and possible fracture zones in the bedrock. Seismic-refraction methods were used to determine the velocity of the subsurface material; to identify the depth of the interfaces between overburden, weathered bedrock, competent bedrock, and different bedrock units; and to identify low-velocity locations that may relate to zones of highly fractured rock. A multi-frequency electromagnetic induction and two inductive terrain-conductivity methods were used to determine system response to variable bedrock types, and potentially to identify fluid-filled fractures in the bedrock. All surface-geophysical surveys were located using a differential global-positioning system (GPS). In addition to the surface-geophysical surveys, direct seismic-velocity measurements were made on bedrock outcrops.

\section{Ground-Penetrating Radar}

GPR is used to detect contrasts in electromagnetic (EM) properties (primarily dielectric permittivity, but also electrical conductivity and magnetic permeability) of subsurface materials and the fluids in these materials. A transmitting antenna, placed on the surface, is used to transmit an EM pulse into the subsurface using frequencies in the radar frequency range $(10-1,000 \mathrm{MHz}$ (megahertz)). When an EM pulse encounters materials with different EM properties, some energy is reflected and some is transmitted deeper into materials. Reflected energy is returned to the surface and recorded by a receiving antenna. By profiling along the surface, a two-dimensional record of EM reflections is created, with distance shown along the horizontal axis and two-way traveltime displayed on the vertical axis.
After the data are collected, the two-way traveltime is converted to distance. The velocity of the subsurface material can be determined by digitizing hyperbolas in the radar record or by measuring the traveltime to reflectors of known depth. The resultant velocity can then be used to convert traveltime to an approximate depth.

GPR data were collected using a single-channel RAMAC radar system. The system supports surface and borehole applications and can be interfaced with a number of different shielded and unshielded antennas. For this study, a shielded antenna was used with the transmitter and receiver antennas in the same housing, and separated by a distance $0.46 \mathrm{~m}$, with a center frequency in air of $100 \mathrm{MHz}$. Different antennas with center frequencies (in air), ranging from 50 to $400 \mathrm{MHz}$ were tested to select the antenna frequency that maximized penetration and resolution. A shielded antenna has more stable electronics and provides "protection" from unwanted radar reflections from objects such as trees and overhead power lines. The cables and control unit accompanying the shielded antenna are able to endure extreme cold conditions, whereas the fiber optic cables used with the unshielded antennas are vulnerable to breaking in extreme cold temperatures. Spatial and waveform sampling frequencies were selected to ensure proper waveform recording and subsurface structural imaging. All data were recorded using an approximate sampling frequency of $2,000 \mathrm{MHz}$ and with 512 samples per trace. The data were collected in time mode at a rate of 20 traces per second and a record length of approximately $256 \mathrm{~ns}$ (nanoseconds). GPS data were simultaneously recorded with the GPR data using a common acquisition system. All GPS and GPR data were tagged with a uniqe fiducial, indicating time and position.

Data were collected in a manner consistent with ASTM guidelines for the surface GPR method (American Society for Testing and Materials, 1999). GPR reflection profiles were acquired using a common offset mode in which the separation between the transmitting and receiving antennas is fixed, and the entire unit was incrementally moved or pulled along the survey line. Assuming suitable reflectors are present in the common-offset data, EM propagation velocities can be determined using the common mid-point (CMP) method. In the CMP method, the transmitting and receiving antennas are centered about a mid-point and a measurement is made. Then, the distance, $d$, between the transmitter and receiver is increased and the process is repeated. The CMP data can be processed to determine EM propagation velocities using $X^{2}-T^{2}$ (arrival-time versus offset) or semblance methods. Extremely cold temperatures, however, resulted in the control unit and fiber-optic cables freezing and becoming unusable. Because CMP data could not be obtained. EM propagation velocities were determined using the hyperbolic search method, which is described in the ASTM guidelines (American Society for Testing and Materials, 1999). This method searches for coherency among traces along a hyperbolic curve. EM propagation velocities were used to estimate the depth of reflectors present on the GPR profiles and for other processing purposes. 


\section{Seismic Refraction}

Seismic-refraction methods measure the time it takes for a compressional sound wave, or seismic wave, to travel down through layers of the earth and refract back to detectors at land surface. By measuring the traveltime of the seismic wave and applying laws of physics that govern the propagation of seismic waves, the subsurface geology can be inferred (Haeni, 1988). A sound source is used to generate the seismic wave. The seismic energy travels into the earth and is refracted (bent towards the slower velocity layer) at interfaces between layers with different seismic (acoustic) velocities. In the special case where the seismic wave has been refracted parallel to the interface (at the critical angle), the seismic energy travels along this interface, generating a head wave that returns to the surface. A linear array of acoustic receivers (geophones) placed along the land surface is used to record the traveltime of the first returning seismic signal. The seismic signal at each geophone is digitized and stored on a computer hard drive, and a time-picking program is used to determine the traveltime of the first returning seismic signal. The traveltime information is plotted on a time-distance graph. For the case of plane layer geometry, the time-distance plot shows distinct linear segments that correspond to subsurface layers where the inverse of the slope of the segment is equivalent to the apparent seismic velocity for that particular layer.

Seismic data were collected using a 48-channel Geometrics StrataView seismograph with $14-\mathrm{Hz}$ (hertz) geophones. Analog filters were used for profile L-08, where power line noise was reduced by using a $180-\mathrm{Hz}$ notch filter, and for profile TW-1, where a 10-Hz low-cut filter was applied to reduce wind noise. All data were recorded using a sampling rate of 4,000 samples per second, which is equivalent to a $0.25-\mathrm{ms}$ (millisecond) interval, and a record length of $256 \mathrm{~ms}$.

Geophones were spaced at 1-m intervals for profiles L-04 through L-14, with shot points located at intervals of $5 \mathrm{~m}$. Snow was packed around geophones to ensure coupling with the ground. Shot points were offset up to $30 \mathrm{~m}$ from the ends of the profile, yielding a maximum shot-to-receiver distance of $78 \mathrm{~m}$. Far offset shot points were used to increase the depth from which seismic data were collected, and reverse-spread geometry was used to improve the estimates of bedrock velocity. A 2-m geophone spacing was used for profile TW-1, where a greater depth of investigation was required. The maximum shot-to-receiver distance for profile TW-1 was $116 \mathrm{~m}$. The energy source used was a 6-kg (kilogram) sledgehammer and metal plate, except for a few shot points on profile TW-1 where a weight-drop source (elastic-wave generator) was used.

Data were collected in a manner consistent with ASTM guidelines for the seismic-refraction method (American Society for Testing and Materials, 2000). The original data are on record at the ANL in Chicago, Illinois. Both refractor-interface (SIPT2) and tomographic models were constructed from the measured traveltime data. The SIPT2 algorithm (Scott, 1977) is used to construct earth-layer models using array geometry, first arrival times, and layer assignments from the seismic time-distance data. The model solution obtained by the SIPT2 method assumes an increase in seismic-wave velocity with depth and continuous layers. Layered models are limited by the presence of blind zones, hidden layers, and lateral changes in velocity in the same layer. Blind zones occur when an intermediate layer is thinner than the overlying layer or its velocity contrast is too small, resulting in refracted waves that are not discernible on the seismic data. The hidden-layer problem occurs when an intermediate layer has a lower velocity than a layer above, which results in an overestimation of the depth to layers below the hidden layer.

Tomographic solutions are used to construct a velocity profile using seismic-refraction traveltime measurements, array geometry, and other available data, such as borehole-velocity data. The tomographic solutions provide the capability of overcoming problems associated with blind zone and lateral discontinuities, and in some cases, hidden layers. Tomography software constructs a velocity model using the array geometry, the first arrival traveltime data, and a starting velocity model, which can be an average velocity, the earth-layer solution, boreholevelocity data, or some other a priori information. The tomography velocity model is an optimized solution that best fits the measured arrival-time data. For the preliminary interpretation, the earth-layer solution and average velocity models were used as the starting velocity models. After the boreholes were drilled, the tomographic inversions were repeated, incorporating the borehole-velocity data into the tomographic solutions presented in this report. Limitations of the seismic-refraction tomography method include resolution limits based on geophone spacing, generation of velocity gradients where discrete layers are more applicable, and generation of a "smoothed" output required for stability needs of the inversion. Because the method allows for both lateral and vertical changes in the velocity field, it is suitable for imaging weak or fractured zones (with low velocity) within the bedrock.

\section{Multi-Frequency Electromagnetic Induction}

Multi-frequency EM induction is used to measure changes in electrical conductivity with depth and position. Changes in apparent conductivity might relate to characteristics of rock type, overburden, water quality, or fracturing. Measurements were made using the Geophex, Incorporated GEM-2, a handheld, digital, multi-frequency EM-induction instrument (Won and others, 1996). The GEM2 operates in a frequency range of $330 \mathrm{~Hz}$ to $24 \mathrm{kHz}$ (kilohertz), and can transmit a waveform containing multiple frequencies. The GEM- 2 contains three coils: transmitter (Tx), bucking, and receiver $(\mathrm{Rx})$. The Tx and $\mathrm{Rx}$ coils are separated by about $1.7 \mathrm{~m}$. The bucking coil removes (or "bucks") the primary field from the receiver coil, allowing increased gain at the Rx coil. The system has a fixed coil spacing. The coils are molded into a single boom, removing potential problems associated with coil geometry. The multiple frequency approach takes advantage of EM skin depth, which is the effective depth of penetration of EM energy and is inversely proportional to frequency. Low-frequency signals penetrate 


\section{Surface-Geophysical Investigation of the Formerly Used Defense Site, Machiasport, Maine}

deeper than high frequency signals and image deeper structures, whereas higher frequency signals penetrate a shorter distance and thus image shallower structures. Therefore, scanning over a range of frequencies is equivalent to depth sounding.

\section{Inductive Terrain Conductivity}

Inductive terrain conductivity is an EM method that measures the apparent subsurface electrical conductivity. An alternating current in a transmitter coil induces EM fields in the earth. The induced EM fields produce a time-varying primary magnetic field. The primary magnetic field produces alternating electric currents in the earth that generate a secondary magnetic field, which is measured along with the primary magnetic field by the receiver coil. Subsurface conductivity is affected by variations in the subsurface materials or lithology and the ionic concentration of the subsurface water (McNeill, 1980). Conductive anomalies produce a strong secondary magnetic field. For example, inductive terrain-conductivity instruments can detect conductive features, such as landfill leachate or saltwater intrusion, ore bodies, or buried metal objects. These instruments also can be used to map conductive features such as fluid-filled fractures (Powers and others, 1999).

Inductive terrain-conductivity equipment consists of a transmitting coil, a receiving coil, a control unit for each, and intercoil cables. The coils are held coplanar at a constant offset, and data are collected at discrete intervals along a survey line. The transmitter-receiver midpoint is considered to be the measurement location. The coils can be used in two configurations-horizontal dipole and vertical dipole. In the horizontaldipole configuration, the coils are positioned vertically, whereas in the vertical-dipole configuration, the coils are positioned horizontally; the axis of the dipolar magnetic field is in the center of coil perpendicular to the plane of the coil. The electromagnetic field is induced deeper into the ground with the vertical-dipole configuration than with the horizontal-dipole configuration (table 1). Increased coil spacing and more resistive materials also increase the penetration depth of the induced electromagnetic field. An inductive terrain-conductivity measurement gives an average value for the volume approximated by the distance between the two coils and the depth of the measurement. In the vertical-dipole mode, the materials in the middle of the depth of penetration dominate the signal. In the horizontal-dipole mode, the materials in the shallow depths of penetration dominate the signal (McNeill, 1980). The measurements are apparent conductivities rather than true conductivities, because a conductively homogeneous subsurface is assumed (Powers and others, 1999).

For this study, two Geonics ground-conductivity meters were used, the EM-31 with a 3.66-m coil spacing and the EM34-XL with 20- and 40-m coil spacings. The data were collected at spacings of 5-m along the profile. During data collection, the sensitivity and scale functions were adjusted to ensure conductivity readings were taken from the upper third of the scale (Geonics Limited, 1991).
Table 1. Approximate maximum depths of investigation using the inductive terrain-conductivity method.

[From McNeill, 1980]

\begin{tabular}{ccc}
\hline \multirow{2}{*}{$\begin{array}{c}\text { Coil spacing, } \\
\text { in meters }\end{array}$} & \multicolumn{2}{c}{ Depth of investigation, in meters } \\
\cline { 2 - 3 } & Horizontal dipole & Vertical dipole \\
\hline EM-31-3.66 & 2.5 & 5.5 \\
EM-34-20.0 & 15.0 & 30.0 \\
EM-34-40.0 & 30.0 & 60.0 \\
\hline
\end{tabular}

\section{Direct Seismic-Velocity Measurements on Bedrock Outcrops}

Direct seismic-velocity measurements were made at two sites at Howard Mountain on exposed outcrops of the uppermost unit of the Eastport Formation (bimodal volcanic unit), which is a flow-banded stony rhyolite containing vitrophyre and autobreccia zones. The first outcrop site (OC-1) is southwest of the Downeast Correctional Facility. The second outcrop site (OC-2) is approximately $200 \mathrm{~m}$ southeast of profile L-08, near the access road.

For the direct-velocity measurements, $40-\mathrm{Hz}$ geophones were affixed directly to the outcrop, and the distance from the geophones to the shot point was measured. A sledgehammer and plate were used as the energy source, and the traveltimes were measured using a Geometrics Strataview 48-channel seismograph. Data were recorded at a sampling rate of $31.25 \mu \mathrm{s}$ (microsecond), with a record length of $32 \mathrm{~ms}$, and without ana$\log$ filters set. At OC-1, six geophones were spaced 3.48 to $3.75 \mathrm{~m}$ from the shot point, and the traveltimes were measured. At OC-2, nine geophones were spaced 4.17 to $10.90 \mathrm{~m}$ from the shot point, and the traveltimes were measured.

\section{Borehole-Velocity Surveys}

Borehole-velocity surveys, or check shots, are used to measure the velocity of the underlying sediment and rock, and to confirm velocity information for the seismic-refraction models. The general configuration for recording the downhole seismic data consists of a borehole geophone, an impulsive energy source, and a seismograph. A GeoStuff BHG-2, three-component geophone with $40-\mathrm{Hz}$ receiver elements, was used in the borehole, and seismic data were recorded using an ABEM Terraloc Mark 6, 24-channel seismograph using a 50- $\mu$ s sampling rate and a record length of $58 \mathrm{~ms}$. The downhole geophone was moved in 1.5-m increments within the borehole. A sledgehammer and plate were used as the energy source, and placed at an offset of $1.5 \mathrm{~m}$ from the borehole. Three additional $30-\mathrm{Hz}$ geophones were placed on the ground surface at offsets of $0,1.5$, and $3.3 \mathrm{~m}$ from the borehole. The surface geophones are 
required to resolve any shot-timing variations that occur when using impact sources. The fast sampling rate was required so that very small changes of less than $0.3 \mathrm{~ms}$ in arrival time could be detected. Small arrival time changes were expected due to the presence of high-velocity silicic volcanic and crystalline bedrock (granodiorite and gabbro), which typically transmit compressional waves with velocities ranging from 3,000 to $7,000 \mathrm{~m} / \mathrm{s}$ (meters per second).

\section{Analysis of Surface-Geophysical Methods and Data}

Data were collected using four surface-geophysical methods to determine which individual or complementary methods were best suited to identify areas of highly fractured bedrock at the FUDS site in Machiasport under winter conditions:

(1) GPR, (2) seismic-refraction tomography, (3) multi-frequency electromagnetic induction (GEM-2), and (4) inductive terrain conductivity (EM-34 and EM-31). All methods were preliminarily tested at the transmitter and radar tracking station sites. Of the methods tested, GPR and seismic-refraction tomography yielded usable data, and the results are presented in this report. GPR and seismic-refraction tomography surveys were run along six profiles. A seventh seismic-refraction tomography survey was run along profile TW-1. The multi-frequency electromagnetic induction and inductive terrain-conductivity methods were largely unsuccessful because of EM interference from a nearby naval computer and telecommunications station. The results from those surveys will not be discussed, except for the EM-31 and EM-34 surveys run along profile TW-1.

\section{Processing Ground-Penetrating Radar Data}

The common-offset GPR data were processed to improve their presentation and for interpretation. In the processed data, reflections from the overburden-bedrock interface are more continuous and therefore, more easily distinguished. GPR processing was conducted using commercially available software packages, GRADIX and IXeTerra (developed by Interpex International, Inc., Golden, Colorado). Processing steps include filtering, application of gain, background-removal, migration, spatial-resampling, elevation conversion, and digitization of subsurface hyperbolic reflectors to obtain velocity information. Two types of filtering were conducted on these data. The first was frequency filtering to remove natural and cultural noise as well as the direct-current (DC) shift. Noise can be introduced into the GPR data by outside sources such as overhead power lines, radio transmissions, and by the electronics and cables of the GPR unit itself; shielded antennas were used to minimize potential noise from the nearby radio transmitter towers. The second type of filtering used was bandpassfrequency filtering to remove frequencies less than and greater than the frequency range of interest (Interpex, 1996). Frequencies greater than $300 \mathrm{MHz}$ were removed. The bandpass filtering also eliminated high-frequency components that do not contain useful reflection information. Two types of gain were used together and applied to the GPR data to compensate for attenuation of the radar wave. The first gain was a linear decibel gain translated into an exponential curve on a linear scale, which accounts for spherical divergence; and the second was an exponential gain, which accounts for absorption of the radar energy by the bedrock. Spherical divergence occurs when a spherical wave traveling through a medium continually spreads out, and thus, the energy density decreases (Sheriff, 1991). The direct arrival of the radar wave was removed through a process called background removal. Background removal is useful for revealing the near-surface reflectors that may be obscured by the direct arrival of a radar wave. Migration also was performed on the GPR data to convert the vertical axis from time to depth. The GPR data were spatially resampled to display the horizontal axis as distance. Elevation information was collected and applied to the GPR profiles. Digitizing subsurface hyperbolic reflectors requires GPR reflections from point reflectors that result in a hyperbolic pattern on the radar record. This information is used to find the depth to the reflector when a distance along the ground and two-way traveltime to an object is known. For this investigation, hyperbolic fitting was conducted on all GPR profiles, and a uniform radar velocity of $95 \mathrm{~m} / \mathrm{s}$ was calculated for both overburden and bedrock. This velocity was used to convert traveltime to an approximate depth after migration was performed.

\section{Processing and Modeling Seismic-Refraction Data}

Seismic-refraction data were processed and modeled to develop velocity-depth profiles for each survey line using two different methods: (1) an earth-layer model (SIPT2) and (2) a tomographic inversion method (GeoCT-II). The results were compared with outcrop and borehole-velocity measurements, as well as lithologic data obtained from drilling. The velocity and lithologic data were used to guide the interpretation of the resulting SIPT2 earth-layer and tomographic models, and were required to resolve the top-of-rock interface on the tomographic models for all profiles except L- 08 . Consistency between independent measures of velocity, such as refraction-derived and borehole-derived velocity provides a measure of confidence in the estimated subsurface velocity structure.

No borehole-velocity data were obtained along profiles L-07 and L-09. As a result, the overall similarity to the other profiles, as well as the lithologic information, were used to interpret the seismic data. For profile L-08, the borehole velocity was incorporated using the "soft" control feature of GeoCTII. In this case, a large damping factor was applied to the estimated borehole velocities in the tomographic inversion; consequently, the velocities of the resulting tomogram and the borehole-derived velocities may differ. The agreement between the tomographic solution and the borehole results can be assessed if 
it is assumed that there is little change in subsurface character away from the borehole where the model is not influenced by the borehole control.

The refraction data were processed by:

1. Verifying the shot timing using the air-coupled seismic event;

2. Picking the first arrival time of the return energy at each geophone for each shot;

3. Assigning array geometry to the traveltime data;

4. Inverting the traveltime information for velocity and depth using layered earth (refractor interface) modeling (SIPT2);

5. Inverting the traveltime data into a velocity depth cross section using a tomographic modeling package (GeoCTII); and

6. Comparing the resulting velocity structures with the direct outcrop measurements and borehole velocity surveys.

Earth-layer (refractor interface) models were generated using the SIPT2 (version 2.3) seismic-refraction software produced by RimRock Geophysics (1992). SIPT2 is based on the modeling code of Scott (1977). The model output consists of discrete layers of constant velocity, from which the underlying geology is interpreted. The algorithm uses the delay-time method of Pakiser and Black (1957) to calculate depth and position of refracting horizons. A ray-tracing algorithm is then applied, which overcomes difficulties associated with dipping or undulating horizons and further refines the generated refraction model.

Tomographic inversion was performed using the GeoCTII (version 2.1) software package produced by GeoTomo LLC (2002). GeoCT-II performs a non-linear inversion to construct a velocity model using traveltime measurements for many shotreceiver combinations. Starting from an initial model, the inversion iteratively updates a velocity model using the inversion algorithm described in Zhang and Toksoz (1998) and Zhang and others (1998). In the inversion process, the model uses values of slowness, which is the inverse of velocity. A conjugategradient algorithm seeks to identify the model that minimizes a composite objective function of three terms: (1) the leastsquares misfit between measured and predicted average slowness values, which are defined as traveltime divided by raypath length; (2) the least-squares misfit between measured and predicted apparent slowness values, defined as the derivative of the traveltime curve with respect to offset distance; and (3) a measure of solution complexity based on Tikhonov regularization. Whereas most inversion methods minimize a two-term objective function including (1) and (3), the approach used here includes information (2) about the shape of the traveltime curve. Zhang and Toksoz (1998) demonstrated the effectiveness of this approach for reducing the problem of model ambiguity.

To test the robustness of each solution, tomographic inversions were performed for a suite of initial models for each profile. The initial models included two- or three-layered starting models constructed from the traveltime versus offset data; the SIPT2 model solutions; a generic model with a uniform vertical gradient from 1,000 to $6,500 \mathrm{~m} / \mathrm{s}$ and no horizontal structure; and uniform velocity fields of 1,500 and $3,500 \mathrm{~m} / \mathrm{s}$. In general, the tomographic inversions resolved the same gross velocity structure regardless of starting model; the only major differences occurred near the model edges where geophone and shot coverage were sparse. Tomographic inversions obtained using the SIPT2 solution as the starting model are presented.

For each profile, the tomographic algorithm was allowed to iterate 10 to 15 times until the root-mean-square (rms) error between the calculated and measured traveltimes approached the $0.5-$ to $2-\mathrm{ms}$ noise level calculated from the reciprocal times and estimated from the traveltime picks. For most profiles, there was little change in model output after seven or eight iterations. Further refinement of each tomographic model was performed using an a priori constraint, which preserves the velocity curvature (second order derivative) of the initial model, and tends to sharpen the tomographic image.

For all profiles, the model cell spacing was half of the geophone spacing $(0.5 \mathrm{~m}$ for profiles L-04 through L-14; and $1 \mathrm{~m}$ for profile TW-1). The $\mathrm{X} / \mathrm{Y}$ (number of horizontal cells versus vertical cell) smoothing ratio ranged from 2 to 4 , where the greater the $\mathrm{X} / \mathrm{Y}$ ratio, the greater the amount of horizontal smoothing. Smoothing control was set to 0.1 , which allowed for a "rougher" model, though the inversion was terminated when the rms-misfit error approached the noise level as discussed above.

The seismic data are presented using a common contourcoloring scheme, where magenta to blue colors represent relatively low velocities, and red to white colors represent relatively high velocities. In general, the lowest velocities occur in the unsaturated, unconsolidated sediments, and the highest velocities are observed in the solid crystalline bedrock. Shown on each profile are the locations of adjacent boreholes with borehole-velocity measurements and lithologic contacts noted. Highly fractured, saturated, crystalline rock has a velocity higher than overburden, but lower than velocities in unfractured rock.

\section{Analyzing Multi-Frequency Electromagnetic Induction and Inductive Terrain-Conductivity Data}

Data collected using the multi-frequency electromagnetic induction and inductive terrain-conductivity methods generally were unusable. The GEM-2, EM-31, and EM-34 instrument responses were adversely affected by a very-low frequency (VLF) transmitter station located across the bay in Cutler, Maine, and by the low terrain conductivities associated with the shallow high silica-bearing volcanic and intrusive rocks in the Machiasport area. The transmitter at the naval computer and telecommunications station in Cutler has an output of 2 million $\mathrm{W}$ (watts) and operates in a frequency range of 14 to $60 \mathrm{kHz}$, which interfered with the GEM-2, EM-31, and EM-34. Also, the regional ground conductivity in the Machiasport vicinity is 
about 1 to $2 \mathrm{mS} / \mathrm{m}$ (millisiemens per meter) (Fine, 1954). Natural, low-conductivity conditions such as these make it more difficult to induce sufficient current in the ground to produce a measurable magnetic field at the receiver coil (McNeill, 1980). These factors also may explain the poor quality data collected with the GEM-2, EM-31, and EM-34. Therefore, the multi-frequency electromagnetic induction and inductive terrain-conductivity methods were considered largely unsuccessful and the results are not discussed here, except for the EM-31 and EM-34 surveys along profile TW-1.

\section{Processing and Modeling Borehole-Velocity Data}

Borehole-velocity data were used to generate detailed velocity profiles for $1.5-\mathrm{m}$ depth increments along the boreholes. The results were used to help constrain the interpretation of the SIPT2 and tomographic seismic models, and for profile L-08 to help improve the tomographic inversion of the seismicrefraction data.

Processing borehole-velocity data consisted of the following steps:

1. Picking first-arrival traveltime for the downhole and reference geophones;

2. Sorting the arrival time data by depth;

3. Computing and applying shot-timing corrections using the arrival time picks obtained from three reference geophones at fixed distances from the shot;

4. Computing the average velocity to each downhole geophone location using straight-line distance from the shot to the geophone divided by corrected arrival time;

5. Converting to vertical traveltime using the depth point for the receiver and the computed average velocities;

6. Computing interval velocities using both point-to-point slope measurement between time picks and fitting a series of least-squares lines, with a moving window length of three to nine points, through the measurement points. The point-to-point calculations are only in the upper part of the log where slower velocity zones are present, and time-picking errors are less sensitive to the calculated velocity. Point-to-point calculations are needed to correctly calculate the change in velocity across the soil-rock interface (least-squares fitting tends to smooth over the sharp break in depth-time data associated with the soil-rock interface). The least-squares operators are valid for the deeper section of the vertical profile where it will smooth over small time-picking errors, which would produce unrealistic changes in velocity if not accounted for.

7. Constructing a final velocity log by visually comparing the automated velocity estimations (both point-to-point and the series of least-squares fits) with the corrected (and raw) arrival-time curves, and selecting those velocities that correspond with breaks in the traveltime versus depth curves, and with observed changes in lithology. If the borehole intersected layers with uniform velocity and discrete changes in velocity at the layer boundary, the velocity plot produced a stair-step pattern. A gradational velocity field would produce a velocity curve that increases gradually with increasing depth.

\section{Results of Geophysical Surveys}

For this investigation, seismic-velocity data were collected at two outcrops (OC-1 and OC-2). GPR and seismic-refraction data were collected along seven profiles (L-04, L-06, L-07, L08, L-09, L-14, and TW-1), and borehole-velocity surveys were conducted at five boreholes (MW-4, MW-6, MW-8b, MW-14, and TW-1) associated with the profiles. Locations of all datacollection points are shown in figure 1. An integrated interpretation of all geophysical data is presented for each survey line, and the data are provided in appendixes 1-7.

\section{Direct Seismic-Velocity Measurements on Bedrock Outcrops}

Direct seismic-velocity measurements made on outcrops were collected at outcrop sites (fig. 1) OC-1 and OC-2. Using six geophones, a mean velocity of $6,273 \mathrm{~m} / \mathrm{s}$ was determined for OC-1. Using nine geophones, a mean velocity of $6,144 \mathrm{~m} / \mathrm{s}$ was calculated for OC-2. The raw traveltimes, distances, and velocity data from which these mean velocities were determined are shown in table 2.

The velocities measured at the outcrop sites are expected to be similar to the higher seismic velocities for the silicic volcanic units in the Machiasport area. The outcrops are thought to represent more competent sections of the bedrock that are resistant to erosion. Therefore, the velocities measured at the outcrops likely indicate more competent, unfractured, and unweathered units of the bedrock.

\section{Interpretation of Surface-Geophysical Data}

The GPR and seismic data were interpreted to estimate depth to bedrock and to identify the presence of bedrock fractures. The data and interpretations are shown in appendixes 1-7.

Both reflectors and diffractions were interpreted on the GPR profiles (fig. 2). Reflectors occur in GPR profiles when electromagnetic energy from a GPR source is reflected from an electromagnetic contrast in the subsurface. Reflectors are interpreted as the top of bedrock or as relatively continuous fractures within the bedrock, and they can provide information about the geologic structure of the subsurface material. Diffractions occur in GPR profiles when electromagnetic energy from a GPR source is reflected away from a point in the subsurface, such as a boulder. Diffractions are interpreted as areas having increased fracturing of bedrock. There was good depth of penetration of the $100-\mathrm{MHz}$ GPR signal at this study area; thus, reflectors were imaged from as deep as $10 \mathrm{~m}$. 
Table 2. Distance, traveltime, and velocity data from direct seismic-velocity measurements at the Air Force Radar Tracking Station formerly used defense site, Machiasport, Maine.

\begin{tabular}{lccc}
\hline Site/Receiver & $\begin{array}{c}\text { Shot-receiverdistance, } \\
\text { in meters }\end{array}$ & $\begin{array}{c}\text { Traveltime, } \\
\text { in milliseconds }\end{array}$ & $\begin{array}{c}\text { Velocity, } \\
\text { in meters per second }\end{array}$ \\
\hline OC-1/R-1 & 3.74 & 0.61 & 6,131 \\
OC-1/R-2 & 3.73 & .62 & 6,016 \\
OC-1/R-3 & 3.75 & .65 & 5,769 \\
OC-1/R-4 & 3.47 & .53 & 6,547 \\
OC-1/R-5 & 3.48 & .52 & 6,692 \\
OC-1/R-6 & 3.50 & .54 & 6,481 \\
OC-2/R-1 & 4.17 & .69 & 6,043 \\
OC-2/R-2 & 5.17 & .83 & 6,229 \\
OC-2/R-3 & 6.64 & 1.07 & 6,206 \\
OC-2/R-4 & 8.40 & 1.33 & 6,316 \\
OC-2/R-5 & 8.92 & 1.45 & 6,152 \\
OC-2/R-6 & 9.33 & 1.53 & 6,098 \\
OC-2/R-7 & 9.99 & 1.63 & 6,129 \\
OC-2/R-8 & 10.70 & 1.76 & 6,079 \\
OC-2/R-9 & 10.90 & 1.80 & 6,056 \\
\hline
\end{tabular}

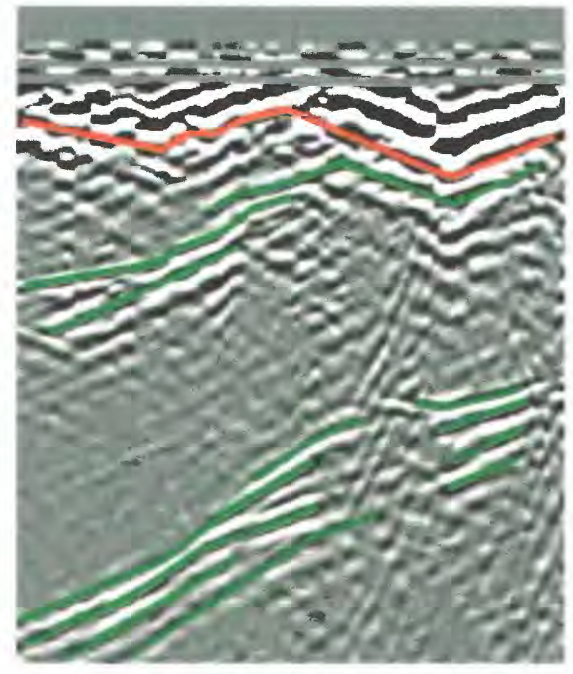

(a) Reflectors in GPR profile

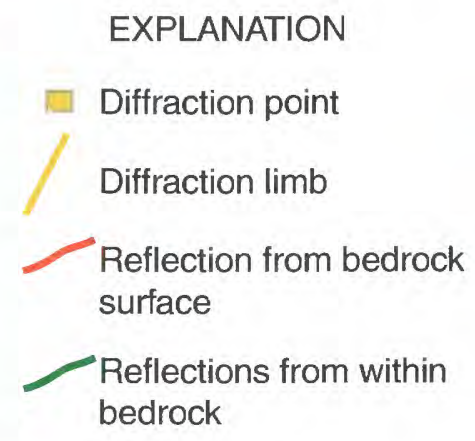

Diffraction point

Diffraction limb

Reflection from bedrock surface

Reflections

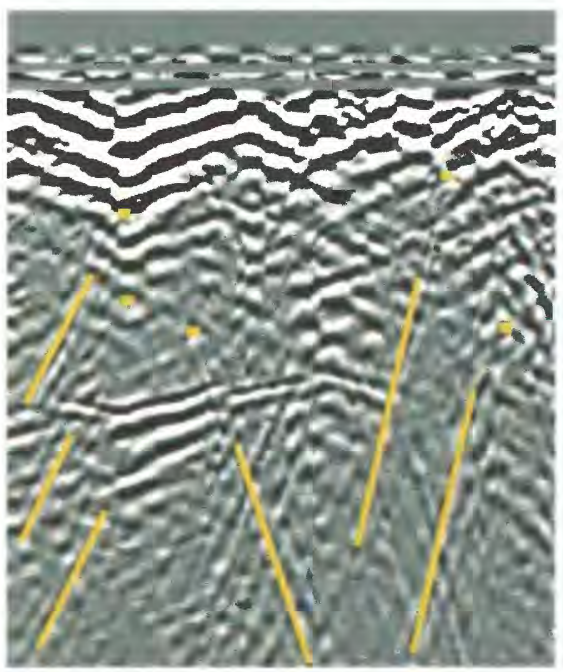

(b) Diffractions in GPR profile

Figure 2. Examples of selected (a) reflectors and (b) diffractions interpreted/observed in ground-penetrating-radar data. Gray lines at the top of the record are artifacts of filtering for removal of direct arrival. 
On the GPR profiles, the bedrock surface was interpreted as the high amplitude, most continuous reflector positioned just above less continuous reflectors. The interpreted overburdenbedrock interface is shown with a red trace line on the GPR profiles. The less continuous reflectors are interpreted as fractures in the bedrock below the overburden. The resolution of the GPR data is estimated to be about $0.25 \mathrm{~cm}$ (centimeter), one-quarter of the wavelength of the EM wave.

From the seismic data, SIPT2 modeling produced two- or three-layered models. The bottom layer was interpreted as competent bedrock; the interface between the bottom layer and the layer above it is shown as a black line. In the two-layered models, the upper layer is interpreted as overburden. In the threelayered models, the upper two layers have velocities below $1,900 \mathrm{~m} / \mathrm{s}$, and both layers were interpreted as overburden or unconsolidated sediment. For the three-layered models, the upper layer could be interpreted as unsaturated overburden and the second layer as saturated overburden. Another interpretation could be that the upper layer in the three-layered models contains more soil or organic matter than the middle layer.

The seismic-tomography inversions produce a profile of seismic velocity versus depth. Variations in velocity were interpreted as changes in the competency of the underlying rock. The seismic tomography inversions were not able to directly define the bedrock interface. Based on borehole-velocity surveys across the overburden-bedrock contact in boreholes MW4, MW-6, MW-8b, and MW-14, the overburden-bedrock interface was interpreted to be present within the velocity gradient ranging from 1,700 to $2,600 \mathrm{~m} / \mathrm{s}$. A yellow trace was drawn along the $2,100-\mathrm{m} / \mathrm{s}$ velocity contour on each profile and is the interpreted position of the top of bedrock. Regions of low velocity in the seismic tomography profiles were interpreted as zones containing more fractured bedrock.

In theory, the tomographic models should have a horizontal resolution equal to twice the geophone spacing; however, the modeling algorithm applies a horizontal smoothing operator to avoid discontinuities in the velocity field. Therefore, the horizontal resolution of the seismic data is estimated at 3 to 4 times the geophone spacing, giving a horizontal resolution of about 3 to $4 \mathrm{~m}$ for profiles L-04, L-06, L-07, L-08, L-09, and L-14, and about 6 to $8 \mathrm{~m}$ for profile TW-1. The vertical resolution is estimated at $3 \mathrm{~m}$ based on the gradient that is modeled across the observed overburden-bedrock interface.

The borehole velocities are estimated to have a vertical resolution of about $1.5 \mathrm{~m}$ in the upper 5 to $7 \mathrm{~m}$ of the subsurface. This resolution most likely decreases with depth.

\section{Profile L-04}

Profile L-04 (fig. 1) is on Howard Mountain, southwest of the transmitter site, and extends from southeast to northwest. Borehole MW-4 is approximately $70 \mathrm{~m}$ from the southeastern end of the line.

\section{Ground-Penetrating Radar and Seismic Surveys}

Ground-penetrating radar. Ground-penetrating radar results are shown in appendix 1a. GPR data were collected from 100 to $270 \mathrm{~m}$ along the profile. The red trace line is the interpreted top of bedrock surface. Overburden along this profile ranges in thickness from approximately 0.8 to $1.5 \mathrm{~m}$. The bedrock surface is interpreted as fairly nonuniform because of the discontinuous nature of the reflector. High-amplitude reflectors from within the bedrock are visible throughout the profile and are interpreted as broken sections of less competent rock. A prominent zone of high-amplitude reflections is present from about 150 to $180 \mathrm{~m}$ along the profile. This zone was interpreted as a highly fractured zone in the bedrock, and based on this interpretation of the GPR data, borehole MW-4 was drilled at a point $64 \mathrm{~m}$ from the southeastern end of the profile at the $170-\mathrm{m}$ location. The coring log indicates that 2.7 to $8.2 \mathrm{~m}$ below land surface, the bedrock is vitrophyric rhyolite; below $8.2 \mathrm{~m}$, the bedrock is a flow-banded vitreous stony rhyolite and vitrophyre (Weston Solutions, 2003).

Borehole-velocity survey. The velocity-survey data from borehole MW-4 are shown in appendix $1 \mathrm{~b}$, along with the approximate depth limit (about $16 \mathrm{~m}$ ) of the seismic-refraction model constructed for profile L-04 and the relevant geologic interfaces. The total range of velocities computed from the MW-4 data is from 400 to $5,000 \mathrm{~m} / \mathrm{s}$. The uppermost $10 \mathrm{~m}$ of the log indicates a zone of increasing velocity (from about 400 to $4,100 \mathrm{~m} / \mathrm{s}$ ), which corresponds to a change from overburden sediments to mafic dike material and then to flow-banded rhyolite and vitrophyre. These bedrock velocities are low relative to the velocities determined from the outcrop measurements (table 2), but are indicative of highly fractured rock. The low velocities from 5 to $10 \mathrm{~m}$ below land surface are consistent with results of rock coring, which showed that the core was highly fractured (Weston Solutions, 2003).

The borehole-velocity $\log$ below the $10-\mathrm{m}$ depth shows that the velocity ranges from 4,000 to $5,000 \mathrm{~m} / \mathrm{s}$. These velocities also are lower than the outcrop velocities, likely due to the fractured nature of the bedrock in MW-4. A zone of slightly lower velocity, at a depth of 14 to $20 \mathrm{~m}$ below land surface (at an elevation from 45 to $51 \mathrm{~m}$ ), correlates with a more highly fractured section of the borehole. The traveltime and velocity data place the top of competent bedrock at approximately $3.5 \mathrm{~m}$ below land surface; this is consistent with the drilling record, which gives the top of competent bedrock at a depth of $2.9 \mathrm{~m}$. This interface corresponds to a change in velocity from about $1,500 \mathrm{~m} / \mathrm{s}$ above the interface to about $2,440 \mathrm{~m} / \mathrm{s}$ below the interface.

Seismic-model results. Seismic-tomographic and earthlayer (SIPT2) model results are shown in appendix 1c. A threelayer model was used for the SIPT2 solution. The SIPT2 model interfaces are labeled with a gray line at the land surface, a green line at the top of the second layer, and a black line at the top of the bedrock layer. The corresponding layer velocities are labeled on the plot. The vertical strip at $170 \mathrm{~m}$ is the color-contoured velocity $\log$ for borehole MW-4, with the driller's depth 


\section{Surface-Geophysical Investigation of the Formerly Used Defense Site, Machiasport, Maine}

to competent bedrock indicated by the horizontal yellow bar. The yellow trace line along the $2,100-\mathrm{m} / \mathrm{s}$ velocity contour is the interpreted position of the top of bedrock.

The upper layer of the earth-layer model was modeled with a velocity of $670 \mathrm{~m} / \mathrm{s}$ with the intermediate layer resolved to a velocity of $1,200 \mathrm{~m} / \mathrm{s}$. One interpretation is that these two layers represent unsaturated and saturated sediments, respectively. The basal layer is interpreted as competent bedrock due to the relatively high velocity of $5,200 \mathrm{~m} / \mathrm{s}$. The SIPT2 modeled velocities are consistent with the MW-4 borehole-derived velocities of $450 ; 1,500$ to 2,500 ; and 3,500 to $5,000 \mathrm{~m} / \mathrm{s}$ for the corresponding SIPT2 layers.

Velocities obtained with the tomographic model are generally consistent with the borehole-velocity survey and SIPT2 model, though the tomographic solution indicates more variability within the bedrock. The velocities range from 2,500 to more than $5,000 \mathrm{~m} / \mathrm{s}$, with prominent zones of relatively low velocity centered at 158,180 , and $193 \mathrm{~m}$ along the profile. These lower-velocity zones are interpreted as decreases in the competency of the bedrock. The velocity survey for borehole MW-4 also indicates a similar change in velocity across the overburden-bedrock interface, from less than $2,000 \mathrm{~m} / \mathrm{s}$ above the interface to more than $2,400 \mathrm{~m} / \mathrm{s}$ below the interface.

The overburden sediments are interpreted to vary in thickness from approximately $2 \mathrm{~m}$ near the 192-m location on the profile up to $5 \mathrm{~m}$ at the $130-\mathrm{m}$ location. The bedrock surface rises near the middle of the profile where the tomographic model shows the greatest degree of lateral variability in the bedrock. Two possible borehole locations were selected along this profile, with the final position of MW-4 placed where the GPR data also indicated more complexity in the bedrock. The slight rise in the bedrock surface modeled at the southeastern end of the model is supported by the shallow overburden-rock interface indicated in borehole MW-2 (located approximately $10 \mathrm{~m}$ southeast of the profile).

\section{Integrated Interpretation}

Combined interpretation of GPR and seismic-refraction tomography data indicates that the low-velocity zone in the seismic-refraction tomography cross section at approximately $170 \mathrm{~m}$ correlates to a zone interpreted as highly fractured bedrock in the GPR cross section. The depth to bedrock in the GPR profile was fairly uniform ranging from 0.8 to $1.5 \mathrm{~m}$ below land surface. The seismic-refraction tomography indicated a depth to bedrock ranging from 2 to $5 \mathrm{~m}$ below land surface. The velocity data from borehole MW-4 shows a zone of higher velocity at about $9 \mathrm{~m}$ below land surface, which is interpreted as a possible textural variation in the bedrock. This contact was confirmed in the natural gamma, optical, and acoustic imaging logs (Weston Solutions, 2003). The lithologic contact and velocity contrast occurs between the mafic dike and an underlying flow-banded, stony rhyolite and vitrophyre.

\section{Profile L-06}

Profile L-06 (fig. 1) is on Howard Mountain, southeast of the transmitter site. The profile, oriented north-northeast southsouthwest, was conducted to look for structures within the bedrock that run parallel to the northwest-trending faults mapped in the study area and downgradient from the transmitter site. Borehole MW-6 is approximately $87 \mathrm{~m}$ from the northeastern end of the line at a position $187 \mathrm{~m}$ along the profile.

\section{Ground-Penetrating Radar and Seismic Surveys}

Ground-penetrating radar. Ground-penetrating radar results for profile L-06 are shown in appendix 2a. The interpreted bedrock surface is superimposed on the GPR records. Overburden thickness is fairly uniform at about $1 \mathrm{~m}$ over the length of the profile; the bedrock surface is fairly nonuniform. Reflections in the bedrock indicate competent rock and depths of penetration of about 4 to $5 \mathrm{~m}$, which is among the deepest of the GPR profiles, with uniform attenuation.

High-amplitude reflectors within the bedrock are visible throughout the GPR profile and are interpreted as broken sections of less competent rock. The bedrock along profile L-06 has been mapped as stony rhyolite and vitrophyre. The GPR signal is highly diffracted at approximately $235 \mathrm{~m}$ along the profile, suggesting that the bedrock is highly fractured or faulted at that location. One reflector is nearly vertical, and diffractions from this reflector are visible on the GPR record to a depth of approximately $12 \mathrm{~m}$ below land surface. The drilling $\log$ from MW-6 indicates that the weathered bedrock surface is at a depth of approximately $1.1 \mathrm{~m}$, which is consistent with the GPR results.

Borehole-velocity survey. The velocity-survey data from borehole MW- 6 are shown in appendix $2 b$, along with the approximate depth limit of the seismic-refraction model constructed for profile L-06 and the relevant geologic interfaces. The total range of velocities computed from the MW-6 data is 400 to $5,600 \mathrm{~m} / \mathrm{s}$. The upper $3 \mathrm{~m}$ of the $\log$ (from land surface to $3 \mathrm{~m}$ below land surface) gives a low velocity of less than $2,000 \mathrm{~m} / \mathrm{s}$. Below a depth of $5 \mathrm{~m}$, the subsurface velocities increase to approximately $4,500 \mathrm{~m} / \mathrm{s}$ at a depth of about $10 \mathrm{~m}$, and range from 3,400 to $5,600 \mathrm{~m} / \mathrm{s}$. A zone of relatively low velocity $3,700 \mathrm{~m} / \mathrm{s}$, is observed at a depth from 17 to $19 \mathrm{~m}$ and may correspond to a fracture zone that yielded approximately $1 \mathrm{~L} / \mathrm{min}$ (liter per minute) of water during drilling of MW-6 (Weston Solutions, 2003). Using only the arrival time and velocity data for interpretation, the top of competent rock would probably be placed at approximately $3.5 \mathrm{~m}$ below land surface at the location of MW-6 (elevation of $64 \mathrm{~m}$ ). The driller's record indicates competent rock at a depth of $1.2 \mathrm{~m}$ below land surface.

Seismic-model results. The earth-layer and seismictomographic models constructed for profile L-06 are shown in appendix $2 c$, as well as the velocity $\log$ (color-contoured vertical strip) for MW-6. The yellow trace line corresponds with the interpreted bedrock position from the tomographic model 
$(2,100 \mathrm{~m} / \mathrm{s}$ trace line $)$. The drilling record indicates a depth of approximately $1.1 \mathrm{~m}$ to the top of weathered rock at MW-6, as indicated by the yellow horizontal bar labeled "Rock."

A two-layered solution was required for the SIPT2 model. The upper layer was modeled with a velocity of $1,700 \mathrm{~m} / \mathrm{s}$ and corresponds to overburden sediment including unsaturated and saturated sediments. The lower layer is interpreted as competent bedrock, because of its high velocity of $5,270 \mathrm{~m} / \mathrm{s}$. There is good correlation between velocities in borehole MW- 6 and the SIPT2 model, with the borehole survey indicating velocities ranging from 1,500 to $2,600 \mathrm{~m} / \mathrm{s}$, and from 3,500 to $5,000 \mathrm{~m} / \mathrm{s}$ for the corresponding SIPT2 layers. The SIPT2 model indicates the bedrock surface at a depth of $8.7 \mathrm{~m}$ below land surface, which is deeper than actually indicated by the driller's log. One explanation is that the modeled refractor corresponds to a more competent zone within the bedrock than what was observed in the core. This is corroborated by the velocity survey in MW-6 where velocities higher than $3,500 \mathrm{~m} / \mathrm{s}$ were measured at a depth of approximately $5 \mathrm{~m}$ below land surface. The tomographic model shows lateral changes in velocity near borehole MW-6. The variations in velocity are interpreted as changes in the competency of the underlying bedrock. The top of bedrock was interpreted as the $2,100-\mathrm{m} / \mathrm{s}$ velocity-contour line. This interpretation is supported by the borehole-velocity survey in borehole MW-6, which indicates velocities less than $2,000 \mathrm{~m} / \mathrm{s}$ above the overburden-rock interface, and velocities more than $2,400 \mathrm{~m} / \mathrm{s}$ below the interface.

The interpretation of the seismic-tomographic data indicates the overburden thins towards the southwest from approximately $6 \mathrm{~m}$ thick at the north-northeast end of the profile to about 2 to $3 \mathrm{~m}$ at the south-southwest end. The top of bedrock was modeled at an average elevation of approximately $63 \mathrm{~m}$, with local topographic changes of 1 to $2 \mathrm{~m}$. The upper part of the interpreted bedrock shows lateral variation in velocity from relative lows of $2,800 \mathrm{~m} / \mathrm{s}$ to more than $5,000 \mathrm{~m} / \mathrm{s}$. Two potential drilling locations were identified along profile L-06. One location was at a distance of about $130 \mathrm{~m}$ on the profile and corresponded to subtle changes in GPR character. The second proposed location, at $187 \mathrm{~m}$ along the profile, corresponded to lateral changes in the seismic and GPR data.

\section{Integrated Interpretation}

The depths to bedrock determined by using the GPR and seismic-refraction methods differ by approximately $2 \mathrm{~m}$ at MW-6; the shape of the interpreted contact between the overburden and bedrock differ in details. The seismic model predicts a greater depth to bedrock towards the north-northeast than does the GPR. A steeply dipping fracture at approximately $235 \mathrm{~m}$ on the profile was imaged with the GPR survey but not with the seismic-refraction survey. This reflector is nearly vertical and diffractions from this reflector are visible on the GPR record to a depth of approximately $12 \mathrm{~m}$ below land surface. The reflector is interpreted as a fracture. A borehole was not installed at this location to confirm the interpretation of this feature.

\section{Profile L-07}

Profile L-07 (fig. 1) is on Howard Mountain, southwest of the transmitter site. The profile, oriented southeast to northwest was conducted to look for structures within the bedrock that are downgradient from the transmitter site. Borehole MW-7 is at approximately $175 \mathrm{~m}$ on the line.

\section{Ground-Penetrating Radar and Seismic Surveys}

Ground-penetrating radar. Ground-penetrating radar results for L-07 are shown in appendix 3a. The interpreted bedrock surface is indicated by a red trace. Overburden along this profile ranges in thickness from approximately 0.7 to $1.8 \mathrm{~m}$. The thickness of the snowpack at the time of data collection ranged from approximately 0.4 to $2.5 \mathrm{~m}$ along the profile. Hence, the depths to reflectors in the GPR record are actually greater than the depths from land surface.

Reflections from within the bedrock are visible throughout the profile. The GPR signal was highly diffracted at intervals of 100 to $115 \mathrm{~m}, 130$ to $175 \mathrm{~m}$, and 255 to $320 \mathrm{~m}$ along the profile, suggesting the presence of highly fractured bedrock. Another very narrow zone of highly diffracted signal was identified at $180 \mathrm{~m}$ along the profile. The drilling $\log$ from MW-7 indicates a depth of $0.2 \mathrm{~m}$ to weathered bedrock and $0.6 \mathrm{~m}$ to competent bedrock (Weston Solutions, 2003). Considering the depth of the snowpack at that location (about $0.4 \mathrm{~m}$ ), the GPR interpretation is consistent with the drilling log.

Seismic-model results. Seismic-tomographic and earthlayer (SIPT2) model results are shown in appendix 3b. The interfaces for the three-layered SIPT 2 model are included on the profile. The SIPT2 model layer interfaces are drawn as a green trace line for the top of the second layer and as a black trace line for the top of the bedrock, with the corresponding layer velocities labeled. The interpreted bedrock surface from the tomography solution is marked by the yellow trace line, which corresponds to the $2,100-\mathrm{m} / \mathrm{s}$ velocity contour. Also shown are the positions of boreholes MW-2, which was drilled prior to this investigation, and MW-7, which was drilled after the surfacegeophysical data were collected.

The SIPT2 solution required a three-layered model using velocities of 850 (layer 1), 1,830 (layer 2), and 4,200 m/s (layer $3)$. One interpretation is that the upper two layers represent unsaturated and saturated sediments, respectively. The velocity computed for layer 2 is consistent with velocities obtained for the upper $3 \mathrm{~m}$ in borehole MW-4 (which is approximately 170 $\mathrm{m}$ to the northwest). Layer 3 is interpreted as representing competent rock because of its relatively high velocity. Depth to the layer 3 (competent rock) ranges from approximately $5 \mathrm{~m}$ below land surface near $125 \mathrm{~m}$ along the profile to less than $2 \mathrm{~m}$ below land surface at $180 \mathrm{~m}$ along the profile from the southeast end of the profile. The depth and velocity of layer 3 are consistent with borehole-velocity survey results in boreholes MW-4 and MW-6. 


\section{Surface-Geophysical Investigation of the Formerly Used Defense Site, Machiasport, Maine}

The tomographic solution shows abrupt changes in the velocity that are interpreted to represent changes in the competency of the rock. The yellow trace line (coincident with the $2,100-\mathrm{m} / \mathrm{s}$ velocity contour) is interpreted to represent the top of a transition zone from weathered to more competent rock. Velocity surveys in boreholes MW-4 and MW-6 document an increase in velocity from approximately $2,400 \mathrm{~m} / \mathrm{s}$ to more than $3,800 \mathrm{~m} / \mathrm{s}$ in the upper 3 to $6 \mathrm{~m}$ of the bedrock.

As modeled, the top of bedrock rises to near land surface between profile distances of 170 and $220 \mathrm{~m}$. The drilling log for borehole MW-7 (175 m) indicates the top of weathered bedrock at a depth of approximately $0.2 \mathrm{~m}$ below land surface. Borehole MW-2 (approximately $5 \mathrm{~m}$ perpendicular to the profile at 225 $\mathrm{m}$ ) indicates a shallow depth to bedrock (less than $1 \mathrm{~m}$ ). Highly fractured and broken bedrock was observed cropping out at horizontal distances from 195 to $200 \mathrm{~m}$ along the profile, further corroborating the presence of bedrock near land surface. The zones of low velocity modeled within the bedrock at both ends of the bedrock rise probably are artifacts from the inversion.

In the tomographic model, the bedrock surface is interpreted to deepen to approximately $4 \mathrm{~m}$ below land surface towards the northwest, which is consistent with the modeling results for the southeast end of profile L-04. The bedrock surface deepens from a topographic high towards the southeast to an average depth of $3 \mathrm{~m}$ below land surface, with local variations in topographic relief of 1 to $1.5 \mathrm{~m}$.

\section{Integrated Interpretation}

The seismic-refraction method was used to identify the depth to bedrock along profile L-07, which was very near to the land surface at the two borehole locations along the profile. The GPR data indicated the possibility of densely fractured bedrock where there were numerous diffractions in the radar signal occurred; however, no low-velocity zones were identified at the same locations in the seismic record. The high-velocity zone located at about $200 \mathrm{~m}$ along the seismic tomography profile may correlate to reflectors from fractures in more competent bedrock visible at about $200 \mathrm{~m}$ along the GPR profile.

\section{Profile L-08}

Profile L-08 (fig. 1) is south of Howard Mountain, east of the transmitter site and south of the radar tracking station. The profile extended from the southwest to the northeast and was hydrologically downgradient of the surface drainage between the two peaks of Howard Mountain. The profile was designed to look for structures within the bedrock that are parallel to faults mapped within the study area and downgradient from the transmitter and radar tracking station sites. Borehole $\mathrm{MW}-8 \mathrm{~b}$ is approximately $105 \mathrm{~m}$ from the southwest end of the profile at $205 \mathrm{~m}$.

\section{Ground-Penetrating Radar and Seismic Surveys}

Ground-penetrating radar. Ground-penetrating radar results are shown in appendix $4 \mathrm{a}$. The interpreted bedrock surface is indicated by a red line. Overburden thickness is fairly uniform at about $1 \mathrm{~m}$ over the length of the profile. High-amplitude reflectors from within the bedrock are visible throughout the profile and are interpreted as broken sections of the less competent rock. Distinct high-amplitude reflectors extend from about 105 to $135 \mathrm{~m}$ along the profile at depths of about 5 to $6 \mathrm{~m}$ and 7 to $10 \mathrm{~m}$ below land surface, and appear to dip towards the southwestern side of the profile. Less prominent, nearly horizontal reflectors are present near 145 to $160 \mathrm{~m}$ along the profile at depths of about 5.5 and $6.5 \mathrm{~m}$ below land surface. A topographic high in the GPR profile near $175 \mathrm{~m}$ is caused by a buried pipe. Near the northeastern end of the profile, from 210 to $215 \mathrm{~m}$, high-amplitude reflectors that have an apparent dip to the northeast can be traced.

Core logs and geologic mapping indicate that the bedrock in this area is a zone of stony rhyolite and vitrophyre (Weston Solutions, 2003). The drilling $\log$ from MW-8b indicates that the weathered bedrock surface is at a depth of approximately $0.9 \mathrm{~m}$ below land surface, and the competent bedrock is at a depth of about $1.1 \mathrm{~m}$ below land surface at $205 \mathrm{~m}$ along the profile, which is consistent with the GPR results.

Borehole-velocity survey. Velocity information for borehole MW-8b is shown in appendix $4 \mathrm{~b}$, with the approximate depth limit of the seismic-refraction model indicated. The total range of velocities computed from the MW- $8 \mathrm{~b}$ data is from 600 to $4,800 \mathrm{~m} / \mathrm{s}$. Low velocities are computed for the upper $1.5 \mathrm{~m}$ of the borehole, intermediate velocities of 2,000 to $3,000 \mathrm{~m} / \mathrm{s}$ are computed for the 1.5- to 6.0-m depth range, and high velocities of more than $4,000 \mathrm{~m} / \mathrm{s}$ for below $6 \mathrm{~m}$ in depth. These transitions in velocity are interpreted as representing the velocity changes from unconsolidated sediments to weathered rock to competent rock with increasing depth. Based solely on the arrival-time curve, the top of competent rock is interpreted to be approximately $1.5 \mathrm{~m}$ below land surface, which is very close to the $1.1 \mathrm{~m}$ indicated by the driller's log for MW- $8 \mathrm{~b}$.

The borehole-velocity survey shows a break in slope of the traveltimes between 36 and $38 \mathrm{~m}$ in elevation. The data for the reference geophone (gray curves) show a similar break in traveltime, which indicates a timing problem with the triggering system. This break was partially corrected during processing, as indicated by the corrected traveltime curve (red); however, the resulting low-velocity zone near $36 \mathrm{~m}$ in elevation is most likely an artifact of the timing break.

Seismic-model results. The seismic-tomographic model results for profile L- 08 are shown in appendix $4 \mathrm{c}$. The velocity $\log$ from MW-8b is shown as a color-contoured vertical strip at approximately $205 \mathrm{~m}$ on the profile, and uses the same color scheme as the tomographic model. The black trace line is the interpreted top of competent rock computed from the SIPT2 model, and the yellow trace line is the $2,100-\mathrm{m} / \mathrm{s}$ velocity contour from the tomographic solution. The relatively high bedrock 
velocities in the model are consistent with direct measurements at OC-2, which is approximately $200 \mathrm{~m}$ south of the profile.

A two-layered model was required for the SIPT2 solution with a velocity of $1,120 \mathrm{~m} / \mathrm{s}$ for the upper layer and $4,950 \mathrm{~m} / \mathrm{s}$ for the lower layer. The upper layer is interpreted as undifferentiated and unconsolidated sediments. The velocity of the upper layer, which is bounded by the gray line on top and the black line on the bottom of the profile, is most likely an average of velocities for unconsolidated sediment and weathered rock. The second layer is interpreted as competent rock. The top of the bedrock (layer 2 in the SIPT2 model) at MW-8b is modeled at approximately $4.5 \mathrm{~m}$ in depth, which is considerably deeper than the $1.1-\mathrm{m}$ depth indicated by the driller's log. The SIPT2 depth and velocity however, are consistent with the borehole logging results for $\mathrm{MW}-8 \mathrm{~b}$, where velocities more than $3,500 \mathrm{~m} / \mathrm{s}$ occur at depths greater than $5 \mathrm{~m}$ below land surface.

Velocity results obtained from the tomographic modeling are consistent with the SIPT 2 model for the first $90 \mathrm{~m}$ along the profile (from the southwestern end). In general, the black SIPT2 line is between the $2,100-\mathrm{m} / \mathrm{s}$ velocity contour and the $3,500-\mathrm{m} / \mathrm{s}$ contour. Northeast of the $190-\mathrm{m}$ location, the SIPT2 and tomographic models diverge, with the tomographic model indicating a greater depth to the top of the high-velocity material (greater than $3,500 \mathrm{~m} / \mathrm{s}$ ). The pinnacle feature observed in the tomographic model at borehole MW-8b is a processing artifact caused by restricting the tomographic solution to retain the velocities from the borehole-velocity survey. Without the MW$8 \mathrm{~b}$ velocity constraints, the tomographic model would indicate a much greater depth to rock. The yellow trace line, which is coincident with the $2,100-\mathrm{m} / \mathrm{s}$ velocity contour, is interpreted as the top of bedrock. The $2,100-\mathrm{m} / \mathrm{s}$ contour corresponds to a change from less than $2,000 \mathrm{~m} / \mathrm{s}$ (unconsolidated overburden) to greater than $2,400 \mathrm{~m} / \mathrm{s}$ (bedrock) observed in the boreholevelocity logs for the Howard Mountain area boreholes (MW-4, MW-6, and MW-8b).

Using the $2,100-\mathrm{m}$ velocity contour in the tomographic model, the bedrock surface is modeled at a depth of 1 to $2 \mathrm{~m}$ below land surface between profile distances of 110 and $168 \mathrm{~m}$. These interpreted depths are consistent with the drilling log from the abandoned borehole MW-8a, where weathered rock was encountered at a shallow depth (less than $1 \mathrm{~m}$ ) (Weston Solutions, 2003), and consistent with the GPR interpreted depth to weathered rock. In addition, the zone of relatively low velocity near a distance of $115 \mathrm{~m}$ at $40-\mathrm{m}$ elevation is in the approximate position of the (apparent) southwestward dipping reflectors observed on the GPR section.

Northeast of $168 \mathrm{~m}$, the interpreted bedrock surface deepens to approximately $5 \mathrm{~m}$ below land surface near the profile distance of $185 \mathrm{~m}$. At $205 \mathrm{~m}$, the model forces the bedrock to a depth of $1.1 \mathrm{~m}$, because the borehole-velocity model constraints from MW-8b were used. Northeast of MW-8b, the bedrock surface again deepens to about $5 \mathrm{~m}$ at a distance of $215 \mathrm{~m}$, and rises to a depth of about $3 \mathrm{~m}$ below land surface at the northeast end of the profile. The 1.4-m depth to bedrock, indicated by drilling results for borehole FAMW-002 (at the 185-m location), is much shallower than the depths modeled in the tomographic and SIPT2 solutions, which were 5 and $6 \mathrm{~m}$ below land surface, respectively. It is unclear why the tomographic and SIPT2 models indicate a deeper interface for the top of bedrock in this part of the profile. Re-examination of the first-arrival time picks, shot-receiver geometry, and recorded data, with a remodeling of the seismic data, did not appreciably change the initial model results. The $1,300-\mathrm{m} / \mathrm{s}$ velocity contour more closely matches the depth to bedrock indicated by the FAMW-002 and MW-8b boreholes.

\section{Integrated Interpretation}

Combined interpretation of GPR and seismic-refraction tomography data identified three structural features. The first feature is between 110 and $125 \mathrm{~m}$ on the profiles at a depth of about $7 \mathrm{~m}$ below land surface. The feature is characterized by high-amplitude radar reflections from bedrock fractures and by a low-velocity zone in the seismic model. The second feature is between 140 and $155 \mathrm{~m}$ along the profile at a depth of approximately $7 \mathrm{~m}$ below land surface, and is characterized by a lowamplitude, discontinuous reflection in the GPR record and by a low-velocity zone in the seismic model. The third feature is between 210 and $215 \mathrm{~m}$ along the profile at a depth of approximately $2.5 \mathrm{~m}$ below land surface, and is characterized by a highamplitude, discontinuous reflector in the GPR record and by low velocities in the seismic model. Collectively these characteristics indicate fractured zones in the bedrock.

\section{Profile L-09}

Profile L-09 (fig. 1) is on Howard Mountain southeast of the radar tracking station. The profile was oriented northeast to southwest, and was designed to look for structures within the bedrock that are parallel to faults mapped within the study area and downgradient from the radar tracking station. Borehole MW-9 is $200 \mathrm{~m}$ from the southwestern end of the profile.

\section{Ground-Penetrating Radar and Seismic Surveys}

Ground-penetrating radar. Ground-penetrating radar results are shown in appendix 5a. The red trace line is the interpreted top of bedrock surface. Overburden along this profile ranges in thickness from approximately 0.5 to $1.0 \mathrm{~m}$. Reflections from weathered bedrock are visible throughout most of the profile. The drilling logs from MW-9 indicate the bedrock is $1.1 \mathrm{~m}$ below land surface.

Three zones of high-amplitude reflections observed in the bedrock are at intervals from 105 to $125 \mathrm{~m}$, from 145 to $160 \mathrm{~m}$, and from 165 to $200 \mathrm{~m}$ along the profile. These zones are interpreted as places where the bedrock is highly fractured near the bedrock surface.

Seismic-model results. Tomographic and earth-layer (SIPT2) results for the seismic modeling of profile L-09 are shown in appendix $5 \mathrm{~b}$. A green trace line for the intermediate interface and a black trace line for the lower interface mark the 
SIPT2 refractor surfaces. The velocities for the SIPT2 models are labeled in appendix $5 b$, as are the position of borehole MW9 and the depth to bedrock found during drilling (horizontal yellow line). In the tomographic model, the interpreted top of bedrock is indicated by the yellow trace line, which corresponds to the $2,100-\mathrm{m} / \mathrm{s}$ velocity contour in the tomographic solution. Low-velocity, highly weathered rock was observed in the upland area in the northeast section of the profile from 100 to $180 \mathrm{~m}$.

The presence of the sharp break in topography near $190 \mathrm{~m}$ required breaking the SIPT2 model into two sections. The SIPT2 models on both sides of the break in topography required three-layered solutions. On the northeastern side of the profile, the upper two layers had velocities of 900 and $1,900 \mathrm{~m} / \mathrm{s}$. On the southwestern side of profile L-09, the upper two layers had velocities of 1,350 and $1,405 \mathrm{~m} / \mathrm{s}$. One interpretation is that the upper two layers of the SIPT2 model represent unsaturated and saturated sediments. The third layer in the SIPT2 model was modeled using a velocity of $3,000 \mathrm{~m} / \mathrm{s}$ in the upland region and using a velocity of $4,975 \mathrm{~m} / \mathrm{s}$ in the southwestern and lower part of the profile. The third layer is interpreted as bedrock. On the southwestern side of the profile, the depth to competent bedrock was noted as $1.1 \mathrm{~m}$ below land surface at MW-9 in the drilling $\log$ (Weston Solutions, 2003) and $1.5 \mathrm{~m}$ below land surface at borehole STMW-001 (U.S. Army Corps of Engineers, 2003), about $7 \mathrm{~m}$ south of the profile. These depths are shallower than that indicated in the SIPT2 model, which gives $7 \mathrm{~m}$ at a profile distance of $196 \mathrm{~m}$. One possible explanation is that the SIPT2 model has not adequately corrected for the topographic break between distances of 175 and $195 \mathrm{~m}$.

Velocities obtained from the tomographic solution are in rough agreement with those computed with the SIPT2 method. As with the other profiles, the top of competent rock is interpreted to correspond with the $2,100 \mathrm{~m} / \mathrm{s}$-velocity contour (yellow trace line). The bedrock surface is observed within 1 to $1.5 \mathrm{~m}$ of land surface in the upland area between 90 to $180 \mathrm{~m}$, with an increase in depth to $4.0 \mathrm{~m}$ near $155 \mathrm{~m}$. Southwest of the topographic high, the bedrock surface is modeled at approximately $3.5 \mathrm{~m}$ below land surface. The overburden layer then begins to thin between distances of 205 and $210 \mathrm{~m}$ along the profile. The position of this break is consistent with the change in bedrock elevation observed on profile L-08 (approximately $100 \mathrm{~m}$ to the south, appendix $4 \mathrm{c}$ ).

\section{Integrated Interpretation}

Because profile L-09 is near the top of Howard Mountain, the area is exposed to high winds which prevents the accumulation of aeolian deposits. In addition, recent demolition activities have reworked much of the thin overburden deposits. As a result, the thickness of the overburden ranges from approximately 0 to $1 \mathrm{~m}$.

Zones of high-amplitude reflections in the bedrock on the GPR profile correspond to thick regions of low velocities (blue) on the tomographic model at intervals from 105 to $120 \mathrm{~m}$,
145 to $165 \mathrm{~m}$, and 175 to $200 \mathrm{~m}$ along the profile. These zones are interpreted as areas of highly fractured bedrock near the surface. A substantial lithologic contact was observed in the borehole-geophysical logs at a depth of approximately $23 \mathrm{~m}$ below land surface, between stony rhyolite and the underlying mafic intrusion. This contact was not imaged by the GPR, which did not return a signal from that depth, or by the seismic-refraction tomography. Borehole-velocity data were not collected in borehole MW-9. Acoustic imaging logs indicate the upper part of borehole MW-9 is moderately fractured, which is consistent with the interpretations of the seismic and GPR surveys.

\section{Profile L-14}

Profile L-14 is on Miller Mountain southeast of the former ground/air transmitter/receiver site (fig. 1). The profile was oriented from west-southwest to east-northeast and was designed to look for structures within the bedrock downgradient from this site. Borehole MW-14 is at a distance of approximately $152 \mathrm{~m}$ on profile L-14.

\section{Ground-Penetrating Radar and Seismic Surveys}

Ground-penetrating radar. Ground-penetrating radar results are shown in appendix $6 \mathrm{a}$. The red trace line is the interpreted bedrock surface. Sections of the GPR profile were collected along a driveway at a distance of 100 to $165 \mathrm{~m}$ and 208 to $217 \mathrm{~m}$ along the profile. Overburden along this GPR profile ranges in thickness from approximately 2.3 to $2.7 \mathrm{~m}$. The drilling logs from MW-14 indicate that the weathered bedrock surface is at a depth of approximately $3.7 \mathrm{~m}$, which is deeper than the interpreted GPR bedrock depth. The bedrock interface is discontinuous and somewhat irregular. Reflections from within the bedrock are visible throughout the profile.

Borehole-velocity survey. Results of the velocity survey in borehole MW-14 are presented in appendix $6 \mathrm{~b}$, with the traveltime and depth curve shown in the left panel and the velocity and depth curve shown in the right panel. The horizontal blue bar indicates the approximate depth limit of the seismic-refraction model. The MW-14 survey yielded some of the highest velocities for the borehole surveys in the study area, with a total velocity range of 670 to $6,100 \mathrm{~m} / \mathrm{s}$. The highest velocity measured in MW-14 is comparable to the outcrop velocity measurements made at OC- 1 and OC- 2 .

Low velocities of less than $2,500 \mathrm{~m} / \mathrm{s}$, were observed in the upper $5 \mathrm{~m}$ of the $\log$. Below $5 \mathrm{~m}$, the subsurface velocities average approximately $5,300 \mathrm{~m} / \mathrm{s}$ and ranged from 4,500 to $6,100 \mathrm{~m} / \mathrm{s}$. Based on the time and depth plot, the top of competent rock is interpreted to be approximately $4.5 \mathrm{~m}$ below land surface at an elevation of $25 \mathrm{~m}$, which is consistent with the drilling log that identified competent rock at $4 \mathrm{~m}$ below land surface. A lithologic contact was observed in the drilling log between the granodiorite and underlying gabbro at approximately $16.5 \mathrm{~m}$ below land surface (12.4 m above NAVD 1988), 
which appears to coincide with a change in the borehole velocity from approximately 5,000 to $6,000 \mathrm{~m} / \mathrm{s}$.

Seismic-model results. The seismic-modeling results are shown in appendix $6 \mathrm{c}$. The SIPT2 modeled layers are shown as a green trace line for the intermediate interface, and a black trace line for the bottom interface. SIPT2 layer velocities are labeled, as is the interpreted position of bedrock. The velocity $\log$ for borehole MW-14 is shown as a color-contoured strip using the same color-contouring scheme as the seismic tomogram. The yellow trace line represents the interpreted top of bedrock in the tomographic model.

The survey was split at $150 \mathrm{~m}$ into two profiles for the SIPT2 modeling, which required a two-layered solution in the west-southwestern part of the profile, and a three-layered solution in the east-northeastern part of the profile. The uppermost layer of the eastern part of the profile was modeled using a velocity of $660 \mathrm{~m} / \mathrm{s}$ and is interpreted to correspond with unconsolidated soil and peat units, which have very low velocities. The second layer for the eastern part of the profile and the top layer for the western part have velocities near $1,075 \mathrm{~m} / \mathrm{s}$, which correspond to undifferentiated glacial deposits. The bottom layer has velocities of 4,020 and $4,980 \mathrm{~m} / \mathrm{s}$, which is interpreted as competent rock.

The tomographic model compares favorably with the interpreted bedrock surface in the SIPT2 and borehole-velocity models. The only discrepancies in bedrock velocity were near borehole MW-14 (in the interval from 135 to $160 \mathrm{~m}$ on the profile) where the tomographic model indicates velocities of 2,700 to $3,200 \mathrm{~m} / \mathrm{s}$ for the bedrock, which is considerably lower than the measured velocities of 3,500 to $5,500 \mathrm{~m} / \mathrm{s}$ in borehole MW14. The difference is explained as modeling and (or) errors associated with picking the first arrival traveltimes. Both the SIPT2 and the tomographic models predict an increase in velocity at the approximate depth where competent rock was encountered. Also, the granodiorite-gabbro contact is at an elevation of approximately $13 \mathrm{~m}$ (appendix $6 \mathrm{~b}$ ), a point at which the tomographically defined velocities begin to increase. A low-velocity zone correlates to a prominent fracture and lithologic change at a depth of $16.5 \mathrm{~m}$ below land surface. Higher velocities are observed above and below the fracture zone.

The seismic model indicates an increase in overburden thickness to the east-northeast with a bedrock rise that peaks near a distance of $215 \mathrm{~m}$, which is near the access road to Miller Mountain. Rock outcrops were observed northwest of borehole MW-14. Observations by USACE geologists and anecdotal evidence from local residents indicate that rock was blasted for construction of the access road, which also indicates that the bedrock is near the surface at this location.

\section{Integrated Interpretation}

A zone of high-amplitude reflections in the bedrock between about 130 and $145 \mathrm{~m}$ on the GPR profile corresponds to a region of low velocities (purple and blue) on the seismic- tomographic model at about 137 to $152 \mathrm{~m}$ along the profile. This zone is interpreted as a region of highly fractured bedrock.

The borehole-velocity survey conducted in borehole MW14 shows the presence of low velocities from 0 to $2.0 \mathrm{~m}$ below land surface. This correlates to overburden in both the GPR and seismic-refraction cross sections. Both the GPR and seismicrefraction data show that the overburden layer continues from $160 \mathrm{~m}$ to the end of the line to the east-northeast A discrepancy in the thickness of this zone exists however, between the GPR and seismic-refraction tomography cross sections. The GPR shows this zone to be of nearly uniform thickness of approximately $2.7 \mathrm{~m}$. The seismic-refraction tomography cross section indicates that this zone is approximately $2.8 \mathrm{~m}$ thick at $160 \mathrm{~m}$ along the profile and increases in thickness to approximately $7.5 \mathrm{~m}$ at a distance $175 \mathrm{~m}$ along the profile. At $210 \mathrm{~m}$, the thickness of the overburden zone reduces to approximately $2.9 \mathrm{~m}$, and increases in thickness to approximately $8.1 \mathrm{~m}$ at a distance of $230 \mathrm{~m}$ on the east-northeast end of the profile.

The upper part of borehole MW-14 was highly fractured (Weston Solutions, 2003), which is consistent with the interpretations of the GPR and seismic-refraction surveys. A distinct change in rock type and a large fracture were identified at a depth of $16.5 \mathrm{~m}$ below land surface in MW-14. The seismicrefraction survey showed a low-velocity zone at depth near MW-14.

\section{Profile TW-1}

Profile TW-1 (fig. 1) is north of Howard Mountain and north of the radar tracking station. The profile extends from the north to south and is on the ocean side of a local drainage divide. The profile was designed to look for ground-water production zones within the overburden and bedrock. Borehole TW-1 was drilled at a profile distance of $185 \mathrm{~m}$. Based on the natural gamma-log response, the borehole penetrated a mostly mafic intrusive unit with small amounts of rhyolite to a depth of $42.7 \mathrm{~m}$ below land surface. The remainder of the borehole penetrated rhyolite. The caliper and acoustic televiewer logs show a highly fractured borehole in the depth interval from 33 to 43 $\mathrm{m}$ below land surface. The fractures in this zone strike northsouth \pm 15 degrees and dip 55 to 85 degrees (Weston Solutions, 2003).

\section{Seismic Surveys}

Borehole-velocity survey. The velocity survey for borehole TW-1 is shown in appendix $7 \mathrm{a}$, with the approximate depth limit of the seismic-refraction model indicated at $50 \mathrm{~m}$ below land surface. Velocities range from 400 to $6,100 \mathrm{~m} / \mathrm{s}$, with low velocities (less than $3,000 \mathrm{~m} / \mathrm{s}$ ) dominating the upper $20 \mathrm{~m}$ of the log. Deeper than $20 \mathrm{~m}$ below land surface, velocities average around $4,500 \mathrm{~m} / \mathrm{s}$ and range from 3,050 to $6,100 \mathrm{~m} / \mathrm{s}$. The higher velocities are consistent with the direct outcrop measurements made at OC-1 and OC-2. 


\section{Surface-Geophysical Investigation of the Formerly Used Defense Site, Machiasport, Maine}

Based on the arrival-time curve (approximately $1,900 \mathrm{~m} / \mathrm{s}$ ), the top of bedrock is interpreted to be approximately $15 \mathrm{~m}$ below land surface, which is consistent with the $14.5-\mathrm{m}$ depth indicated on the drilling record. Drilling logs indicate a change from unconsolidated Pleistocene clays to stony flowbanded rhyolite and vitrophyre. The top of competent rock is interpreted from the velocity curve where velocities increase above $3,000 \mathrm{~m} / \mathrm{s}$. The interpreted bedrock surface is approximately $0.5 \mathrm{~m}$ deeper than the top of bedrock determined in drilling logs. The upper $10 \mathrm{~m}$ of the rock column ( 0 to $10 \mathrm{~m}$ elevation) show an increase in velocity with depth from approximately $1,500 \mathrm{~m} / \mathrm{s}$ at the driller's contact $(14.5 \mathrm{~m}$ below land surface) to approximately $4,000 \mathrm{~m} / \mathrm{s}$ about $10 \mathrm{~m}$ below the contact ( $24.5 \mathrm{~m}$ below land surface). This zone is interpreted to correspond to a decrease in weathering and (or) fracturing with depth; this interpretation is supported by caliper and acoustic televiewer results (Weston Solutions, 2003).

Seismic-model results. The seismic-modeling results are shown in appendix $7 \mathrm{~b}$, with the SIPT2 refractor interface indicated by a green trace line for the top of the second layer and a black trace line for top of the bedrock surface. The velocities calculated for the model layers are labeled. The velocity log for borehole TW-1 is shown as a color-contoured strip using the same color scheme as the tomography model. The yellow line corresponds with the $2,100-\mathrm{m} / \mathrm{s}$ velocity contour and represents the interpreted top of the bedrock surface.

The SIPT2 solution for this profile was separated into two lines for the intervals from 105 to $195 \mathrm{~m}$ and from 195 to $295 \mathrm{~m}$ on profile TW-1. Each of the SIPT2 models required three-layer solutions. The average velocities were $640 \mathrm{~m} / \mathrm{s}$ (layer 1), $1,766 \mathrm{~m} / \mathrm{s}$ (layer 2), and $4,370 \mathrm{~m} / \mathrm{s}$ (layer 3). One interpretation is that the upper two layers represent unsaturated and saturated sediments. The upper two layers are interpreted to represent undifferentiated alluvium and Pleistocene units. The velocity computed for layer 2 ranges from 1,672 to $1,860 \mathrm{~m} / \mathrm{s}$, and is slower than data obtained from the velocity survey. The discrepancy in velocities likely reflects the inability of the SIPT2 program to handle lateral changes or vertical gradients in velocity. The results of the SIPT2 model indicate a slightly higher velocity on the northern half of the profile for layer 2 compared to the southern half, possibly indicating higher clay content in the northern part of the profile. The third layer is interpreted as competent rock based on the modeled velocities of 3,860 and $5,080 \mathrm{~m} / \mathrm{s}$.

The tomographic solution shows gradational vertical and horizontal changes in velocity for the depth interval equivalent to the SIPT2 overburden layers ( 1 and 2 ). Overburden was modeled in the tomographic model using velocities that range from 2,100 to $2,400 \mathrm{~m} / \mathrm{s}$ for the northern third of the profile in the interval 90 to $160 \mathrm{~m}$, which is consistent with that measured in borehole TW-1. In the southern two-thirds of the profile, from positions 180 to $295 \mathrm{~m}$, overburden velocities range from 1,300 to $1,600 \mathrm{~m} / \mathrm{s}$, which is consistent with sand. The borehole seismic velocities obtained in borehole TW-1 were not used to constrain the seismic-refraction tomographic inversion.
The yellow trace line along the $2,100-\mathrm{m} / \mathrm{s}$ velocity contour is the interpreted position of the top of the bedrock based on borehole-velocity surveys across the overburden-bedrock contact in boreholes MW-4, MW-6, MW-8b, and MW-14. The tomography model did not resolve the low velocities measured just below the overburden-bedrock interface in borehole TW-1. The bedrock surface is interpreted to average $15 \mathrm{~m}$ in depth below land surface. Over the length of the profile, the land-surface topography has an overall 5-m decrease in elevation towards the south. A slight rise in the bedrock surface is modeled near position $155 \mathrm{~m}$ along the profile.

\section{EM-31 and EM-34 Surveys}

Results from surveys using the EM-31 vertical dipole, and EM-34 vertical and horizontal dipole at 20 - and $40-\mathrm{m}$ coil spacing, are shown in appendix $7 \mathrm{c}$. The bulk conductivity of the sediments underlying profile TW-1 ranged from 5.5 to $16 \mathrm{mS} / \mathrm{m}$. The EM-31 results are best interpreted to represent the thickness of saturated sediments, with the highest conductivities near the center of the profile where standing water was observed. The EM-34 results with the 20-m coil spacing show a smaller range of conductivities ( 5.5 to $12 \mathrm{mS} / \mathrm{m}$ ) with a similar trend, as compared to the EM-31 data, though less pronounced, in the horizontal dipole data. The response of the vertical dipole is slightly different, which may reflect some influence from the deeper clay or bedrock units. No substantive information regarding the bedrock can be inferred from this data set.

Data collected with the EM-34 using a 40-m coil spacing proved unsuitable and exhibited noise spikes up to nearly $15 \mathrm{mS} / \mathrm{m}$ above a mean value of approximately $5 \mathrm{mS} / \mathrm{m}$. The horizontal-dipole data showed less noise, but still proved unsuitable for mapping bedrock features at this site.

\section{Summary and Conclusions}

In February 2003, the U.S. Geological Survey and Argonne National Laboratory, in cooperation with the U.S. Army Corps of Engineers, conducted surface-geophysical surveys as part of an ongoing investigation of the Air Force Radar Tracking Station formerly used defense site at Machiasport, Maine. Multiple surface-geophysical methods were used to characterize the lithology and structure of the bedrock aquifer, and to locate sites for exploratory drilling. The surface-geophysical methods include ground-penetrating radar (GPR), seismic-refraction tomography, multi-frequency electromagnetics (GEM-2), and inductive terrain conductivity (EM-31 and EM34). Preliminary interpretations of the surface-geophysical profiles were used to locate boreholes used for this investigation. Seven boreholes were drilled adjacent to the profiles to further characterize the features that were observed in the profiles and to further describe the subsurface geohydrology. The data were then interpreted in an integrated fashion to improve the overall interpretation of the surface-geophysical data. 
Six GPR surveys and seven seismic-refraction surveys were collected on two mountains at locations downgradient from three suspected contaminant sources. Bedrock near profiles L-04, L-06, L-07, L-08, and L-09 consists of a rhyolitic eruptive unit with flow-banded stony, vitrophyre, autobreccia, and pyroclastic zones. Dacite and tuff breccias also are present Bedrock near profile L-14 consists of granodiorite overlying gabbro. Both bedrock environments are highly fractured. Bedrock near profile TW-1 is a mostly mafic intrusive unit with slivers of rhyolite to a depth of about $40 \mathrm{~m}$ below land surface and above rhyolite.

\section{Integrated Results of Geophysical Investigations}

The GPR and seismic-refraction data were interpreted to estimate depth to bedrock, which might identify the topographic expression of fracture zones; identify locations of fractures that may be capable of transporting ground-water contamination; and optimize sites for exploratory bedrock boreholes. Estimates of depth to bedrock estimated by the different methods for borehole locations along the profiles are shown in table 3. For comparison, the table includes depths to weathered and competent bedrock interpreted from the drilling logs (Weston Solutions, 2003) and the depth to bedrock interpreted from the boreholevelocity surveys. The depth to bedrock interpreted from the GPR data is most likely the depth to weathered bedrock, because the largest electromagnetic property contrast is at the overburden-bedrock interface. The seismic-tomography models were not able to directly define the bedrock surface. The overburden-bedrock interface was interpreted to occur within the velocity gradient ranging from 1,700 to $2,600 \mathrm{~m} / \mathrm{s}$, based on the results of the borehole velocity surveys. The $2,100-\mathrm{m} / \mathrm{s}$ velocity contour interval was considered to be the top of bedrock in the tomographic solutions.

Profiles L-04, L-06, and L-07 are downgradient of a suspected contaminant source near the transmitter site on Howard Mountain. Profiles L-04 and L-07 are oriented northwest-southeast in an effort to identify northeast-trending fractures; profile L-06 is oriented south-southeast to north-northeast to identify southwest-west to northeast-east trending fractures. The depth to bedrock interpreted from the GPR ranges from 0.9 to $1.6 \mathrm{~m}$ on profiles L-04, L-06, and L-07. For profiles L-04 and L-06, the interpreted depth to bedrock at the borehole on the profile is slightly less than the depth from the drilling logs. The GPR profiles for all three lines showed that the bedrock surface is fairly discontinuous. From 2 to $5 \mathrm{~m}$ below the overburden-bedrock interface, many reflections are observed from fractures or weathering within the bedrock. The depth to bedrock interpreted from the seismic refraction tomography inversions is 3.1 to $4.0 \mathrm{~m}$ below land surface, which is deeper than the bedrock surface identified in GPR and drilling log data.

Combined interpretation of the GPR and seismic-refraction tomography data for profile L-04 indicates that a lowvelocity zone in the seismic-refraction tomography cross-section at an approximate distance of $170 \mathrm{~m}$ correlates to a zone interpreted as highly fractured bedrock in the GPR cross-section. Borehole-geophysical logs from MW-04, installed at position $170 \mathrm{~m}$, are consistent with the surface-geophysical interpretations. Borehole-imaging logs indicate highly fractured rock to a depth of about $9.5 \mathrm{~m}$ below land surface, and most of the fractures have an east-west strike and dip to the north or the south.

Table 3. Depth to weathered bedrock and competent bedrock from exploratory drilling, ground-penetrating radar, and seismic-refraction surveys, Air Force Radar Tracking Station formerly used defense site, Machiasport, Maine.

[Depths are from data or interpreted data for the location of the given borehole. All distances and depths in meters. Height of measuring point is relative to land surface. --, no data; WBR, weathered bedrock; CBR, competent bedrock; GPR, ground-penetrating radar]

\begin{tabular}{lccccccc}
\hline & \multicolumn{8}{c}{ Depth } \\
\cline { 3 - 8 } Borehole identifier & $\begin{array}{c}\text { Distance } \\
\text { along } \\
\text { profile }\end{array}$ & $\begin{array}{c}\text { Drilling log } \\
\text { (WBR) }\end{array}$ & $\begin{array}{c}\text { Drilling log } \\
\text { (CBR) }\end{array}$ & $\begin{array}{c}\text { GPR } \\
\text { (WBR) }\end{array}$ & $\begin{array}{c}\text { Borehole } \\
\text { seismic- } \\
\text { velocity } \\
\text { survey } \\
\text { (CBR) }\end{array}$ & $\begin{array}{c}\text { Seismic } \\
\text { SIPT2 } \\
\text { (CBR) }\end{array}$ & $\begin{array}{c}\text { Seismic } \\
\text { tomography } \\
\text { (CBR) }\end{array}$ \\
\hline MW-4 & 170 & 2.0 & 2.9 & 1.5 & 3.5 & 5.5 & 3.5 \\
MW-6 & 187 & 1.1 & 1.2 & .9 & 3.5 & 8.7 & 3.1 \\
MW-7 & 175 & .2 & .6 & 1.6 & -- & 3.3 & 4.0 \\
MW-8b & 205 & .9 & 1.1 & .9 & 1.5 & 4.5 & 1.9 \\
MW-9 & 200 & -- & 1.1 & .5 & -- & 7.8 & 6.1 \\
MW-14 & 152 & 3.7 & 4.0 & 2.7 & 4.5 & 3.0 & 3.5 \\
TW-1 & 185 & -- & 14.5 & -- & 15 & 15 & 15 \\
\hline
\end{tabular}

\footnotetext{
${ }^{1}$ Data from Weston Solutions (2003)
} 
For profile L-06, a steeply dipping feature identified at approximately $235 \mathrm{~m}$ on the survey line was imaged with the GPR survey but not with the seismic-refraction survey. This reflector is nearly vertical, and diffractions from this reflector are visible on the GPR record to a depth of approximately $12 \mathrm{~m}$ below land surface. This reflector is interpreted as a fracture. A borehole was not installed at this location for further characterization of this feature; however borehole MW-6 was installed at a low-velocity zone in the seismic record and diffractions can be seen in the GPR record at $187 \mathrm{~m}$ along the profile. During drilling, MW-6 yielded a substantial amount of water.

On profile L-07, the GPR data indicated the possibility of highly fractured bedrock where numerous diffractions occurred in the radar signal; however, no low-velocity zones were identified at these same locations in the seismic record. The highvelocity zone at about $200 \mathrm{~m}$ along the seismic-tomography profile may correlate to reflectors from fractures in more competent bedrock visible at about $200 \mathrm{~m}$ along the GPR profile. Borehole-geophysical logs from MW-7, which was installed at $175 \mathrm{~m}$ along the profile, indicate that the upper $16 \mathrm{~m}$ of the borehole is highly fractured. Most of the fractures observed in borehole-imaging logs strike east-northeast and west-southwest and dip to the southeast and northwest.

Profiles L-08 and L-09 are downgradient and southeast of a suspected contaminant source on the southern side of the radar tracking station on Howard Mountain. From the GPR data, the depth to bedrock is interpreted to be 0.5 to $0.9 \mathrm{~m}$ below land surface. The bedrock surface is interpreted as being discontinuous along both profiles, and many reflectors from within the bedrock are interpreted to 2 or $3 \mathrm{~m}$ below the overburden-bedrock interface. The depth to bedrock interpreted from the seismic refraction tomography inversions varies from 1.9 to $4.0 \mathrm{~m}$ across the profiles.

Combined interpretation of GPR and seismic-refraction tomography data on profile L- 08 identified three zones of highamplitude reflectors and low seismic velocity at distances of 110 to $125 \mathrm{~m}$ (at a depth of about $7 \mathrm{~m}$ ), 140 to $155 \mathrm{~m}$ (at a depth of about $7 \mathrm{~m}$ ), and 210 to $215 \mathrm{~m}$ (at a depth of about $3 \mathrm{~m}$ ) along the profile. Collectively, these characteristics are indicative of fractured zones in the bedrock. Borehole-geophysical logs from MW-8b, installed at a distance of $205 \mathrm{~m}$ along profile L- 08 , indicate there is a change in rock type at a depth of about $6 \mathrm{~m}$ below land surface. Borehole-imaging logs indicate that the bedrock is densely and uniformly fractured, and the open fractures strike to the northeast and dip to the southeast.

For profile L-09, zones of high amplitude reflections in the bedrock on the GPR profile correspond to thicker areas of lower velocities on the tomographic model at distances of 105 to 120 $\mathrm{m}, 145$ to $165 \mathrm{~m}$, and 175 to $200 \mathrm{~m}$ along the profile; these zones are interpreted as areas of highly fractured bedrock near the surface. Borehole-geophysical logs from MW-9, installed at a distance of $200 \mathrm{~m}$ along the profile, indicate highly fractured rock in the top of the borehole and a change in rock type at a depth of $23 \mathrm{~m}$, which is deeper than the depth of investigation of the surface-geophysical methods used for this investigation. Borehole-imaging methods determined that the open fractures strike east and dip to the south and strike to the southwest and dip to the northwest.

Profile L-14 is southeast and downgradient from a suspected contaminant source on Miller Mountain. From the GPR data, the depth to bedrock is interpreted as ranging from 2.5 to $3 \mathrm{~m}$ along the profile. The bedrock interface is discontinuous and somewhat irregular, and reflections from within the bedrock are visible for 1 to $2 \mathrm{~m}$ below the overburden-bedrock interface. Interpretation of the seismic-tomography profiles indicates that the thickness of the overburden varies from 1 and $8 \mathrm{~m}$ across the profile.

Integrated interpretation of the GPR and seismic data on profile L-14 shows that a zone of high-amplitude reflections in the bedrock between about 130 and $145 \mathrm{~m}$ on the GPR profile corresponds to an area of lower velocities on the seismic-tomographic model at a distance of about 137 to $152 \mathrm{~m}$ along the profile. This zone is interpreted as an area of substantially fractured bedrock. Borehole-geophysical logs from MW-14, installed at a distance of $152 \mathrm{~m}$ along the profile, indicate that the bedrock is densely and uniformly fractured to a depth of about $23 \mathrm{~m}$ below land surface. Borehole-imaging logs indicate that the open fractures dip to the southwest to west-southwest.

Profile TW-1 is north of Howard Mountain and the radar tracking station. It was used to look for ground-water production zones within the overburden and bedrock. The depth to bedrock is interpreted to be about $15 \mathrm{~m}$ along the seismic-tomographic profile, consistent with the location of the profile in a valley. Borehole-geophysical logs from TW-1, installed at a distance of $185 \mathrm{~m}$, indicate that the open features dip predominantly east to southeast.

\section{Evaluation of Geophysical Methods}

During evaluation of the surface-geophysical methods in February 2003, up to $1 \mathrm{~m}$ of snow was present in the area, although most of the profile lines were plowed. The surveys were collected during a week of extremely cold weather. In general, snow on the ground had no negative effects on the surfacegeophysical surveys. In fact, the snow was advantageous for GPR surveys because snow provides excellent coupling of the GPR antennas with the ground. The smoother surface of snow relative to the rougher ground surface and the resistive properties of ice aided in antenna-ground coupling. Snow depth did affect the interpretation of depths on the GPR data profiles, so snow depth should be measured on GPR profile lines. For seismic methods, packed snow was satisfactory for coupling the geophones to the ground. Buried ice mounts also were successful, though rarely used because packing snow around the geophones and mounting them flush with the surrounding snow cover was satisfactory.

The extreme cold temperatures during the data collection negatively affected the surface-geophysical equipment. With average daily temperatures below 0 degrees C, one of the GPR systems had substantial problems with the fiber-optic cables and the control unit freezing. Such extreme cold rendered the 
fiber-optic cables on the unshielded GPR system inoperable, and therefore, it was not possible to conduct common mid-point (CMP) surveys for this study. Use of GPR systems without fiber-optic cables could help avoid this problem. The GPR system used in this study was chosen for use, however, because of its compatibility with global-positioning system (GPS) referencing equipment and for its shielded antennas, which were used to minimize noise in the GPR record and are less susceptible to extreme cold temperatures.

Cold temperatures and snow had no effect on the GEM2, EM-31, and EM-34 instruments. GEM-2, EM-31, and EM-34 instrument responses, however, were adversely affected by a very-low frequency transmitter station across the bay in Cutler, Maine, and by the low terrain conductivities characteristic of this part of northeastern Maine. The transmitter at the Naval Computer and Telecommunications Station has an output power of 2 million watts and operates in a frequency range of 14 to $60 \mathrm{kHz}$, which saturated the receiver coils of the instruments. This interference, coupled with low conductivity conditions of the site, resulted in poor-quality data that could not be interpreted. Although not effective for estimating depth to bedrock, the EM-31 and EM-34 are useful for finding lateral variations in conductivity, conductive bodies, or fractures filled with conductive fluids. During this investigation, the GEM-2 was determined to be better for locating anomalous metallic objects and conductive anomalies rather than for geologic mapping.

The GPR method generally worked well for this study. Interpretation of the GPR data was used to identify the weathered bedrock surface; discontinuous, irregular reflectors off of the bedrock surface that might indicate the presence of highly fractured zones; and reflections in the subsurface from weathering, fractures, or fracture zones. GPR data collection was fast and relatively easy. The resolution of the GPR data was estimated to be about $0.25 \mathrm{~m}$. The $100-\mathrm{MHz}$ (megahertz) antenna was effective for imaging reflections off of fractures within the bedrock to depths of 10 to $12 \mathrm{~m}$ below land surface. Although the reflection off the bedrock surface would have been better resolved by using a higher frequency antenna, it would have been at the expense of reducing the depth of penetration of the radar signal. The best solution may have been to use antennas of different frequencies $(100,250$, and $400 \mathrm{MHz})$ to resolve both the bedrock surface and deeper features, and to use separate antennas to increase the offset between the transmitter and receiver and to permit CMP measurements for EM velocity estimates. Simultaneous collection of GPR and GPS data was successful in providing accurate antenna location information with little noise in the GPS data.

The seismic-refraction data were interpreted with models produced by SIPT2 earth-layer inversions and tomographic inversions. The depth of the investigation limit of the seismic models typically was about $15 \mathrm{~m}$. The SIPT2 models identified refractions at layer boundaries, such as between unsaturated and saturated layers and between overburden and bedrock. In most cases, the depth to bedrock identified by seismic refraction was deeper than the depth to bedrock identified in borehole-velocity surveys, core logs, and GPR surveys.
The tomographic inversions overcame problems associated with gradual contacts, hidden layers, blind zones, lateral velocity changes, and discontinuous layers that hamper earthlayer models. The tomography, however, requires boreholevelocity data to help interpret the model. Moreover, the tomography solution cannot directly define the bedrock surface but rather provides a gradation of velocity contours from which the bedrock surface can be determined. The resolution of the seismic-tomography models is estimated to be about $3 \mathrm{~m}$.

For the GPR profiles, the interpreted depth to bedrock at the location of the borehole generally is a little less than the depth to weathered bedrock observed in the drilling logs. The depths to competent bedrock interpreted from the seismictomography inversions are close to the depths to competent bedrock interpreted from the borehole-velocity surveys, and in most cases, several meters deeper than the depth to competent bedrock from the drilling logs.

On the GPR profiles, the bedrock surface is interpreted as having discontinuities or as being fairly nonuniform. Many reflectors were observed from within the bedrock in the first few meters below the bedrock interface, which is interpreted as an area of more fractured or weathered bedrock. Within each profile, there are zones that are interpreted as highly fractured bedrock. A few reflectors also were observed to depths of 7 or $10 \mathrm{~m}$ below land surface on each of the profiles. In many of the profiles, combined interpretation of the GPR and seismic data indicate that areas interpreted as being especially fractured on the GPR profiles correspond to zones of lower velocities on the seismic profiles.

Using GPR and seismic refraction together in an integrated fashion aided in optimizing the location of exploratory boreholes. On profile L-06, a borehole was proposed to be drilled at approximately $235 \mathrm{~m}$ along the profile to intersect the zone with the near-vertical fracture observed to $12 \mathrm{~m}$ below land surface; however, an alternative location was chosen for the drilling. On profile L- 08 , a borehole was proposed to be drilled to intersect bedrock fractures interpreted at 110 to $125 \mathrm{~m}$ along the profile, but an alternative location was chosen. Boreholes MW-4, MW6 , MW-14, and TW-1 were drilled in areas where the seismictomography models indicated lateral changes in velocity of the underlying bedrock. Borehole MW-8b was drilled at $205 \mathrm{~m}$ along the profile to target dipping reflectors in the bedrock. MW-4 was drilled in an area where bedrock was modeled as a slight topographic low with lateral changes in velocity, and MW-14 was drilled where a broad zone of relatively low velocity (less than $3,500 \mathrm{~m} / \mathrm{s}$ ) was observed.

This investigation demonstrated the successful use and collective application of multiple surface-geophysical methods to characterize subsurface fractures, which might serve as pathways for contaminant transport, near a formerly used defense site. The results should be useful to site investigators and environmental regulators to improve site characterization and to refine the conceptual ground-water-flow model for the site. In addition, the results may prove helpful for selecting appropriate surface-geophysical equipment and methods of interpretation in future fractured-rock investigations. 


\section{References Cited}

ABB Environmental Services, Inc. 1995, Final fracture trace analysis report, Bucks Harbor Former Air Force Radar Tracking Station, Machiasport, Maine: Portland, Maine, Environmental Services, Inc.

ABB Environmental Services, Inc., 1997, Engineering evaluation of contamination, Bucks Harbor Former Air Force Radar Tracking Station, Machiasport, Maine: Portland, Maine, Environmental Services, Inc., 76 p.

American Society for Testing and Materials, 1999, Standard guide for using the surface ground penetrating radar method for subsurface investigation, ASTM designation D 6432-99: West Conshohocken, Penn., American Society for Testing and Materials, p. 1-17.

American Society for Testing and Materials, 2000, Standard guide for using the seismic refraction method for subsurface investigation, ASTM designation D 5777-00: West Conshohocken, Penn., American Society for Testing and Materials, p. $1558-1570$.

Borns, H.W., 1974, Surficial geology of the Machias quadrangle: Maine Geological Survey, Department of Conservation, Open File No. 74-4.

Fine, H., 1954, An effective ground conductivity map for continental United States: Proceedings of the Institute of Radio Engineering, v. 42, p. 1405-1408.

Gates, O., 1981. Bedrock geology of the Machias, Columbia Falls, and Great Wass Island quadrangles: Maine Geological Survey, Department of Conservation, Open File No. 81-11.

Gates, O., and Moench, R.H., 1981, Bimodal Silurian and Lower Devonian volcanic rock assemblages in the MachiasEastport Area, Maine: U.S. Geological Survey Professional Paper 1184, 32 p., scale 1:62,500.

Geonics Limited, 1991, EM-31 and EM-34 operating manuals-Geonics Ltd., TN-8: EM34-3 Survey interpretation techniques: Mississauga, Canada, Geonics Ltd., 61 p.

GeoTomo LLC, 2002, GeoCT-II-Complete seismic traveltime tomography for geophysical engineering, ver. 2.3: Houston, Texas, $41 \mathrm{p}$.

Haeni, F.P., 1988, Application of seismic-refraction techniques to hydrologic studies: U.S. Geological Survey Techniques of Water-Resources Investigations, book 2, chap. D2, 86 p.

Interpex, 1996, GRADIX user's manual, ground-penetrating radar processing and interpretation: Golden, Colorado, Interpex Ltd., July 23, ver. 1, 230 p.

McNeill, J.D., 1980, Electromagnetic terrain conductivity measurements at low induction numbers, Technical Note TN-6: Mississauga, Canada, Geonics, Ltd., 15 p.

Pakiser, L.C., and Black, R.A., 1957, Exploring for ancient channels with the refraction seismograph: Geophysics, v. 22, no. 1, p. 32-47.

Powers, C.J., Wilson, J., Haeni, F.P. and Johnson, C.J., 1999, Surface-geophysical investigation of the University of Connecticut landfill, Storrs, Connecticut: U.S. Geological Survey Water-Resources Investigations Report 99-4211, 34 p.
RimRock Geophysics, 1992, SIPT2 refraction processing software, ver. 3.2: Boulder, Colorado.

Scott, J.H., 1977, SIPT2-A seismic refraction inverse modeling program for time-share terminal computer systems: U.S. Geological Survey Open-File Report 77-366, 27 p.

Shapiro, A.M., Hsieh, P.A., and Haeni, F.P., 1999, Integrating multidisciplinary investigations in the characterization of fractured rock, in Morganwalp, D.W., and Buxton, H.T., eds., U.S. Geological Survey Toxic Substances Hydrology Program-Proceedings of the Technical Meeting, Charleston, South Carolina, March 8-12, 1999: U.S. Geological Survey Water-Resources Investigation Report 99-4018C, v. 3, p. 669-680.

Sheriff, R.E., 1991, Encyclopedic dictionary of exploration geophysics: Society of Exploration Geophysicists, 384 p.

U.S. Army Corps of Engineers, 2002, Howard Mountain/Miller Mountain Former Air Force Radar Tracking Station (AFRTS): Environmental Cleanup News, Issue 12, February 2002.

U.S. Army Corps of Engineers, 2003, Integrated geophysics work management plan Bucks Harbor FUDS site, Machiasport, Maine: Concord, Massachusetts, U.S. Army Corps of Engineers New England District, 29 p.

Weston Solutions, 2003, Remedial investigation report former Bucks Harbor Air Force Radar Tracking Station, Machiasport, Maine [draft September 2003 prepared for the U.S. Army Corps of Engineers New England District]: Manchester, New Hampshire, Weston Solutions, 617 p.

Won, I.J., Keiswetter, D.A., Fields, G.R.A, and Sutton, L.C., 1996, GEM-2: A new multifrequency electromagnetic sensor: Journal of Environmental and Engineering Geophysics, v. 1 , no. 2 , p. $129-138$.

Zhang, Jie; ten Brink, Uri; and Toksoz, M.N., 1998, Nonlinear refraction and reflection traveltime tomography: Journal of Geophysical Research, v. 103, no. B12, p. 29, 743-29, 757.

Zhang, Jie; and Toksoz, M.N., 1998, Nonlinear refraction traveltime tomography: Geophysics, v. 63, no. 5, p. 1726-1737. 


\section{Appendix 1. Geophysical Data from Profile L-04 at the Formerly Used Defense Site, Machiasport, Maine}

a. Processed ground-penetrating radar data.

b. Borehole seismic-velocity survey from borehole MW-4.

c. Seismic-refraction earth-layer and tomography models. 


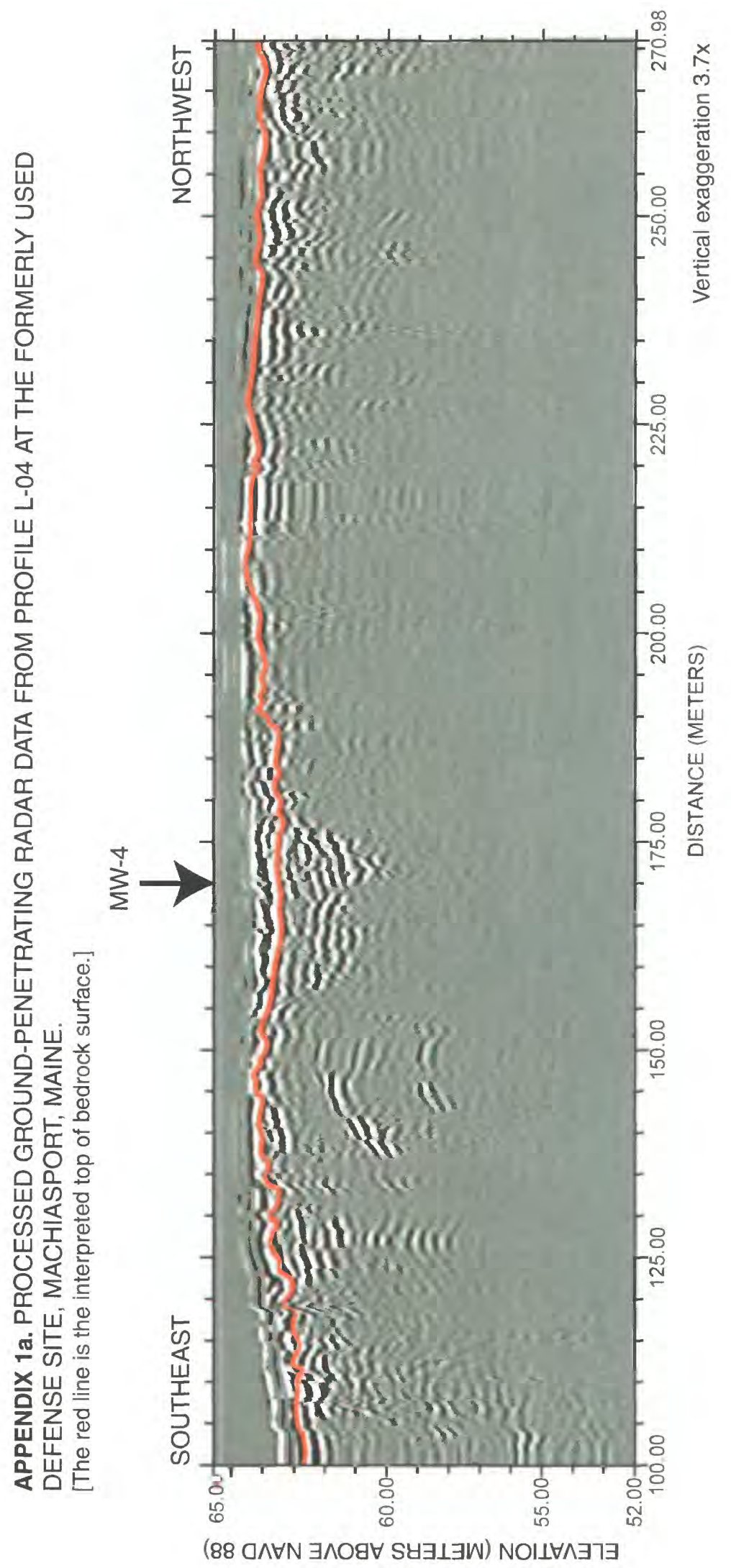


APPENDIX 1b. BOREHOLE SEISMIC-VELOCITY SURVEY FROM BOREHOLE MW-4 AT THE FORMERLY USED DEFENSE SITE, MACHIASPORT, MAINE.

[The panels below are a plot of seismic wave traveltime against elevation (left) and a multi-layered velocity model derived from seismic-refraction tomography (right). Dashed lines indicate interpreted interfaces in seismic-refraction tomography. The horizontal blue bar is the investigation depth limit of the seismic-velocity model. Description of lithology is from core data.]

TIME (MILLISECONDS)

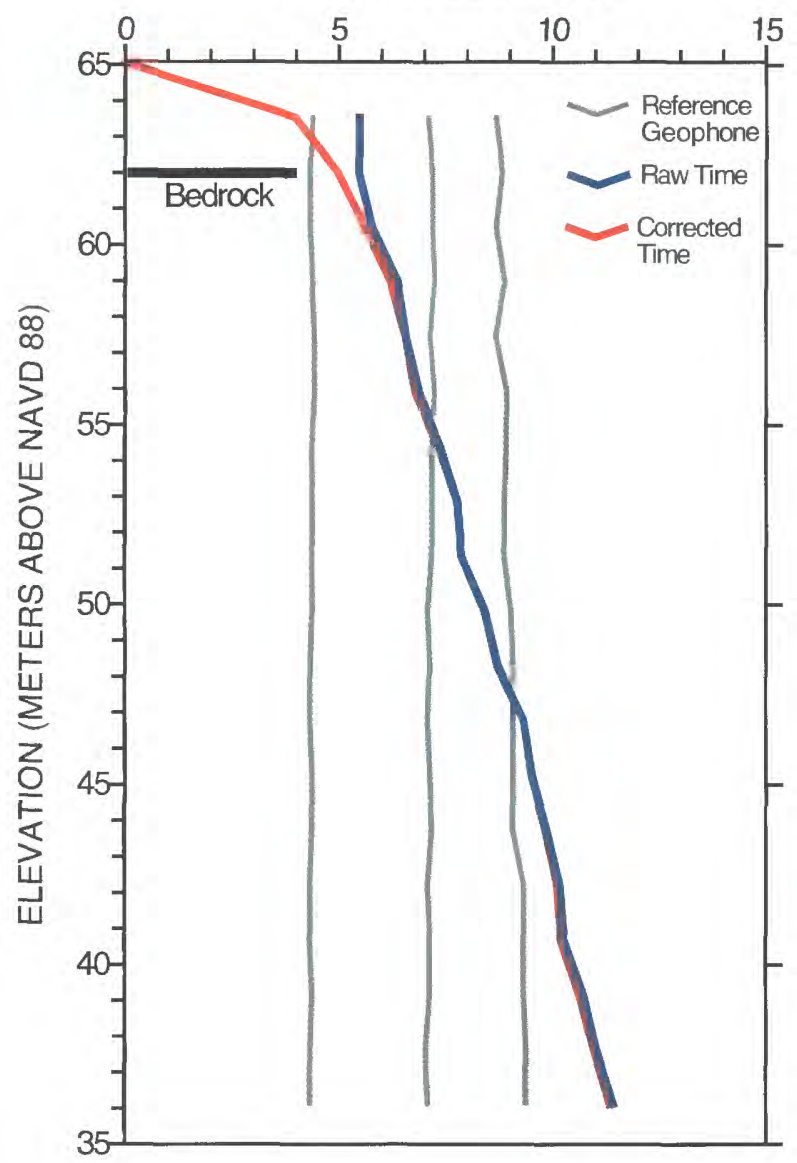

VELOCITY (METERS PER SECOND)

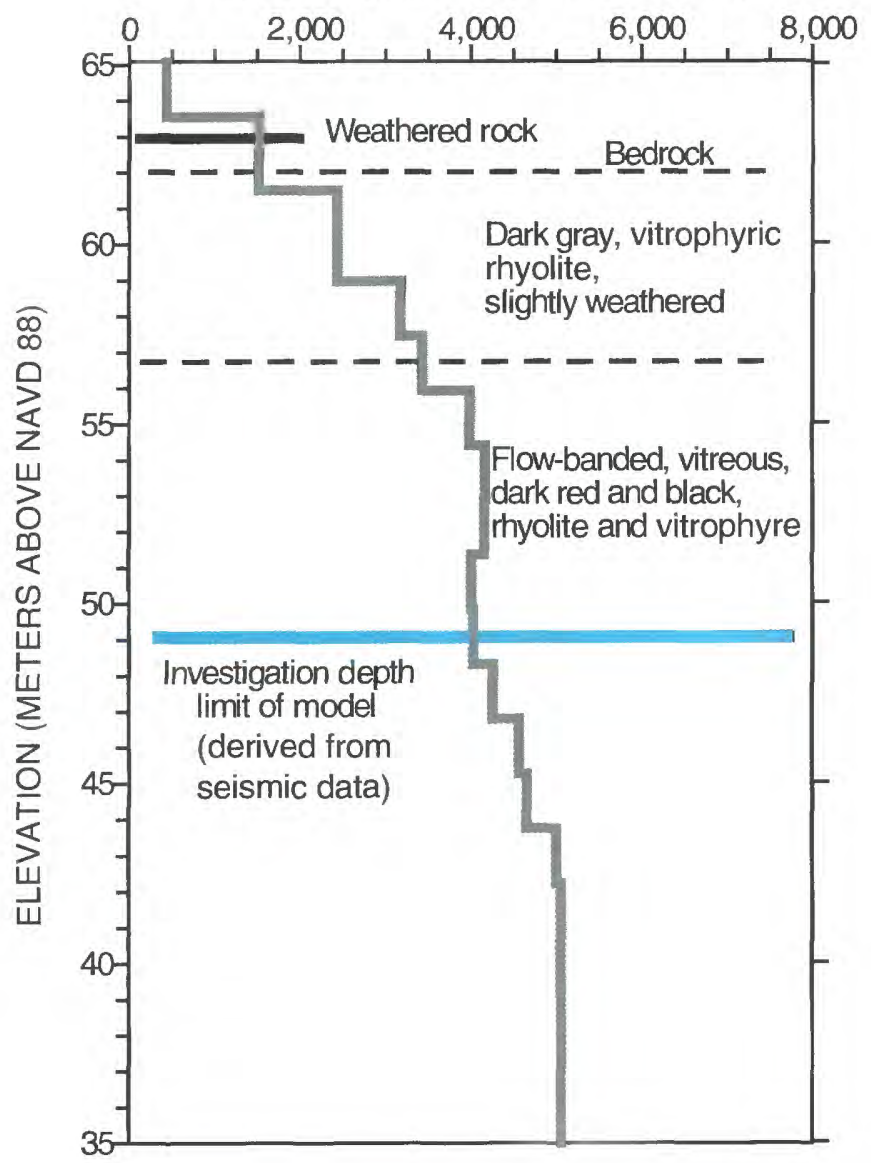



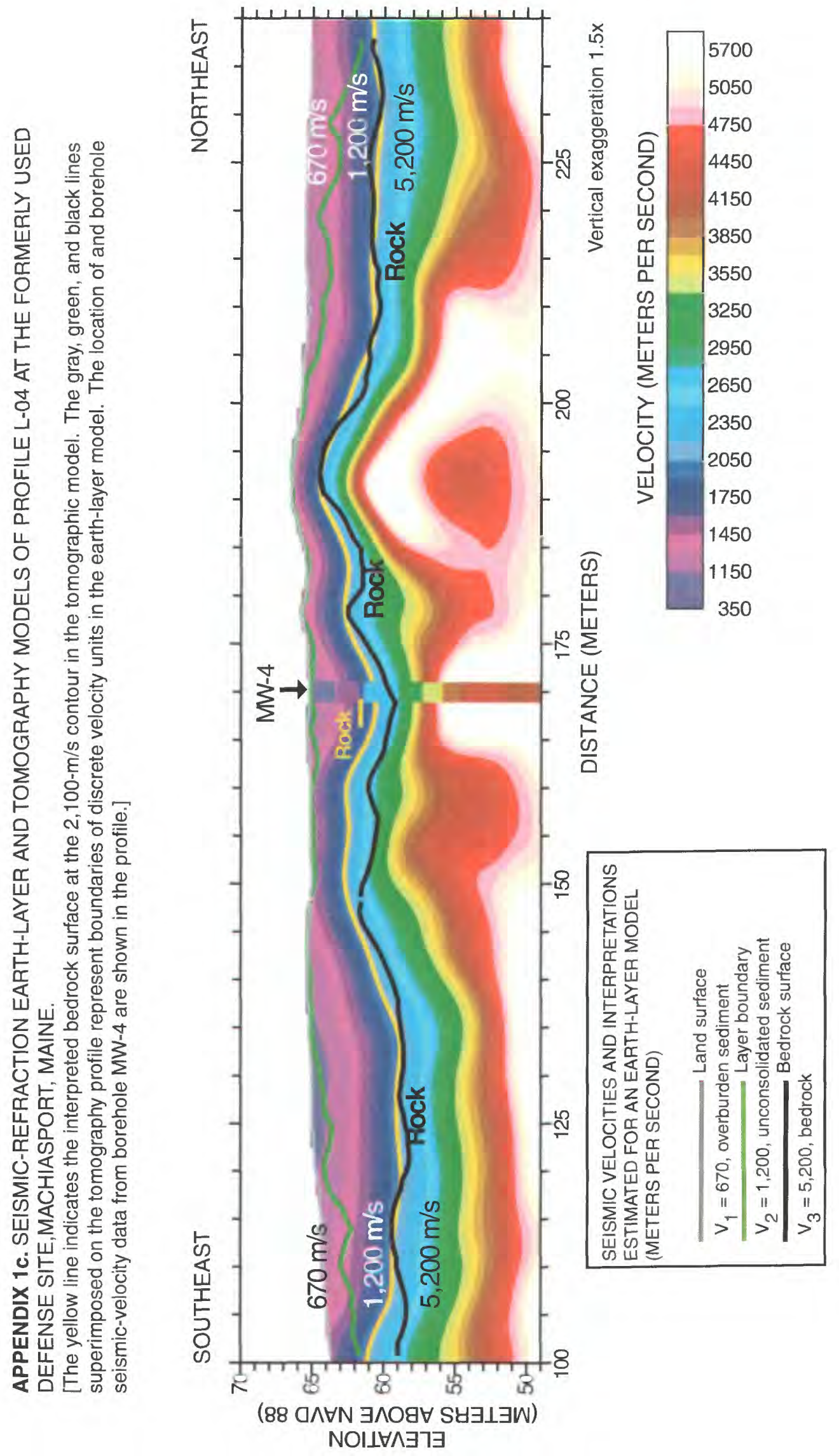

崩政要 는

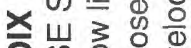
므응응 $\sum_{\mathrm{u}} \sum_{\mathrm{w}} \overline{\mathrm{E}} \frac{\mathrm{E}}{\mathrm{O}}$

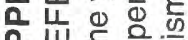
这岩崖旁曾 


\section{Appendix 2. Geophysical Data from Profile L-06 at the Formerly Used Defense Site, Machiasport, Maine}
a. Processed ground-penetrating radar data.
b. Borehole seismic velocity survey from borehole MW-6.
c. Seismic-refraction earth-layer and tomography models. 


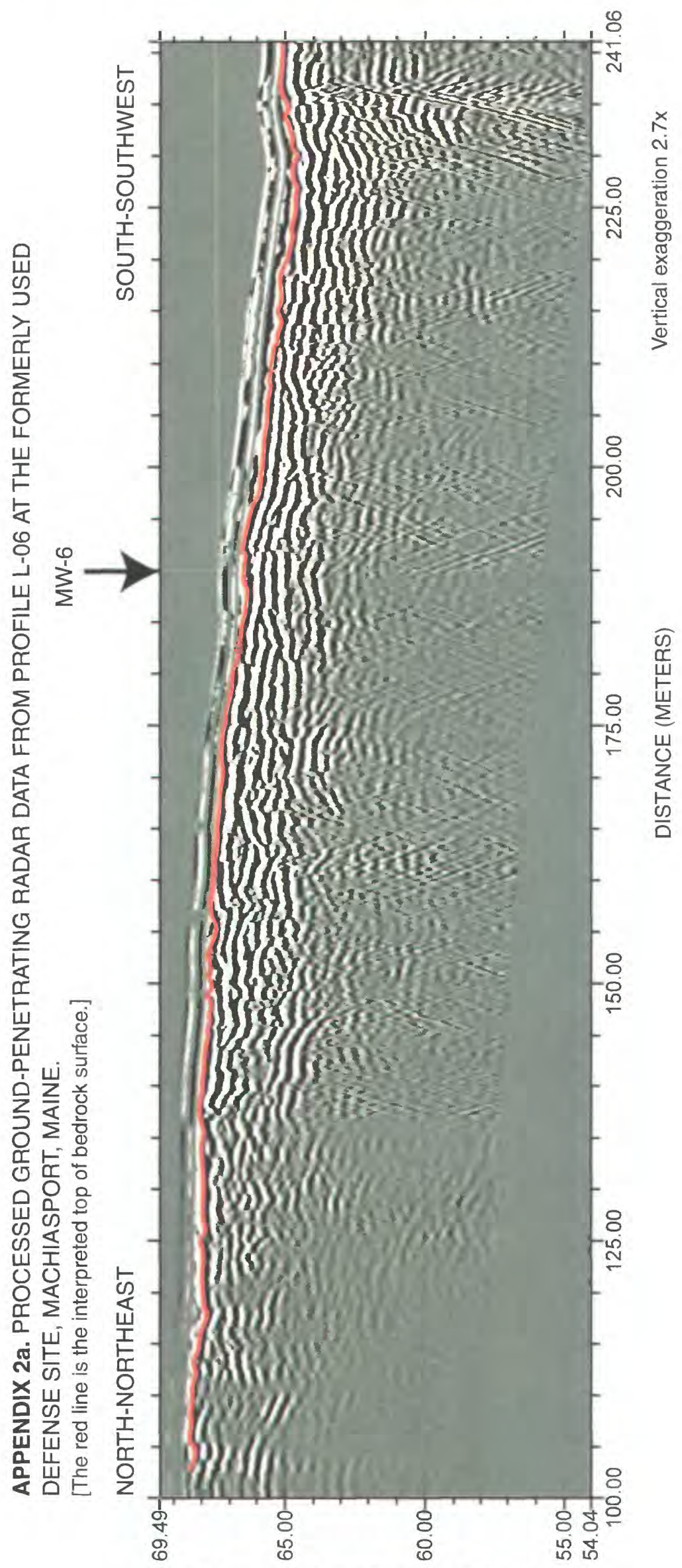

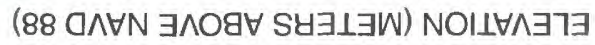


APPENDIX 2b. BOREHOLE SEISMIC-VELOCITY SURVEY FROM BOREHOLE MW-6 AT THE FORMERLY USED DEFENSE SITE, MACHIASPORT, MAINE.

[The panels below are a plot of seismic wave traveltime against elevation (left) and a multi-layered velocity model derived from seismic-refraction tomography (right). Dashed lines indicate interpreted interfaces in seismic-refraction tomography. The horizontal blue bar is the investigation depth limit of the seismic-velocity model. Description of lithology is from core data.]
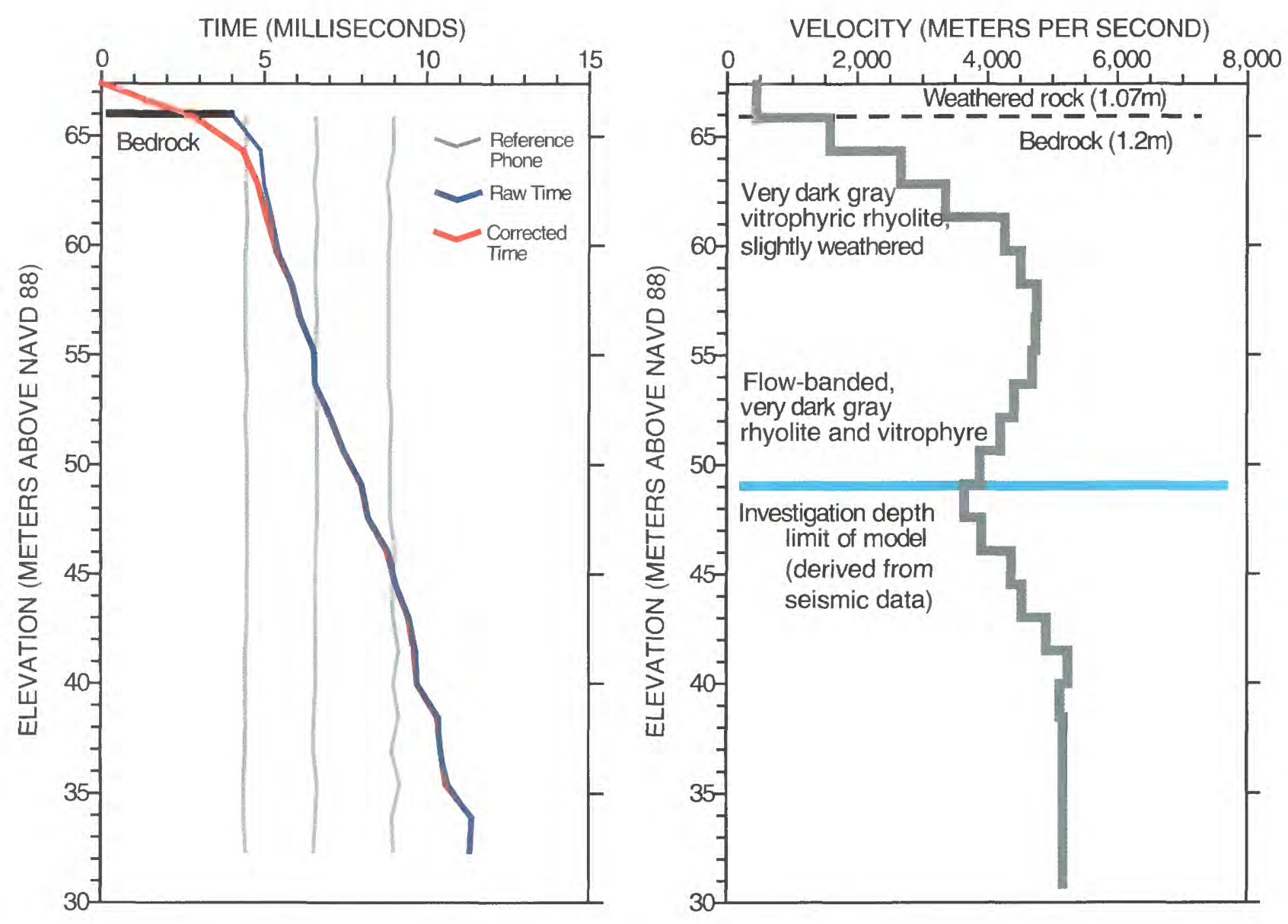


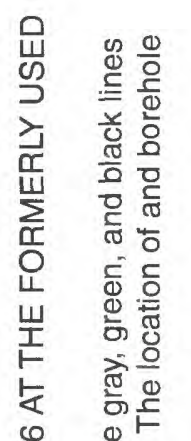

茴

岂

产 है

菭 婇

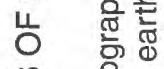

थ है

嵌

인돈

文 言要

엉 응

¿ हैํํㄴ

인 으음

눙휴

z $\stackrel{0}{=}$ 음

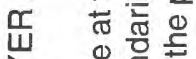

文 过

至

卢

ய山 능 잉

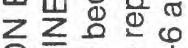

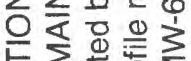

$\sum \sum \overline{0}$

这高응

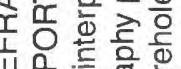

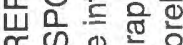

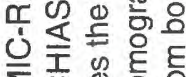

워원

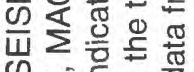

๗山.

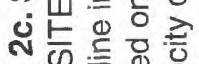

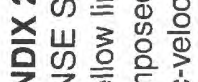

之u $z_{\mathrm{u}}$ ․ㅡㄴ.

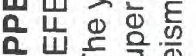

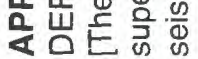

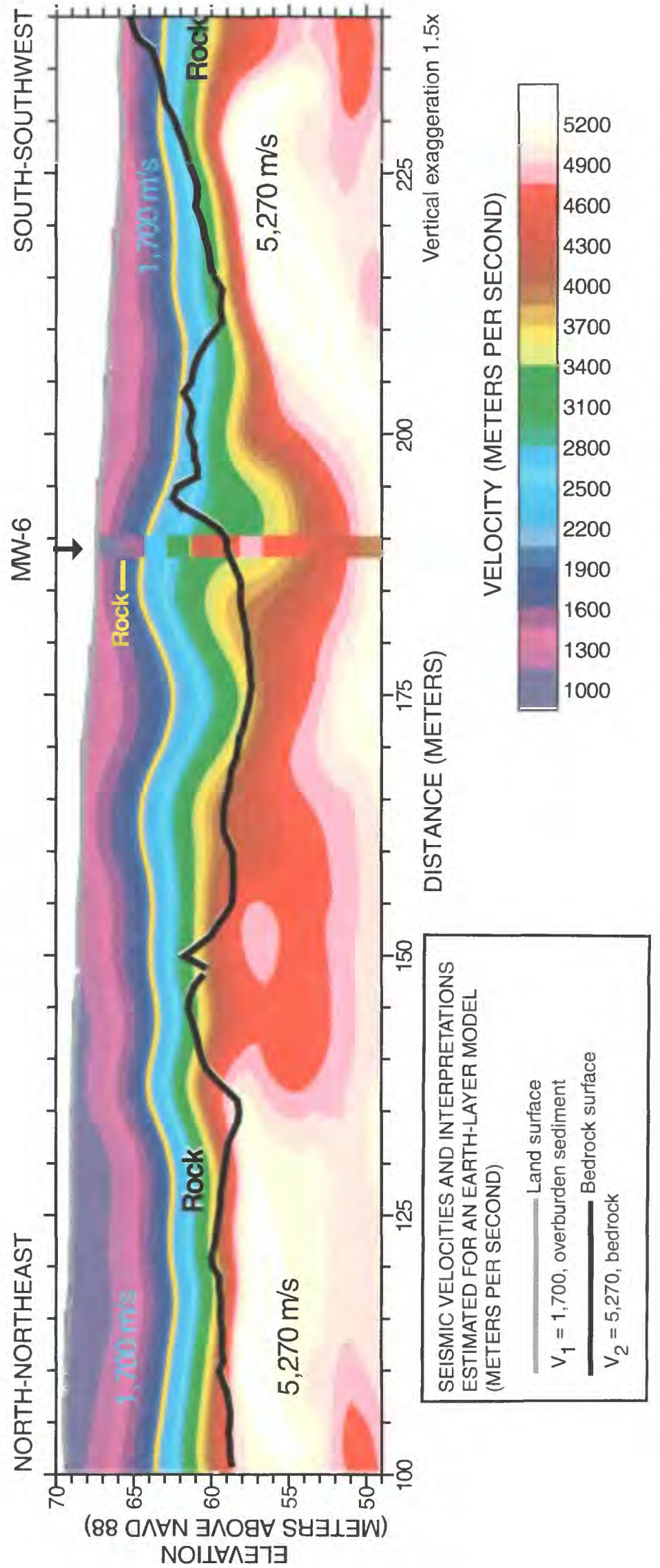




\section{Appendix 3. Geophysical Data from Profile L-07 at the Formerly Used Defense Site, Machiasport, Maine}
a. Processed ground-penetrating radar data.
b. Seismic-refraction earth-layer and tomography models. 


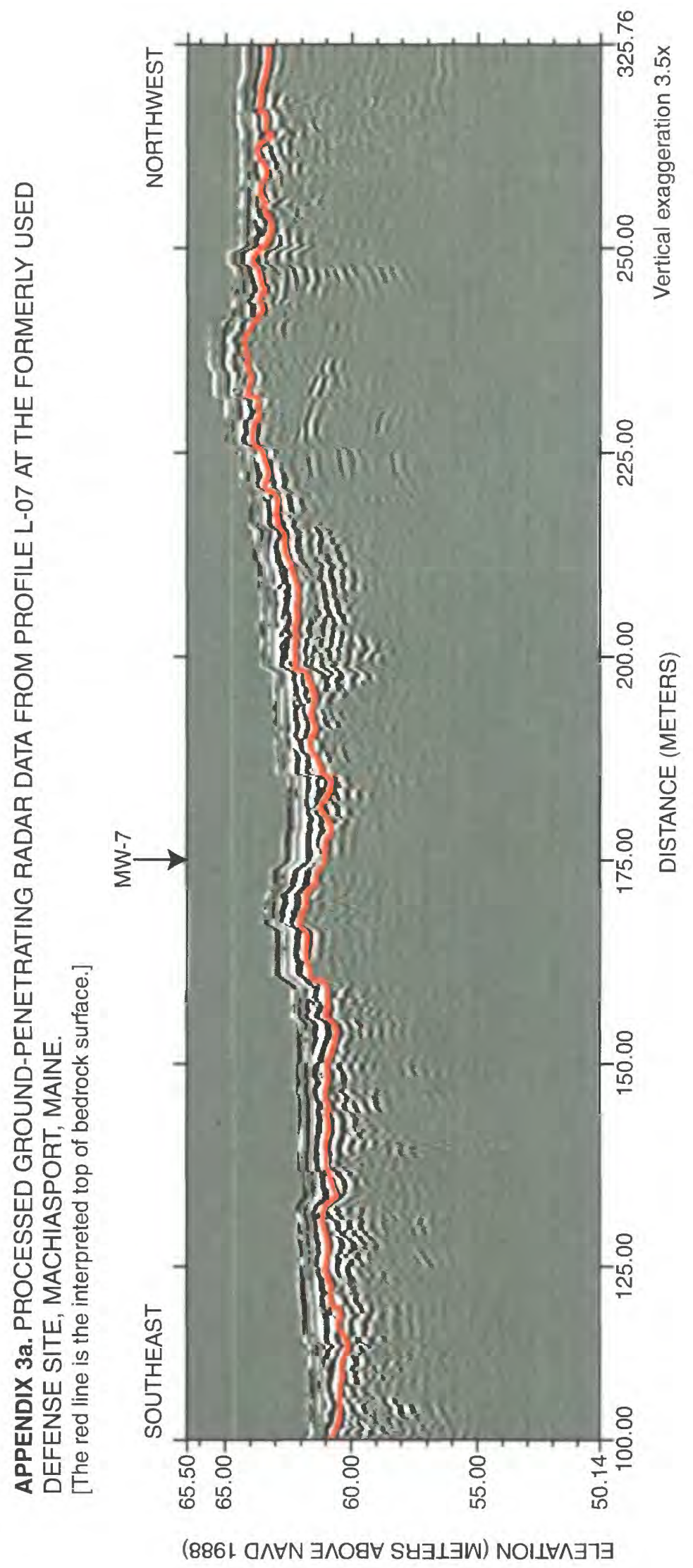


岂

خ

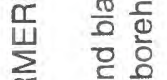

空

崖

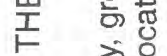

这离잏

今

Ш

एँ

임.인

山 ⿺ㅡㄴ

का

य है

유원돈

$\sum \pm$

文 홍츙

采

है है

은

은

$<\stackrel{9}{ \pm}$

때 के 행

文

I

땅

山山

z之。

은호원

Uド 흠

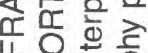

님오릉

舟罂

Uं 文

$\sum_{0} 0$

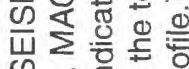

ต

ले

뜨는

是告而

岹出市

员㟧点总的

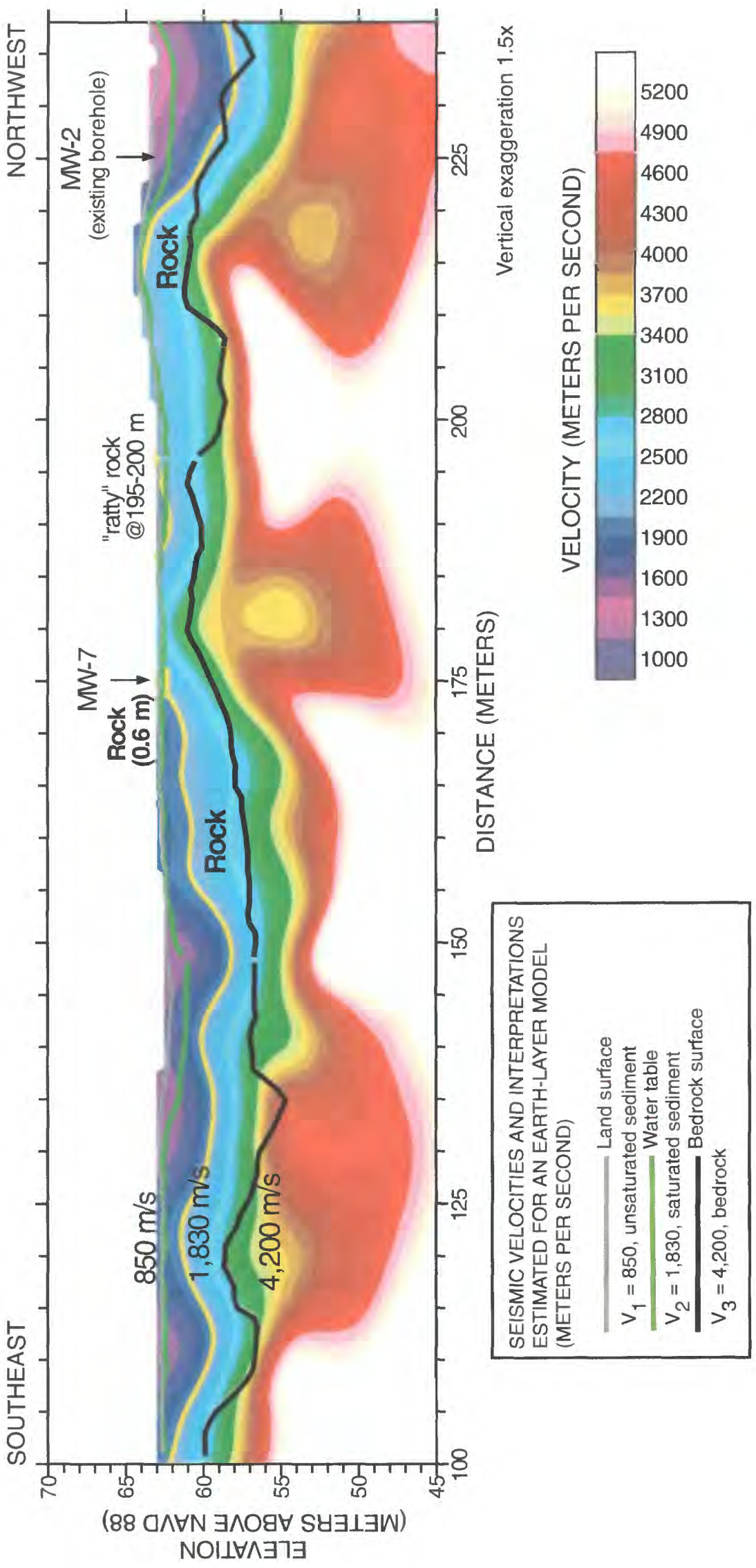




\section{Appendix 4. Geophysical Data from Profile L-08 at the Formerly Used Defense Site, Machiasport, Maine}

a. Processed ground-penetrating radar data.
b. Borehole seismic-velocity survey from borehole MW-8b.

c. Seismic-refraction earth-layer and tomography models. 


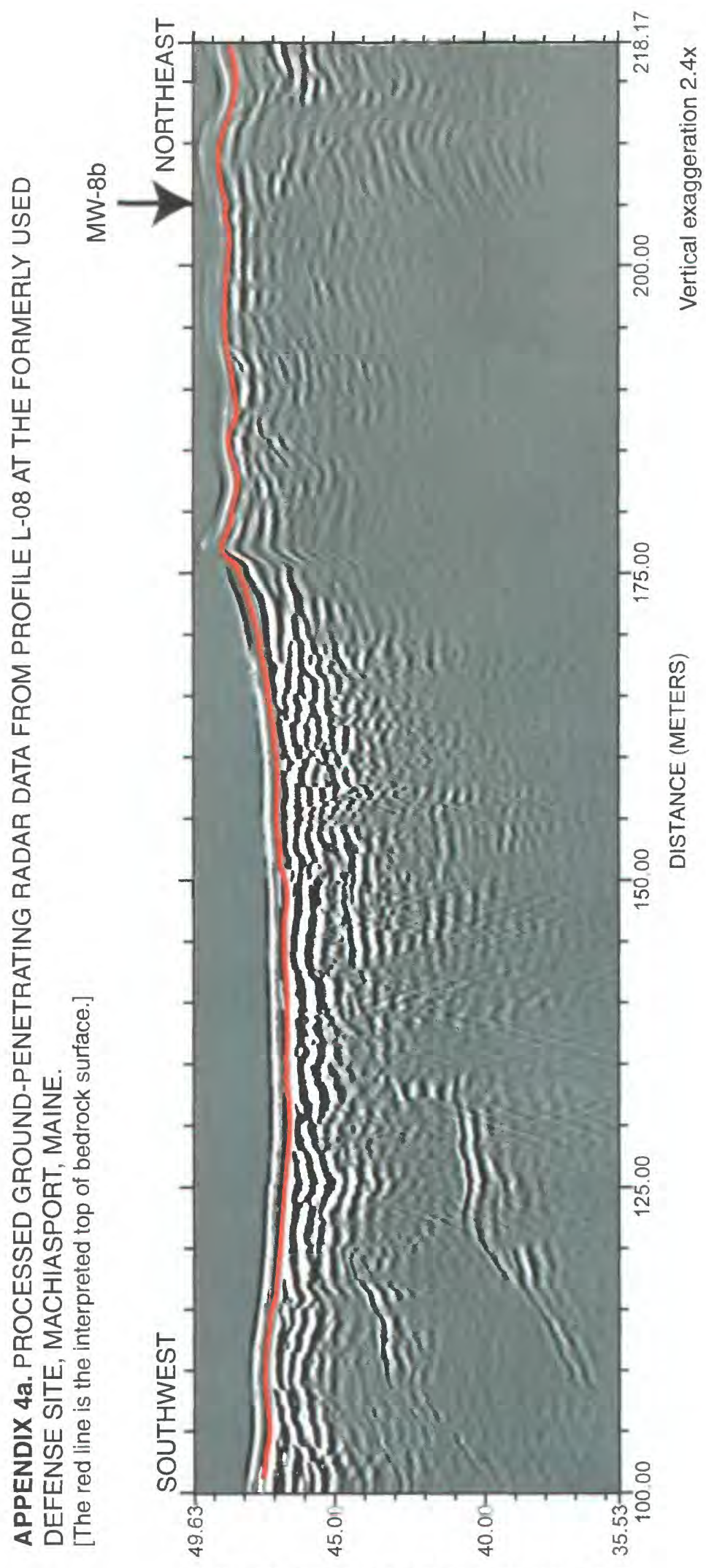

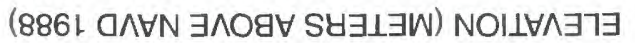


APPENDIX 4b. BOREHOLE SEISMIC-VELOCITY SURVEY FROM BOREHOLE MW-8b AT THE FORMERLY USED DEFENSE SITE, MACHIASPORT, MAINE.

[The panels bleow are a plot of seismic wave traveltime against elevation (left) and a multi-layered velocity model derived from seismic-refraction tomography (right). Dashed lines indicate interpreted interfaces in seismic-refraction tomography. The horizontal blue bar is the investigation depth limit of the seismic-velocity model. Description of lithology is from core data.]
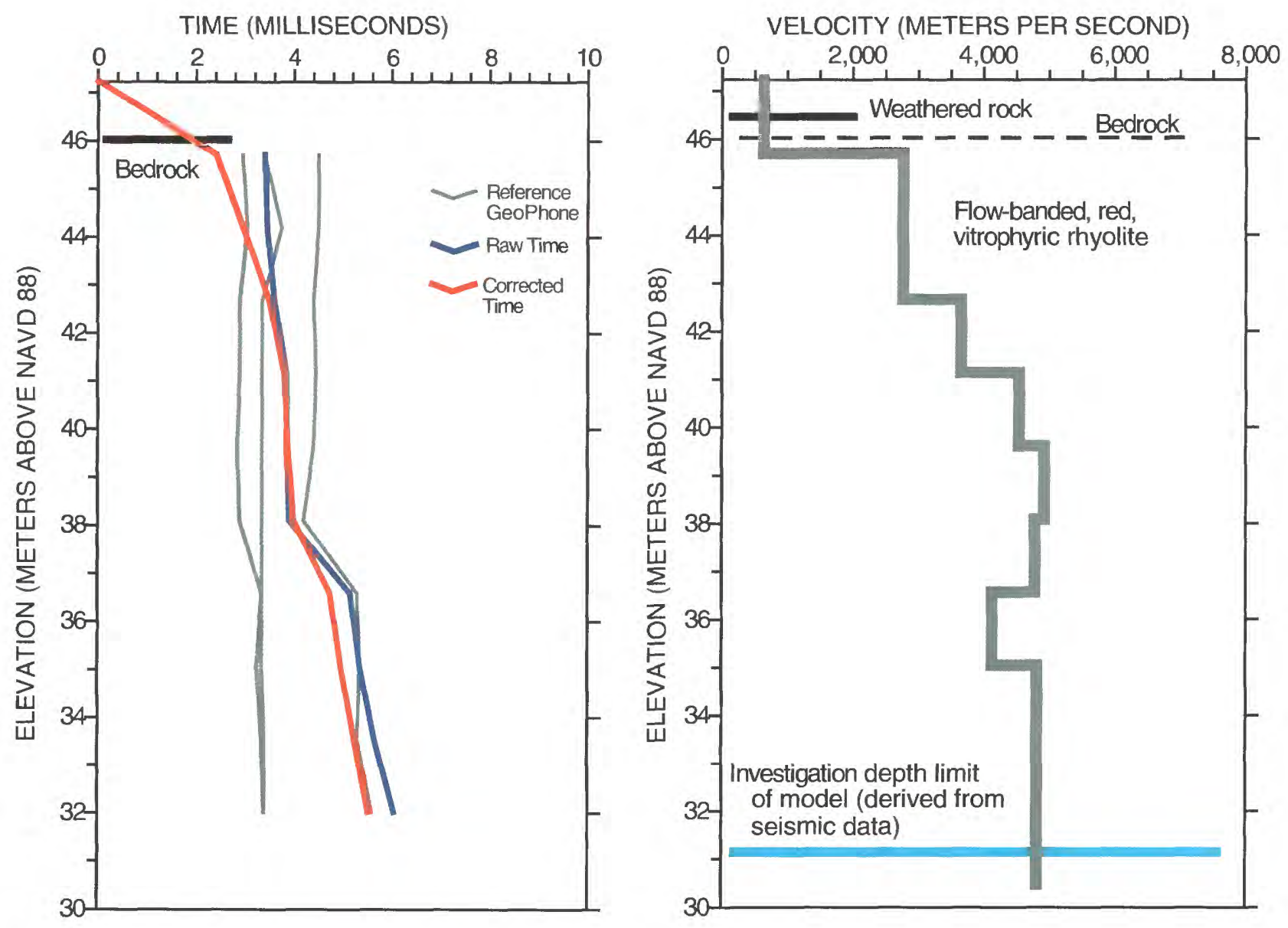


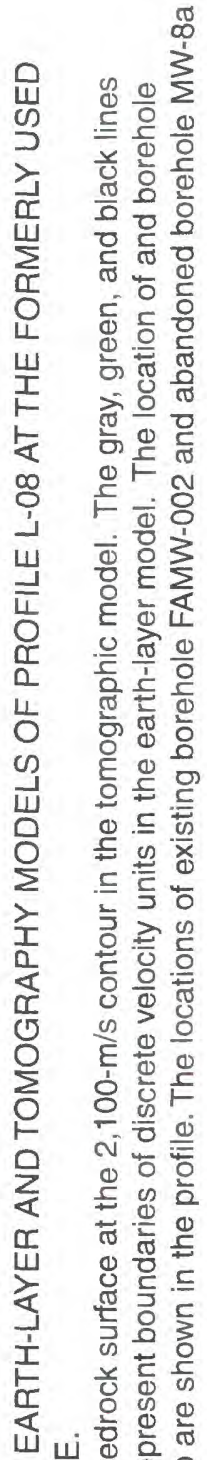

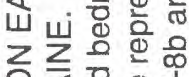

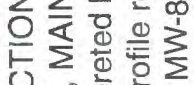

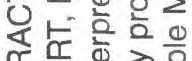

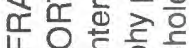

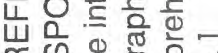

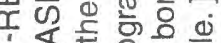

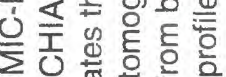
W

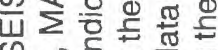
๒

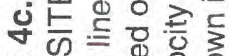

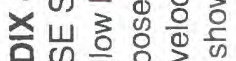

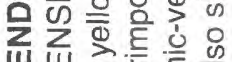
山ய山 है

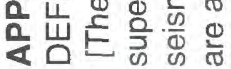

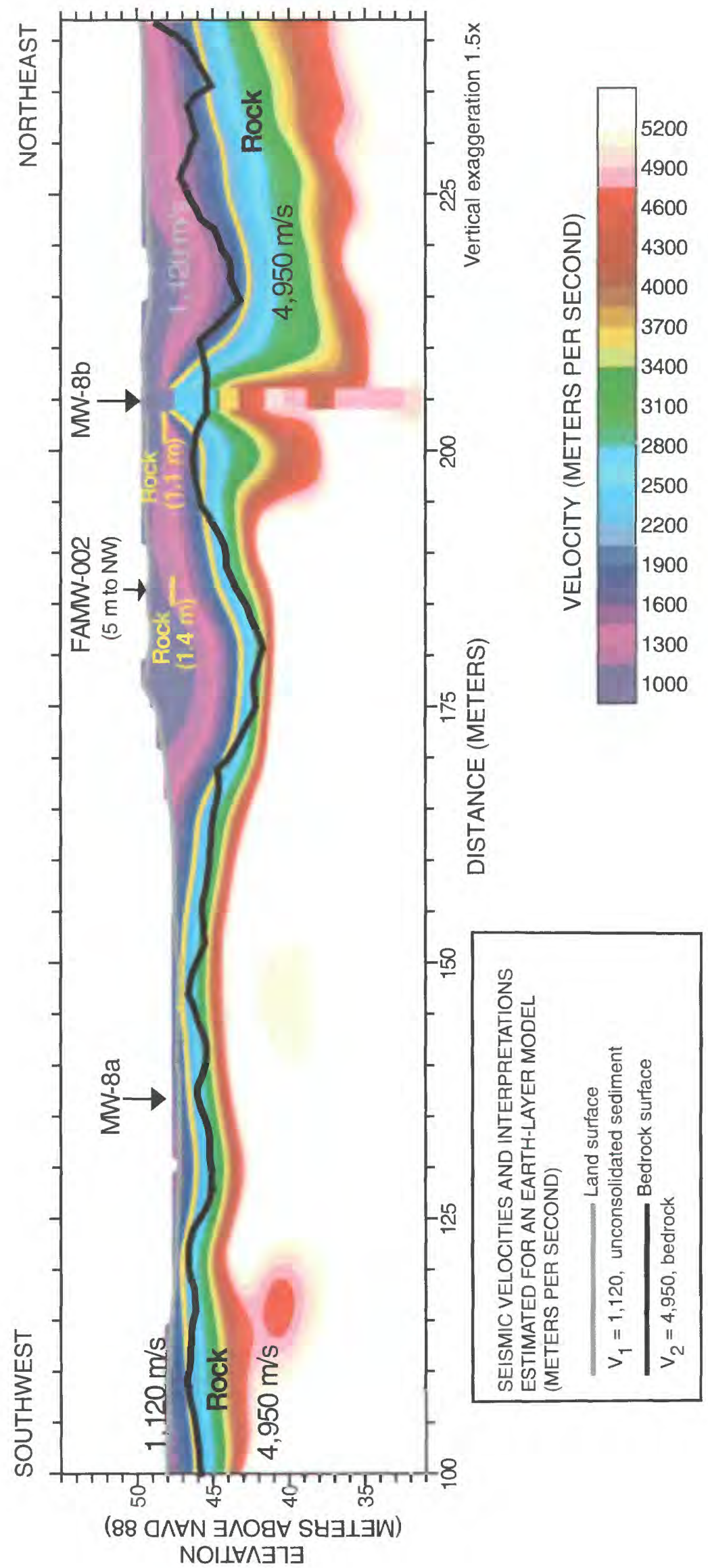




\section{Appendix 5. Geophysical Data from Profile L-09 at the Formerly Used Defense Site, Machiasport, Maine}

a. Processed ground-penetrating radar data.

b. Seismic-refraction earth-layer and tomography models. 


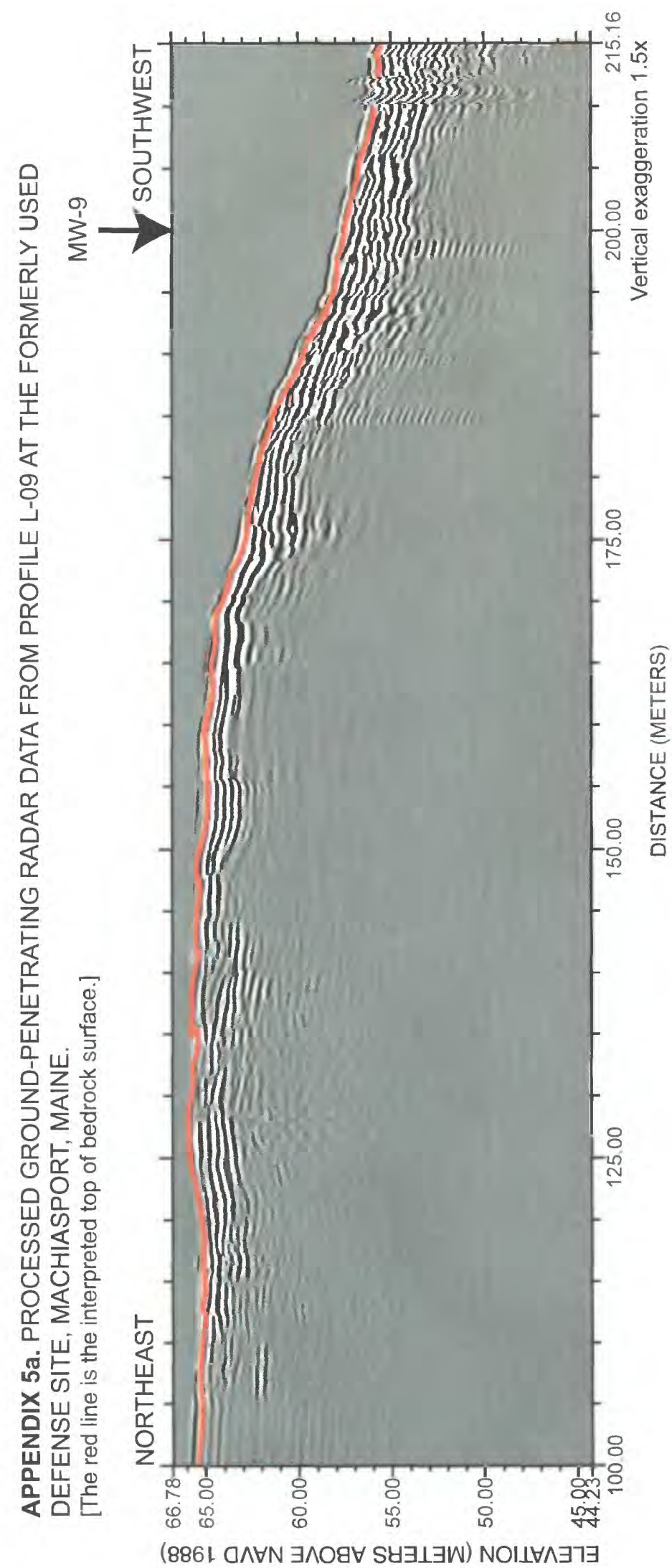




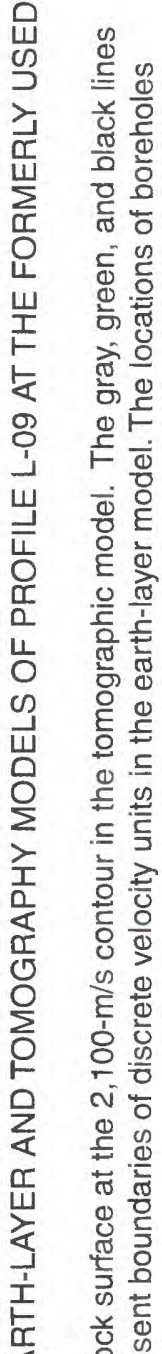

这 ய山் ㅎㅎㅎ흥 $2 \leq 0$

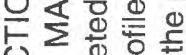

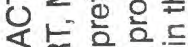

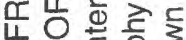

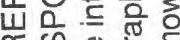
我它的 임일

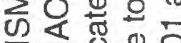

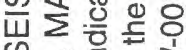
山.

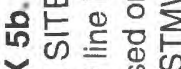
$\times 山 3$ 的 흘을을 $\sum_{i} \sum_{\bar{D}}$ ह

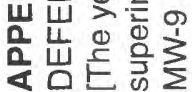

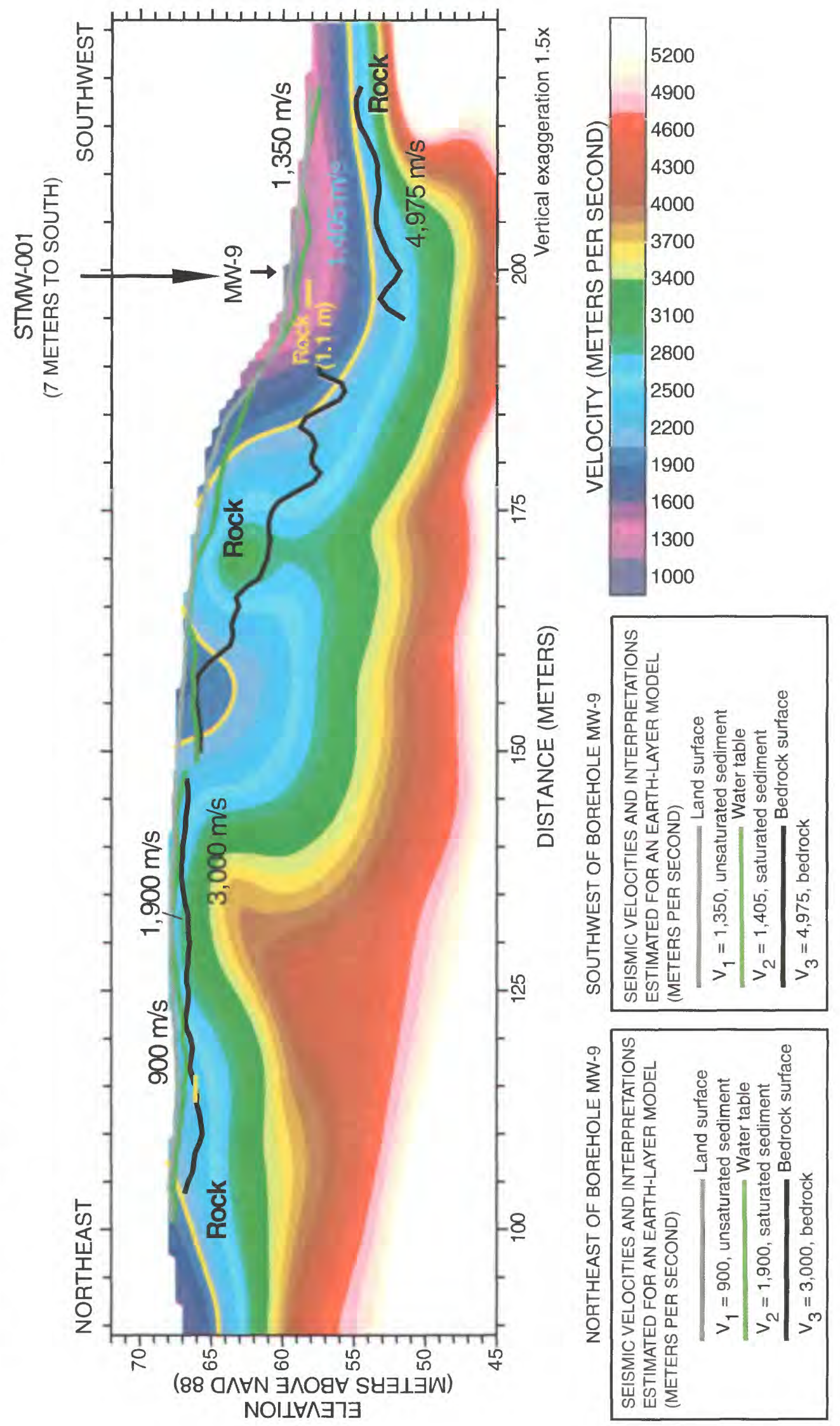




\section{Appendix 6. Geophysical Data from Profile L-14 at the Formerly Used Defense Site, Machiasport, Maine}
a. Processed ground-penetrating radar data.
b. Borehole seismic-velocity survey from borehole MW-14.
c. Seismic-refraction earth-layer and tomography models. 


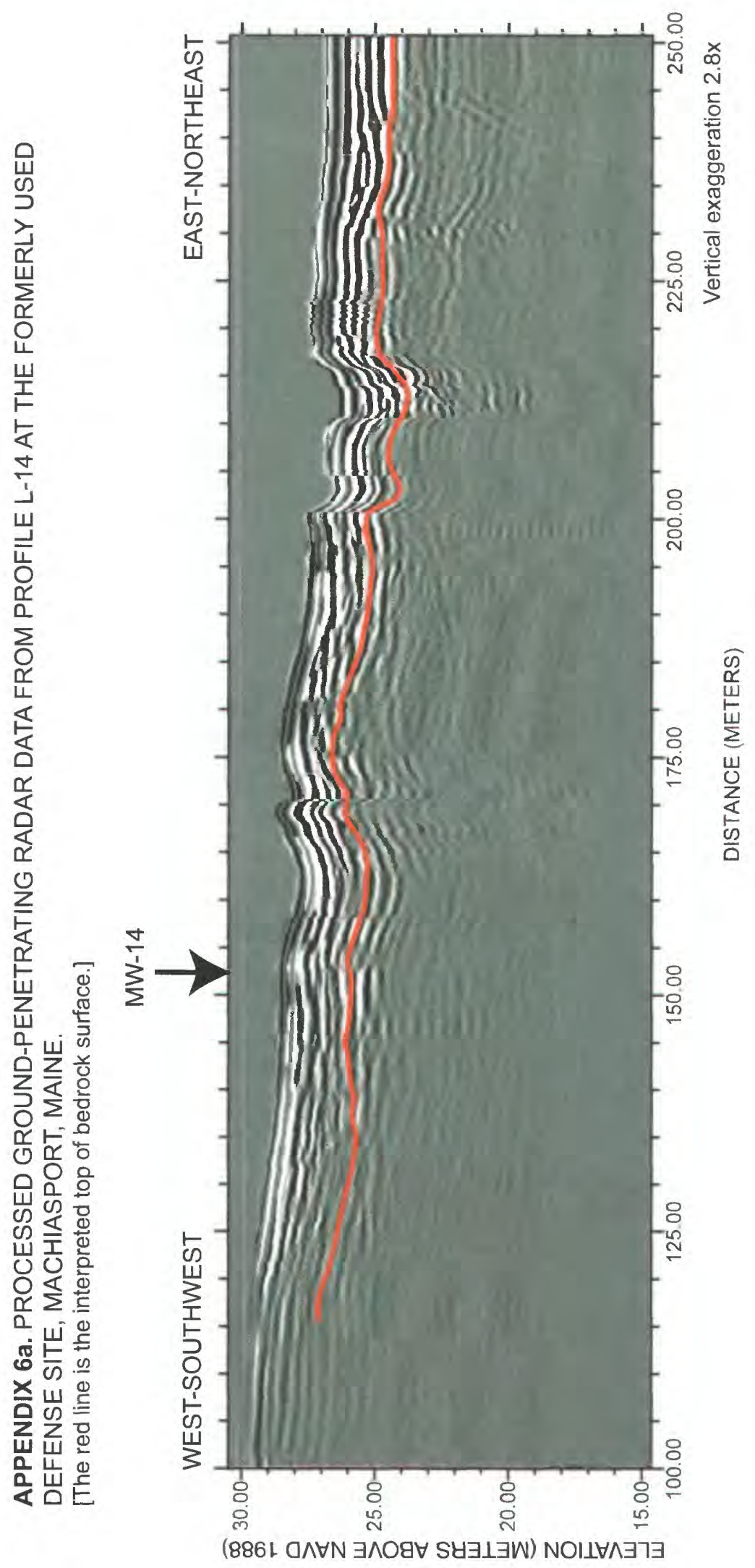


APPENDIX 6b. BOREHOLE SEISMIC-VELOCITY SURVEY FROM BOREHOLE MW-14 AT THE FORMERLY USED DEFENSE SITE, MACHIASPORT, MAINE.

[The panels below are a plot of seismic wave traveltime against elevation (left) and a multi-layered velocity model derived from seismic-refraction tomography (right). Dashed lines indicate interpreted interfaces in seismic-refraction tomography. The horizontal blue bar is the investigation depth limit of the seismic-velocity model. Description of lithology is from core data.]
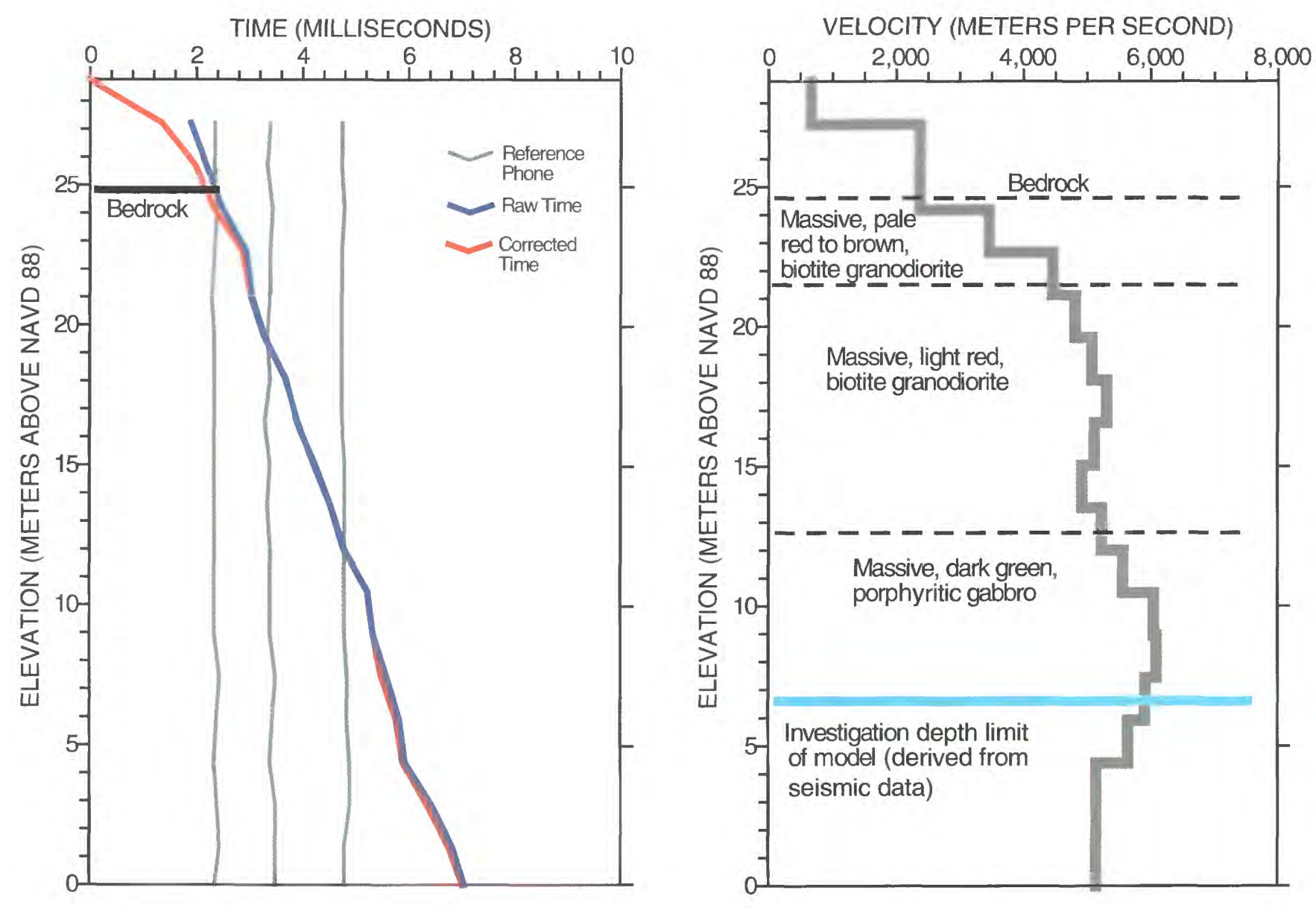


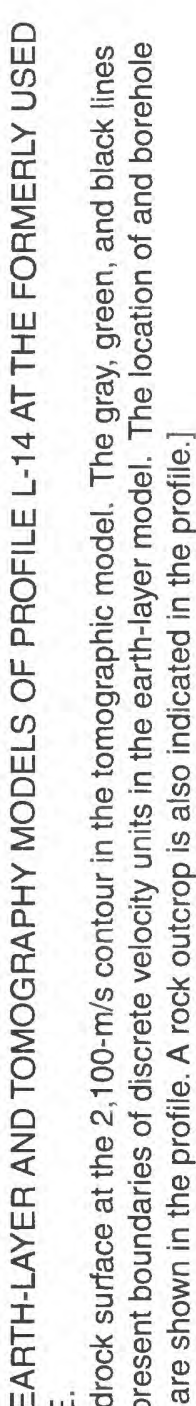

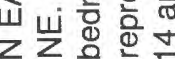

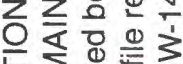

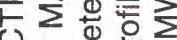

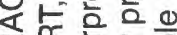

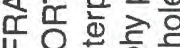
出. 드 응

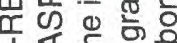

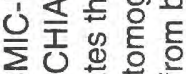

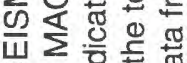
崔要

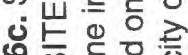

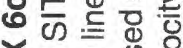
뜽ㅇㅇ Z $\frac{0}{\overline{0}}$ ह 늘 늘

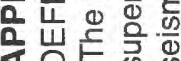

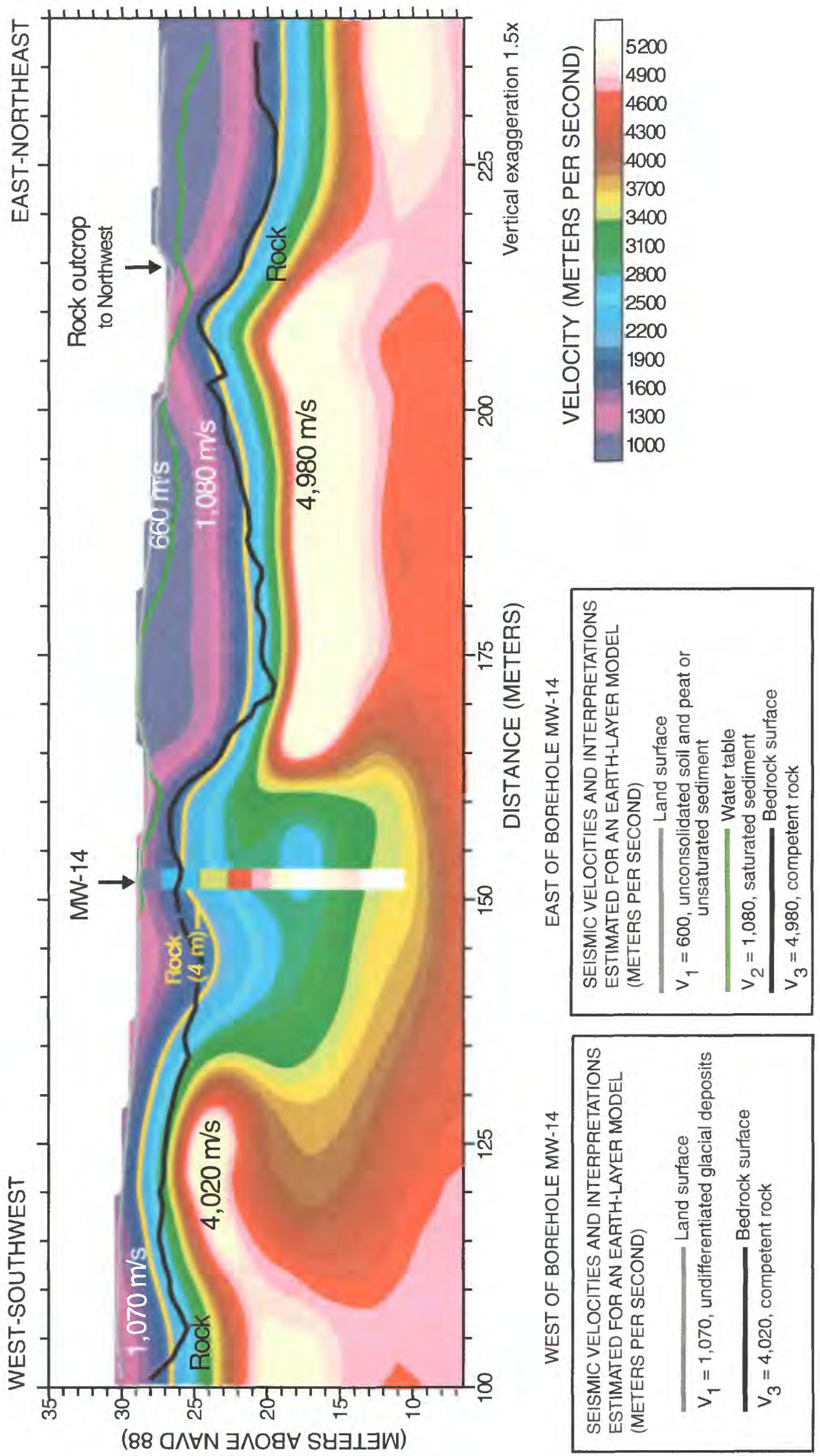
NOII $\forall \wedge \exists า \exists$ 


\section{Appendix 7. Geophysical Data from Profile TW-1 at the Formerly Used Defense Site, Machiasport, Maine}
a. Borehole seismic-velocity survey from borehole TW-1.
b. Seismic-refraction earth-layer and tomography models.
c. Inductive-terrain conductivity profiles. 
APPENDIX 7a. BOREHOLE SEISMIC-VELOCITY SURVEY FROM BOREHOLE TW-1 AT THE FORMERLY USED DEFENSE SITE, MACHIASPORT, MAINE.

[The panels below are a plot of seismic wave traveltime against elevation (left) and a multi-layered velocity model derived from seismic-refraction tomography (right). Dashed lines indicate interpreted interfaces in seismic-refraction tomography. The horizontal blue bar is the investigation depth limit of the seismic-velocity model. Description of lithology is from core data.]
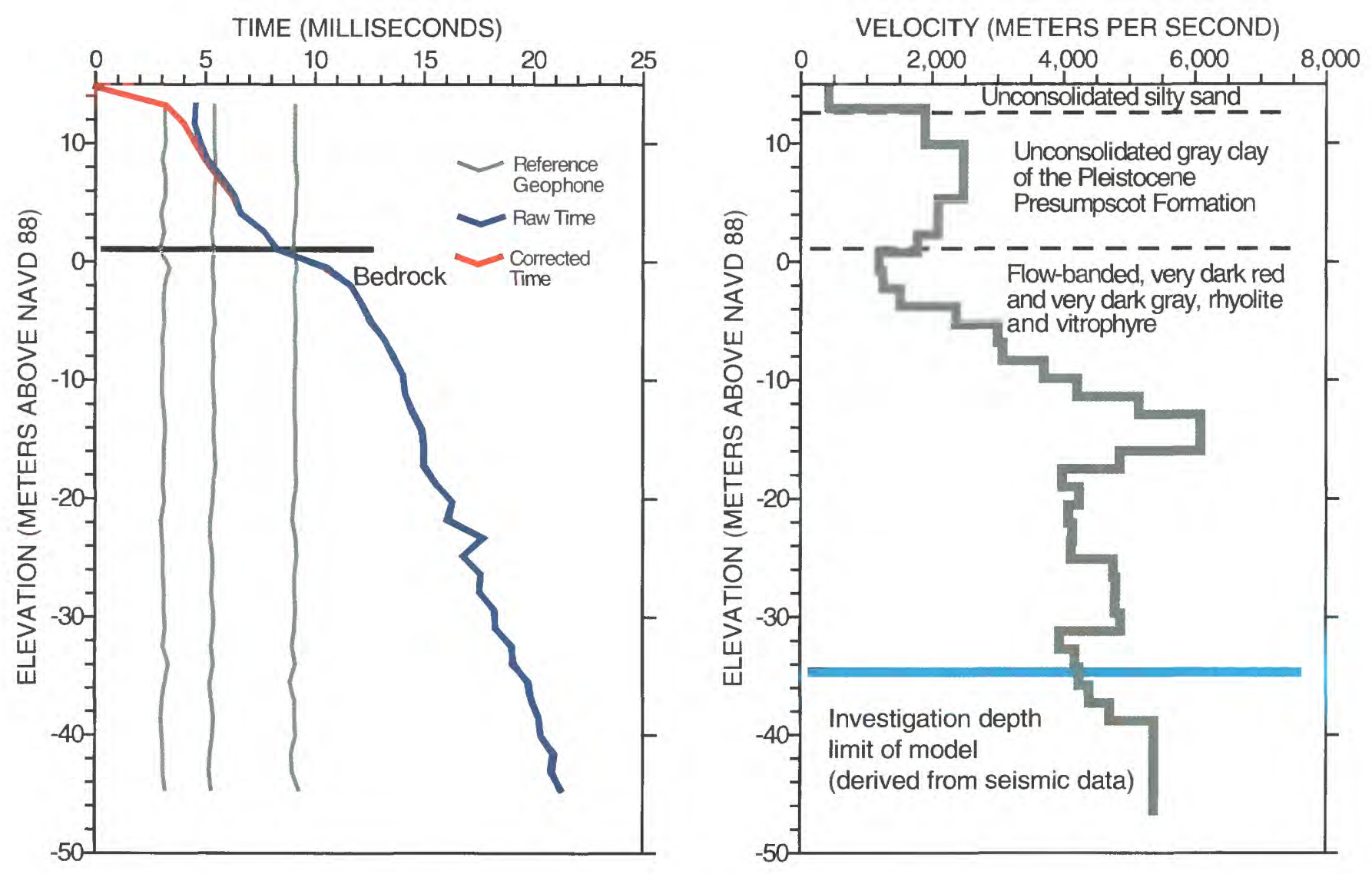

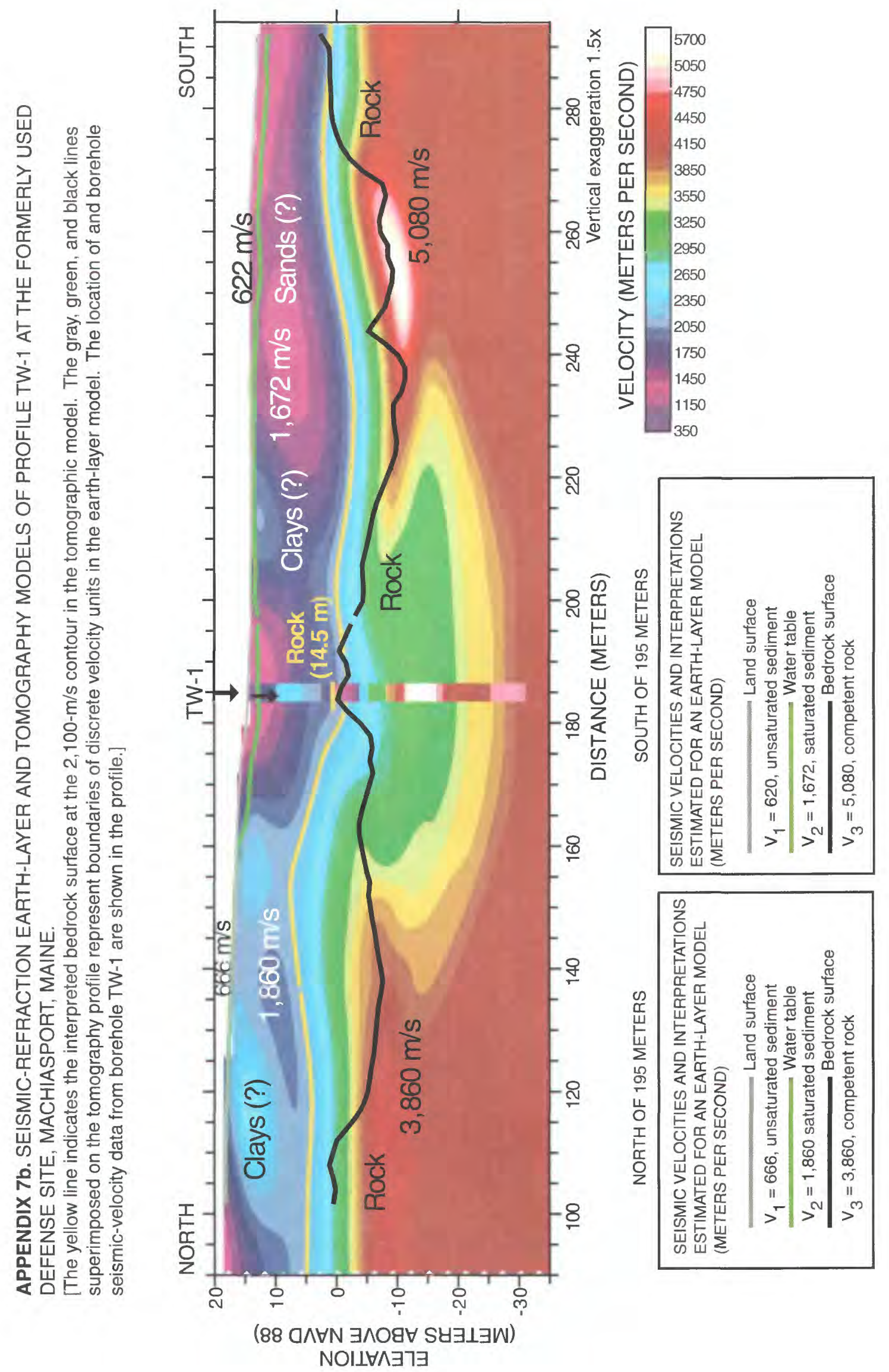


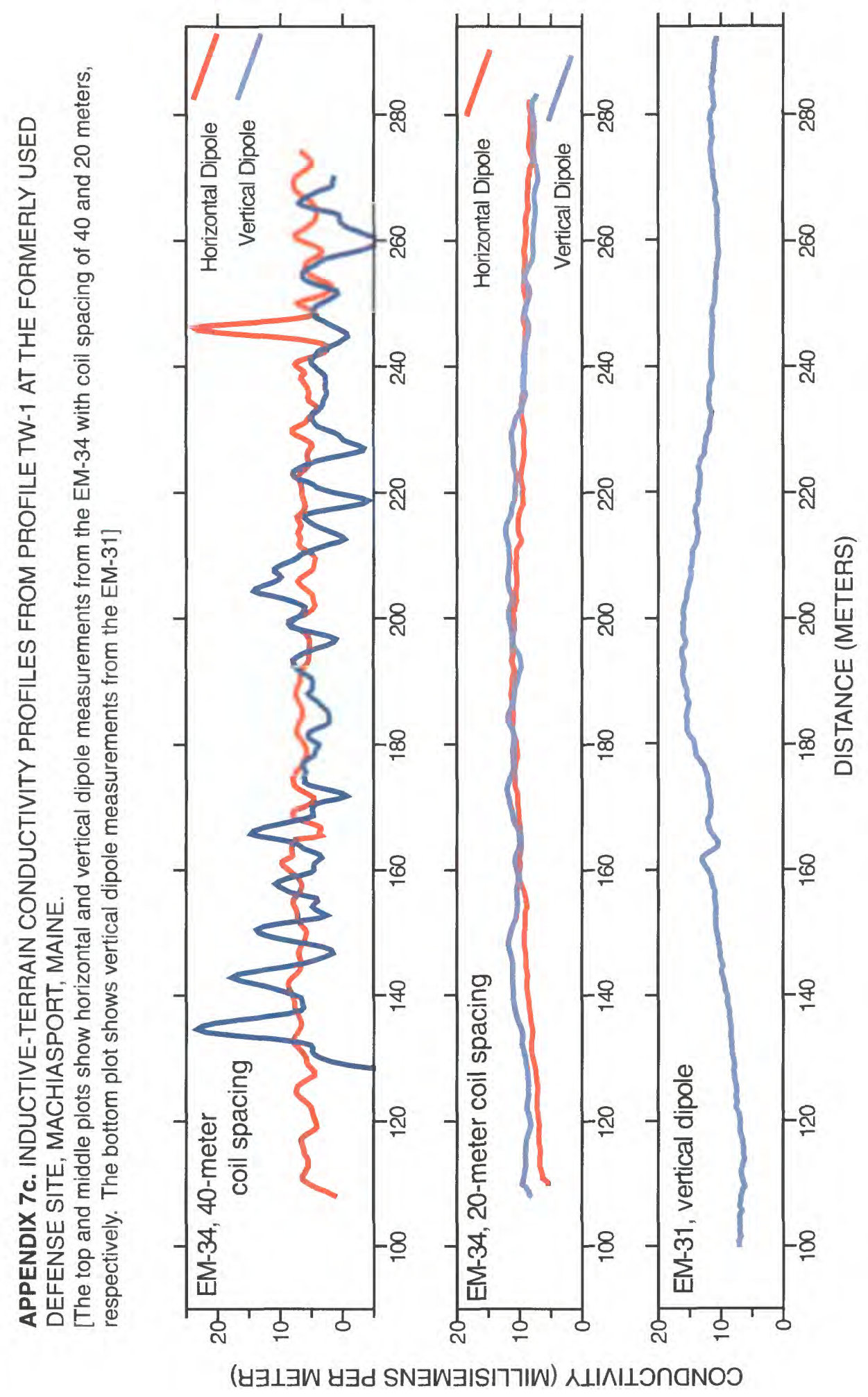





